\title{
"Soziale" Armut aus struktureller und subjektiver Perspektive
}

Die Analyse der standardisierten Netzwerkdaten und der problemzentrierten Interviews erfolgt in drei Schritten. Zunächst werden die Strukturen der sozialen Beziehungsnetzwerke der Befragten unter Anwendung statistischer Verfahren analysiert. Dazu werden Netzwerkmaße berechnet, und einer explorativen Faktorenanalyse unterzogen, mithilfe derer Dimensionen zur Unterscheidung der Netzwerke im Sample identifiziert werden. Die quantitative Typisierung der Netzwerke erfolgt im Rahmen einer Clusteranalyse, aus der drei voneinander zu unterscheidende Netzwerktypen hervorgehen.

Im zweiten Schritt werden die subjektive Wahrnehmung und das Bewältigungshandeln der Befragten analysiert. Im Zentrum dieser Analyse stehen ihre alläglichen Handlungsstrategien unter der Bedingung materieller Knappheit und Statusunsicherheit. Es wird analysiert, inwiefern es den Befragten gelingt, ausgehend von ihrer sozio-strukturellen Einbettung ein Leben im Einklang mit ihren persönlichen und kollektiven Idealen, Interessen und Verbindlichkeiten zu führen ( $\rightarrow$ Agency nach Emirbayer und Goodwin - siehe Abschnitt 2.3.2). Besondere Aufmerksamkeit wird dabei auf die Bewältigungschancen und -hindernisse gerichtet, die aus der Einbettung in soziale Beziehungen resultieren. Auch die Ergebnisse dieser Analyse werden in einer Typologie festgehalten.

Schließlich erfolgt im dritten Schritt die Zusammenführung der qualitativen mit der quantitativen Analyse. Es wird gezeigt, welche Wechselwirkungen zwischen der Einbettung in quantitativ identifizierbare Gelegenheitsstrukturen und der subjektiven Wahrnehmung der Befragten bestehen und welche Bewältigungschancen sich daraus ergeben. 


\subsection{Quantitative Strukturanalyse der egozentrierten Netzwerke}

Im Rahmen der quantitativen Analyse sollen die Strukturen und Zusammensetzungen der egozentrierten Netzwerke der 57 Befragten in voneinander unterscheidbare Cluster eingeteilt werden. Der erste Abschnitt 5.1.1 führt in die für diese Arbeit grundlegenden Begriffe der Netzwerkanalyse ein und gibt einen Überblick über die Verteilung der berechneten Netzwerkmaße (Größe, Dichte, Modularität, Maße zur Zusammensetzung der Netzwerke) im Sample. Darauf folgt ein vertiefender Exkurs zur Identifikation und Berechnung von Teilgruppen in Netzwerken in Abschnitt 5.1.2. Im dritten Abschnitt 5.1.3 wird auf Basis einer explorativen Faktorenanalyse gezeigt, dass sich die Varianz der Netzwerkmaße im Sample auf die übergeordneten Dimensionen "Netzwerkstruktur“ und „Netzwerkzusammensetzung“ zurückführen lässt. Im Abschnitt 5.1.4 werden die egozentrierten Netzwerke der Befragten auf Basis einer Clusteranalyse in drei verschiedene Gruppen unterteilt, die sich entlang der zuvor ermittelten Dimensionen unterscheiden.

\subsubsection{Deskriptive Befunde}

In diesem Abschnitt werden die wichtigsten Grundbegriffe und Maßzahlen der Netzwerkforschung erläutert. Darüber hinaus wird die Varianz der berechneten Netzwerkmaße im Sample betrachtet. Einen ersten Überblick bietet die Tabelle 5.1. Sie fasst die im Folgenden detailliert beschriebene deskriptive Statistik zu den berechneten Netzwerkmaßen zusammen. In Abbildung 5.4 werden zudem Histogramme abgebildet, die die Häufigkeitsverteilungen der Variablenwerte graphisch visualisieren.

\section{Netzwerkgröße}

Die Netzwerkgröße gibt Auskunft über die Zahl der Personen, die im Alltag der Befragten von Bedeutung sind. Das kleinste Netzwerk besteht aus 2 Personen, das größte setzt sich aus 21 Personen zusammen. Im Durchschnitt bestehen die sozialen Netzwerke der Befragten aus etwa 11 Personen. Als eher klein können die Netzwerke im ersten Quartil mit 2 bis 8 Personen bezeichnet werden, während Netzwerke mit mehr als 14 Personen (4. Quartil) als überdurchschnittlich groß bezeichnet werden können. 
Tabelle 5.1 Verteilung der Netzwerkmaße im Sample

\begin{tabular}{l|l|l|l|l|l|l}
\hline & Min. & 1. Quartil & Median & Mittelwert & 3. Quartil & Max. \\
\hline Größe & 2 & 8 & 10 & 10.89 & 14 & 21 \\
\hline Dichte & 0.071 & 0.254 & 0.351 & 0.407 & 0.552 & 1 \\
\hline $\begin{array}{l}\text { Modulari- } \\
\text { tät }\end{array}$ & 0 & 0 & 0.131 & 0.168 & 0.308 & 0.572 \\
\hline $\begin{array}{l}\text { Anteil } \\
\text { Familie }\end{array}$ & 0.000 & 0.222 & 0.333 & 0.344 & 0.444 & 1 \\
\hline $\begin{array}{l}\text { Anteil } \\
\text { Institution }\end{array}$ & 0 & 0.111 & 0.200 & 0.206 & 0.285 & 0.545 \\
\hline $\begin{array}{l}\text { Anteil } \\
\text { Unterstüt- } \\
\text { zung }\end{array}$ & 0 & 0.187 & 0.285 & 0.331 & 0.454 & 0.928 \\
\hline $\begin{array}{l}\text { EI-Index } \\
\text { Erwerb) }\end{array}$ & -1 & 0.111 & 0.400 & 0.321 & 0.777 & 1 \\
\hline
\end{tabular}

Netzwerkdichte, Degree, Isolates und Broker

Die Netzwerkdichte beschreibt den Anteil der bestehenden Beziehungen an den möglichen Beziehungen (Wasserman \& Faust, 1994, 10 f.). Ein Wert von 1 bedeutet, dass alle Personen im Netzwerk miteinander bekannt sind, ein Wert von 0 beschreibt eine Punktwolke, in der es keine Verbindungen zwischen den Netzwerkknoten gibt. Die Dichte korreliert häufig mit der Netzwerkgröße, da die Wahrscheinlichkeit, dass ein hoher Anteil der Alteri miteinander bekannt ist, in einem kleinen Netzwerk größer ist als in einem großen Netzwerk (Borgatti et al., 2018, S. 151).

Die Abbildung 5.1 zeigt vier Netzwerke unterschiedlicher Dichte: Die Netzwerke 2 und 102 haben eine Dichte von 1,0. Das Netzwerk 25 weist eine dem Durchschnitt im Sample entsprechende Dichte von 0,4 auf und das Netzwerk 21 eine vergleichsweise geringe Dichte von 0,1 . An den vier Netzwerkkarten lässt sich erkennen, dass neben der Netzwerkgröße auch die Anzahl unverbundener Alteri, sogenannter Isolates, Einfluss auf die Dichte hat. Die Zahl der Personen, mit denen ein*e Akteur*in im Netzwerk verbunden ist, wird als Degree bezeichnet (Borgatti et al., 2018, S. 14). Isolates haben einen Degree von 0, d. h., sie verfügen über keine Beziehungen zu anderen Personen im Netzwerk (ebd.). In Interview 21 (Abbildung 5.1, unten rechts) gibt es besonders viele Isolates, die Dichte des Netzwerks ist daher gering. In Netzwerken mit einer Dichte von 1 ist der Degree jeder Person gleich groß (im Netzwerk zu Interview 2 beträgt der Degree der beiden Alteri jeweils 1, im Interview 102 haben alle 8 Alteri einen Degree von 7). 


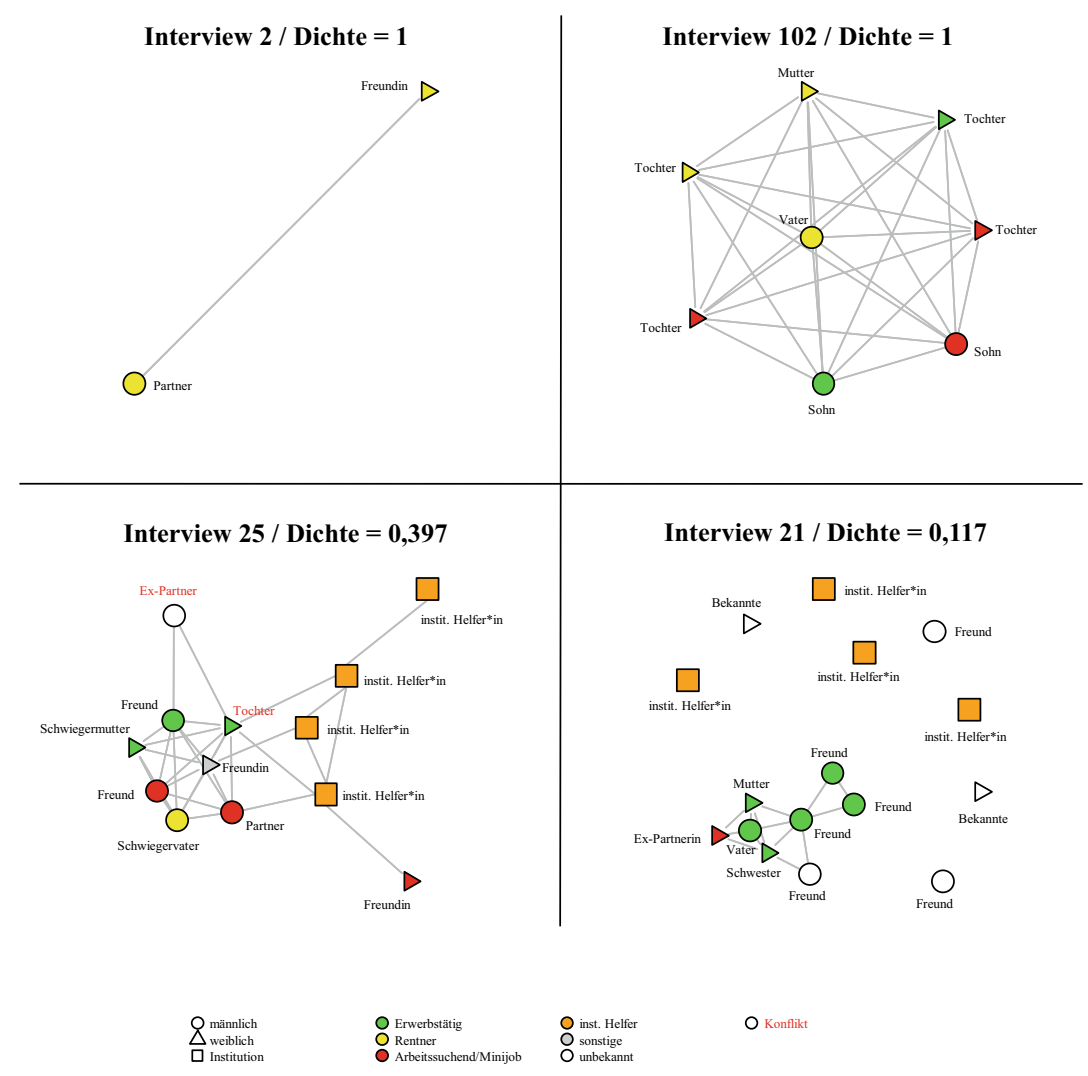

Abbildung 5.1 Netzwerkdichte im Vergleich

Ein hoher Degree gilt als Indikator für eine zentrale Position im Netzwerk (Borgatti et al., 2018, S. 165). Eine solche Position nimmt z. B. die Tochter im Netzwerk zu Interview 25 ein (Abbildung 5.1, unten links), sie ist mit 8 Personen im Netzwerk verbunden (Degree $=8$ ). Zentral ist die Position der Tochter, weil sie nicht nur mit der Familie und engen Freund*innen der Befragten bekannt ist, sondern darüber hinaus auch mit zwei institutionellen Helfer*innen, die einer anderen Subgruppe im Netzwerk angehören als dem Kreis der Familie und Freunde (siehe Exkurs zur Identifikation von Subgruppen im Netzwerk in Abschnitt 5.1.2). Man bezeichnet diese Positionen an der Schnittstelle zweier sozialer Kreise als Brücken (Jansen, 2003, S. 98), Bridges (Wasserman \& Faust, 
1994, S. 114) oder Broker (Henning et al., 2012, S. 131). Solche Positionen gelten als strategisch vorteilhaft, da sie Zugang zu Ressourcen aus unterschiedlichen sozialen Kreisen ermöglichen (Granovetter, 1974). Die Netzwerktheorie geht davon aus, dass die Intensität von brückenbildenden Beziehungen schwächer ist als die der Beziehungen innerhalb einer eng verbundenen Teilgruppe eines Netzwerks (Granovetter, 1973 - siehe Abschnitt 2.2.2).

\section{Modularität}

Um den Zerfall der Netzwerke in Teilgruppen mathematisch bestimmen und den Grad ihrer Segmentierung vergleichend analysieren zu können, wird in dieser Arbeit die Modularität berechnet. Ein grundlegender Überblick über die Möglichkeiten der Berechnung der Modularität sowie die Begründung für die hier ausgewählte Methode wird im Exkurs in Abschnitt 5.1.2 gegeben.

Die Modularität gibt an, zu welchem Grad sich Netzwerke in Subgruppen unterteilen lassen, deren interne Dichte höher ist als die ihrer Umgebung (Newman, 2006). Sie kann Werte zwischen 0 und 1 annehmen, je höher der Wert, desto deutlicher lässt sich das Netzwerk in Teilgruppen unterteilen (ebd.). Bedeutungsvoll wird die Interpretation des Modularitätsmaßes (ähnlich wie bei der Netzwerkdichte) jedoch erst, wenn man sie vergleichend betrachtet (z. B. im Zeitverlauf oder zwischen verschiedenen Netzwerken) - die Zahl ansich sagt noch nicht allzu viel aus (Luke, 2015, S. 117). Die Verteilung der Modularität im Sample ist in Tabelle 5.1 zusammengefasst. Sie liegt zwischen 0 (gar kein Zerfall in Subgruppen) und 0,57 (Zerfall in Subgruppen deutlich erkennbar). Mehr als ein Viertel (1. Quartil) aller Netzwerke untergliedert sich gar nicht in Teilgruppen, der Durchschnitt liegt bei einem Wert von 0,17.

Eine Interpretationshilfe für das Modularitätsmaß liefert Abbildung 5.2. Oben links ist das Netzwerk mit der höchsten Modularität im Sample abgebildet: Das Netzwerk besteht aus zwei Isolates und drei Teilgruppen - augenscheinlich zwei Freundeskreise und die Familie der befragten Person. Dagegen liegt die Modularität bei 0 (wie in Abbildung 5.2, unten rechts), wenn es neben evtl. vorhandenen Isolates nur eine Gruppe im Netzwerk gibt, die sich nicht in Subgruppen einteilen lässt. Sind Subgruppen auffindbar, die jedoch durch mehrere brückenbildende Beziehungen verbunden sind, ergibt sich ein vergleichsweise geringer Wert für die Modularität, wie z. B. im Netzwerk zu Interview 18 (unten links in Abbildung 5.2). 


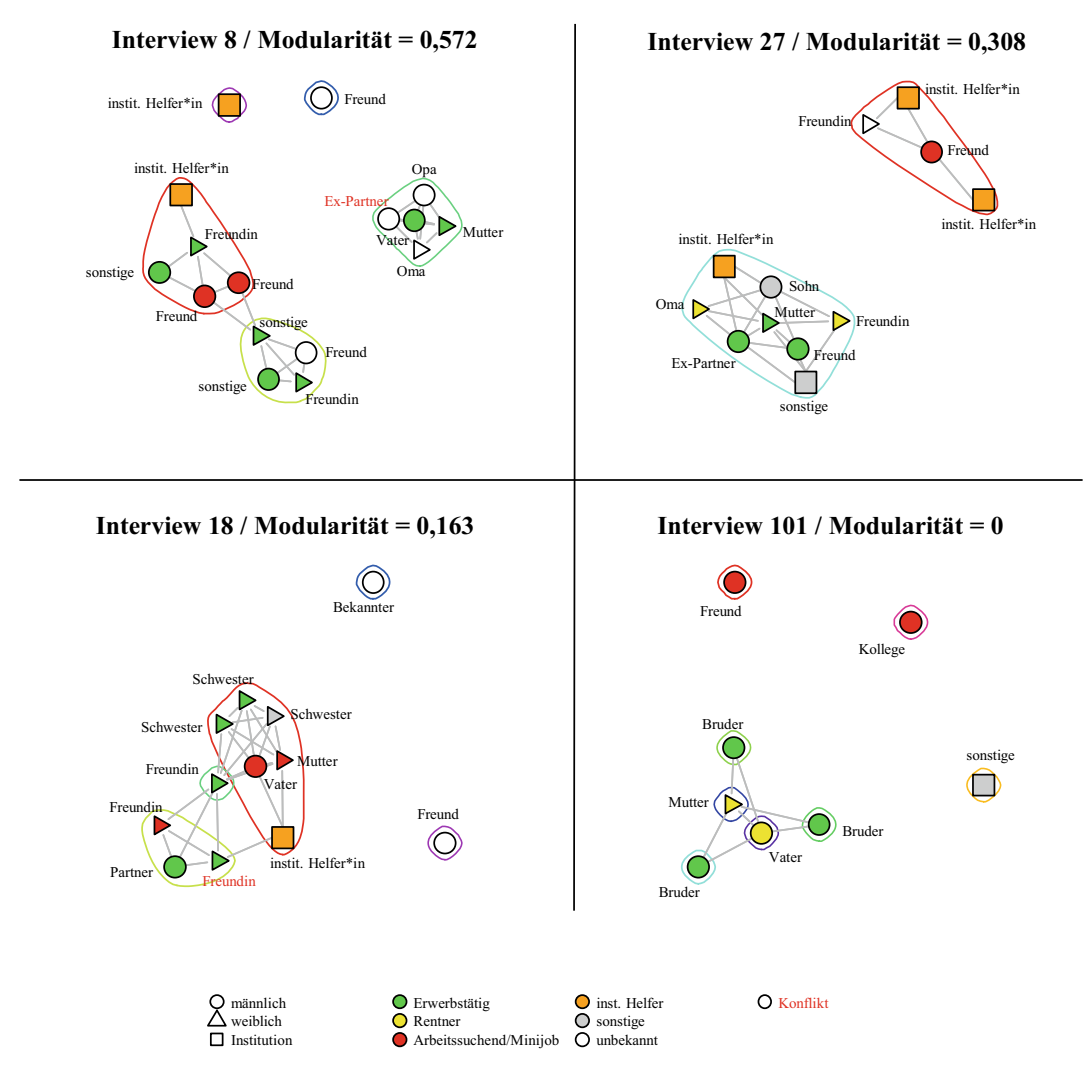

Abbildung 5.2 Modularität im Vergleich

Netzwerkzusammensetzung

Die Zusammensetzung der Netzwerke nach Beziehungstypen wird durch die drei Variablen: „Anteil Familie“, „Anteil Institution“ und „Anteil Unterstützung“ beschrieben (siehe Tabelle 5.1). Der Anteil der familiären Beziehungen ${ }^{1}$ an allen Beziehungen im jeweiligen Netzwerk liegt zwischen 0 und $100 \%$. Im Durchschnitt sind etwa ein Drittel aller Beziehungen in jedem Netzwerk familiäre

\footnotetext{
${ }^{1}$ Zur Berechnung der Variable wurden folgende Beziehungstypen als „,familiäre Beziehungen“ zusammengefasst: Kinder, Partner*innen und Ex-Partner*innen, Eltern und Großeltern, Geschwister, Schwiegereltern und sonstige Verwandte.
} 
Beziehungen. Der durchschnittliche Anteil institutioneller Beziehungen beträgt etwa ein Fünftel, er schwankt zwischen 0 und $54 \% 2$.

Die Variable „Anteil Unterstützung“ bezieht sich im Gegensatz zu den beiden zuvor beschriebenen Maßzahlen nicht auf den Beziehungstyp, sondern auf eine Beziehungseigenschaft. Die Zahl gibt den Anteil der Personen im jeweiligen Netzwerk an, die durch folgende Frage ermittelt wurden: „Werden Sie von Personen, sozialen Gruppen, Organisationen oder Ämtern in irgendeiner Form unterstützt? Können Sie mir die Namen der Personen oder Institutionen nennen? “3. Der Anteil unterstützender Beziehungen an allen Beziehungen im jeweiligen Netzwerk liegt zwischen 0 und $93 \%$ (siehe Tabelle 5.1). Im Durchschnitt sind $33 \%$ aller Beziehungen in jedem Netzwerk Quellen sozialer Unterstützung.

\section{EI-Index (Erwerb)}

Der EI-Index ist ein Maß zur Berechnung der Alter-Ego-Homophilie (Borgatti et al., 2018, S. 274; Crossley et al., 2015, 80 ff.; Krackhardt \& Stern, 1988). Die Idee der Homophilie bezieht sich auf zwei theoretische Überlegungen (Fuhse, 2016, S. 34): Erstens gehen Menschen häufiger Beziehungen zu Personen ein, die ähnliche Eigenschaften (z. B. Einstellungen und Werthaltungen) aufweisen wie sie selbst (z. B.: wer raucht, sucht sich Freunde, die ebenfalls rauchen), zweitens gleichen sich miteinander in Beziehung stehende Personen mit der Zeit aneinander an (Freunde von Raucherinnen werden selbst Raucher). Treffen diese Hypothesen zu, entstehen Netzwerkstrukturen, in denen eng verbundene Cluster aus Personen mit ähnlichen Merkmalen zu finden sind.

In der Analyse egozentrierter Netzwerke wird die Homophilie insbesondere in Bezug auf Eigenschaften von Ego analysiert (Crossley et al., 2015, 80 ff.). Die Berechnung der Ego-Alter-Homophilie gibt Aufschluss darüber, inwiefern die Alteri Ego in einer Eigenschaft ähneln, bzw. zu welchem Anteil sie sich von Ego unterscheiden. Der EI-Index berechnet sich wie folgt:

\footnotetext{
${ }^{2}$ Weitere, in Tabelle 5.1 nicht aufgeführte Beziehungstypen sind: FreundInnen (min: = $0 / \max =0,778 /$ mean $=0,326)$, KollegInnen $(\min =0 / \max =0,546 /$ mean $=0,207)$ und die Kategorie „sonstige“ $(\min =0 / \max =0,188 /$ mean $=0,023)$. Die Kategorie „sonstige“ wurde häufig vergeben für Gruppen aus mehreren Personen sowie für Orte und Treffpunkte.

${ }^{3}$ Die Frage wurde als dritte von insgesamt sechs Generatorfragen gestellt (zur methodischen Umsetzung der Netzwerkerhebung, siehe Abschnitt 4.1.4). Die Befragten wurden gebeten, Personen, die bereits genannt wurden, noch einmal zu nennen, sollten sie von diesen Unterstützung empfangen. Auf diese Weise wurde sichergestellt, dass unterstützende Ego-AlterRelationen auch dann erfasst wurden, wenn die entsprechenden Personen bereits genannt wurden.
} 


$$
E I=\frac{E-I}{E+I}
$$

$E$ bezeichnet externe Beziehungen (external ties) zu Alteri, die die Eigenschaft von Ego nicht aufweisen. I bezeichnet interne Beziehungen (internal ties) zu Personen, die die gleiche Eigenschaft wie Ego aufweisen. Für die in den folgenden Abschnitten 0 und 5.1.4 beschriebenen Analysen wurde der EI-Index in Bezug auf die Erwerbstätigkeit berechnet ${ }^{4}$. $E$ steht hier für die Anzahl der Alteri mit einem anderen Erwerbsstatus als Ego, $I$ für die Anzahl der Alteri mit dem gleichen Erwerbsstatus.

Der EI-Index kann Werte von -1 bis +1 annehmen. -1 bedeutet, dass alle Alteri die gleiche Eigenschaft wie Ego aufweisen $(\mathrm{E}=0),+1$ bedeutet, dass keine der Personen im Netzwerk die gleiche Eigenschaft wie Ego aufweist ( $\mathrm{I}=$ 0 ). Ein Wert von 0 besagt, dass es gleich viele interne wie externe Beziehungen gibt $(\mathrm{I}=\mathrm{E})$.

In Tabelle 5.1 ist die Verteilung des EI-Index über alle Netzwerke im Sample dargestellt. Beide Extremfälle kommen im Sample vor, der Wert schwankt zwischen -1 und +1 . Im Durchschnitt liegt der Wert bei $+0,32$, es überwiegen also Netzwerke, in denen mehr Personen vorkommen, die einen anderen Erwerbsstatus als Ego selbst haben, als solche, die den gleichen Erwerbsstatus wie Ego aufweisen. Von Homogenisierung der Beziehungen und sozialer Schließung (z. B. der Bildung von homogenen Arbeitslosen-Netzwerken) kann auf Basis des EI-Index in Bezug auf den Erwerbsstatus in diesem Sample nicht gesprochen werden.

\subsubsection{Exkurs: Cliquen, k-Cores und Communities}

Oft setzen sich Netzwerke aus mehreren besonders eng verbundenen Teilgruppen zusammen, zwischen denen nur wenige Beziehungen bestehen. Die Netzwerkforschung widmet der Analyse der Bedeutung solcher Gruppen und der brückenbildenden Beziehungen zwischen diesen Gruppen besondere Beachtung. Granovetter (1973) geht z. B. davon aus, dass die Mitglieder solcher Subgruppen durch starke Beziehungen miteinander verbunden sind, während brückenbildende Beziehungen zwischen zwei Subgruppen im Netzwerk eher schwach sind:

\footnotetext{
${ }^{4}$ Folgende Erwerbssituationen wurden erfasst: erwerbslos, in Ausbildung, EU-Rentner*in, Altersrentner*in, Student*in, teilzeit-erwerbstätig, vollzeit-erwerbstätig.
} 
„Weak ties are more likely to link members of different small groups than are strong ones, which tend to be concentrated within particular groups" (Granovetter, 1973, S. 1376).

Auch in egozentrierten Netzwerken lassen sich Teilgruppen identifizieren, z. B. die Familie der befragten Person oder ihre Kolleginnen und Kollegen. Die Analyse von Teilgruppen in egozentrierten Netzwerken gibt Auskunft darüber, ob Ego in voneinander abgrenzbare soziale Kreise integriert ist. Subgruppen lassen sich in der Netzwerkanalyse auf verschiedene Art und Weise berechnen und ermitteln. Allen Verfahren liegt die Annahme zugrunde, dass es in Netzwerken Teilgruppen gibt, die enger miteinander verbunden sind als die Knoten in ihrer Umgebung. Jansen (2003) unterscheidet folgende Verfahren zur Bestimmung sogenannter Cliquen und Communities in Netzwerken:

1. Ermittlung „gegenseitige[r], direkte[r] Beziehungen“ (ebd., S. 195): Jedes Cliquenmitglied ist unmittelbar mit jedem anderen bekannt.

2. „Nähe und Erreichbarkeit der Cliquenmitglieder“ (ebd.): Jedes Cliquenmitglied kann jedes andere über eine vorgegebene Höchstzahl von Beziehungen erreichen, die maximale Pfaddistanz ist kleiner als $n$ ( $n$-Cliquen).

3. „Häufigkeit der direkten Beziehungen zwischen den Mitgliedern“ (ebd.): Der überwiegende Teil der Akteur*innen in einer Clique kann sich direkt erreichen (k-Cores).

4. „Höhere Beziehungsdichte innerhalb der Clique im Vergleich zu ihrem Umfeld“ (ebd. - Communities).

$\mathrm{Zu}$ beachten ist, dass die Wahl der am besten geeigneten Methode zur Identifikation von Subgruppen vom Erkenntnisinteresse der Forschenden abhängt. Der hier durchzuführenden Analyse geht die theoretische Annahme voraus, dass Netzwerke Akteur*innen zum Handeln befähigen, indem sie ihnen voneinander unterscheidbare soziale Kreise, bzw. sogenannte Domänen, bereitstellen, innerhalb derer sie Identitäten etablieren können (z. B. als Tochter, als Kollegin und Fachkraft oder als gute Freundin). Je mehr dieser Domänen den Akteur*innen zur Verfügung stehen, desto mehr Handlungsoptionen und Freiheiten haben sie zur Gestaltung ihrer Netzwerkidentitäten. Übertragen auf das Armutsthema bedeutet das, dass eine Person sich z. B. dann besonders durch Erwerbslosigkeit bedroht sieht, wenn sie sich in besonderer Weise mit dem Beruf identifiziert und bei Wegfall der Domäne „Arbeitsplatz“ keine alternativen Rollen in ihrem Netzwerk zur Verfügung stehen, die sie ausfüllen kann (siehe Abschnitt 2.3.2). 
Gesucht wird also eine Berechnungsmethode, die dazu geeignet ist, Netzwerkdomänen auf Basis der Struktur aus Knoten und Kanten zu voneinander zu unterscheiden. Im Folgenden werden die vier Verfahrensweisen nach Jansen (2003) dahingehend überprüft.

\section{Cliquen}

Die Clique ist die einfachste Möglichkeit zur Berechnung von Subgruppen (Verfahren 1 nach Jansen 2003). Sie wird definiert als eine Gruppe von Knoten im Netzwerk, zwischen denen alle möglichen Beziehungen realisiert sind (Luke, 2015, S. 107). Oben links in der Abbildung 5.3 sind alle möglichen Cliquen aus mindestens drei Personen eingezeichnet. $\mathrm{Zu}$ sehen sind zwei 3er-Cliquen (Bekannter-Freundin-Partner und Bruder-Bruder-Mutter) und eine 5er-Clique ${ }^{5}$. Die Einteilung von Subgruppen auf Basis der Berechnung von Cliquen erscheint mit Blick auf das Interview 039 gut interpretierbar. Es gibt zwei 3er-Gruppen (die eine eher freundschaftlich, die andere familiär geprägt) und einen Freundeskreis, bestehend aus fünf Personen. Allerdings treten bei der Berechnung von Cliquen häufig Überschneidungen zwischen den Subgruppen auf, wie z. B. im Netzwerk zu Interview 008 (siehe Abbildung A.1 im Anhang), die mit Blick auf die Netzwerkvisualisierung nur schwer interpretierbar sind (zum Problem des „clique overlap“ siehe: Prell, 2012, S. 156).

\section{N-Cliques}

In der zweiten Visualisierung des Netzwerks zu Interview 039 in Abbildung 5.3, oben rechts sind sogenannte $\mathrm{N}$-Cliques hervorgehoben (Verfahren 2). In diesen Cliquen müssen alle Personen über maximal $N$ Schritte miteinander verbunden sein (Jansen, 2003, S. 195). Wenn $N=2$ beträgt, werden also auch Knoten in eine Clique aufgenommen, die nur indirekt über eine dritte Person miteinander verbunden sind (z. B. sind Partner und Mutter von EGO-039 indirekt über einen Bruder verbunden). Die Berechnung von N-Cliques in Netzwerken gibt z. B. Aufschluss über die Frage, welche Reichweite Informationen haben, die nur über die vorgegebene Pfaddistanz $=\mathrm{N}$ kursieren (Prell, 2012, S. 158). Auch hier finden sich wieder Überschneidungen zwischen den berechneten Cliquen. Besonders deutlich sticht die zentrale Netzwerkposition des Partners von EGO-039 heraus, da dieser über zwei Schritte mit allen Personen im Netzwerk verbunden ist, außer mit den

\footnotetext{
${ }^{5}$ Die Funktion maximum.cliques im r-package igraph berechnet die größtmöglichen Cliquen (Csardi und Nepusz 2006). So ergibt sich im Kreis aus 4 FreundInnen und einer ,sonstigen“ Person nur eine 5er Clique. Die rechnerisch ebenfalls möglichen fünf 3er-Cliquen sowie fünf 4er-Cliquen innerhalb der 5er-Clique werden nicht mit ausgegeben, da sie Teil der größeren 5er Clique sind. Detaillierte Methoden zur Analyse sich überschneidender Cliquen beschreiben Borgatti et al. (2018, S. 184 f.).
} 


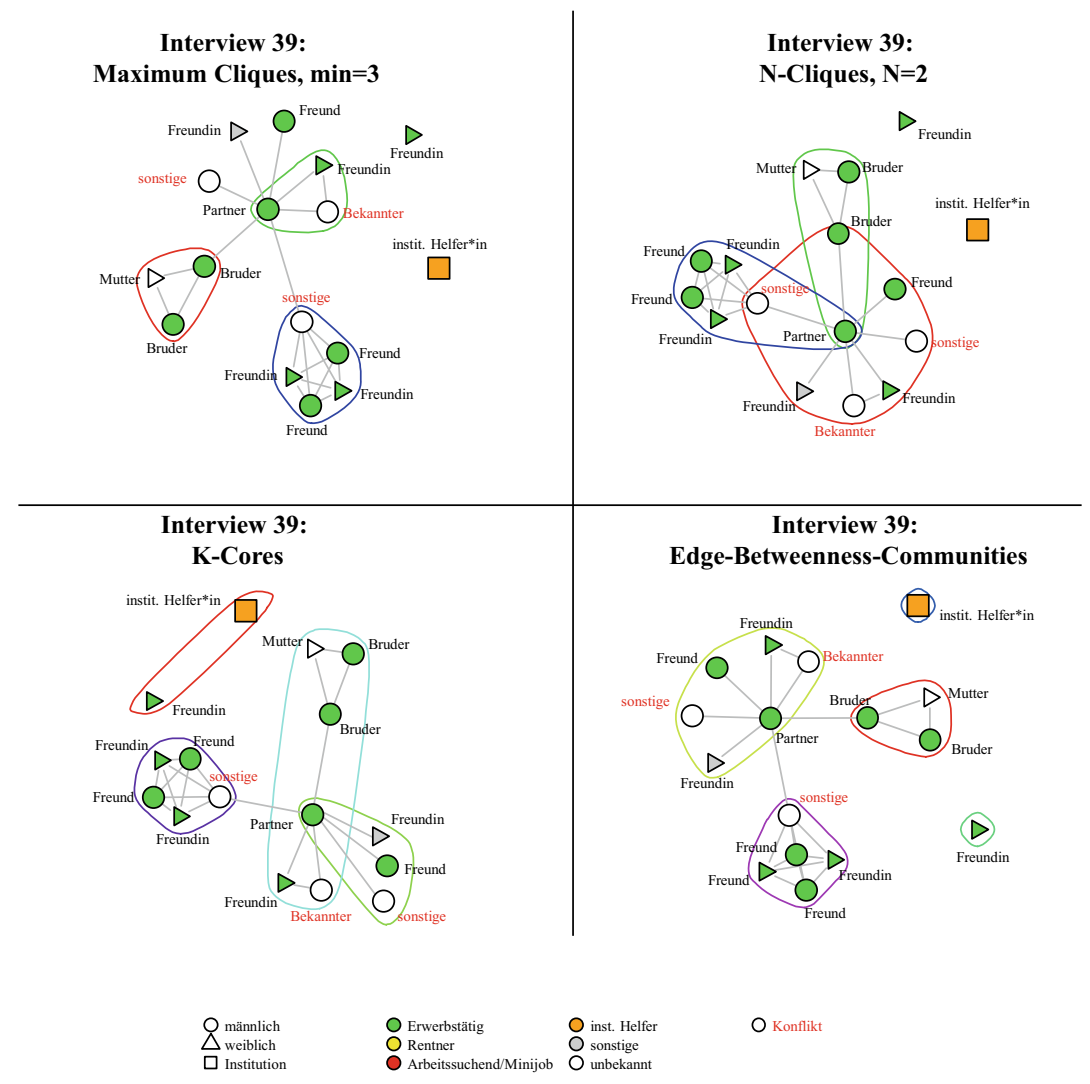

Abbildung 5.3 Berechnung von Subgruppen im Netzwerk zu Interview 039

beiden Isolates. Die Überschneidungen der N-Cliquen im Netzwerk zu Interview 039 sind in Bezug auf die Position des Partners also sehr gut interpretierbar. Doch auch bei diesem Kriterium zur Berechnung von Cliquen kann es zu stärkeren Überlappungen von Cliquen kommen, die eine Interpretation erschweren (siehe Abbildung A.1 im Anhang).

\section{K-Cores}

Zur dritten Kategorie der Verfahren zur Ermittlung von Subgruppen zählt die Berechnung von k-Cores (Verfahren 3 nach Jansen 2003). Ein k-Core beschreibt 
einen Subgraphen, dessen Angehörige alle mit mindestens $k$ Personen in diesem Kreis bekannt sind (Luke, 2015, S. 110). Innerhalb des k-Cores hat jeder Knoten einen Degree von mindestens $k$ (Borgatti et al., 2018, S. 252). Es entstehen Cliquen, in denen zwar relativ viele, aber nicht alle möglichen Beziehungen tatsächlich existieren müssen. Unten links in Abbildung 5.3 sind die k-Cores im Netzwerk zu Interview 039 eingezeichnet. Bei den beiden isolierten Knoten beträgt $\mathrm{k}=0$. In dem aus vier Knoten bestehenden Kreis beträgt $\mathrm{k}=1$, in der 5er Gruppe beträgt $\mathrm{k}=4$ und in der aus 6 Personen bestehenden Subgruppe beträgt $\mathrm{k}=2$. Gut interpretierbar ist an dieser Gruppierung der Alteri lediglich die eng verbundene 5er-Gruppe $(\mathrm{k}=4)$. Die beiden Isolates zu gruppieren erscheint nicht sinnvoll, da es unwahrscheinlich ist, dass sie derselben Domäne angehören. Auch die beiden über den Partner verbundenen 3er Cliquen (Bruder-Bruder-Mutter und Bekannter-Freundin-Partner) zu einer 6er-Gruppe zusammenzufassen erscheint nicht sinnvoll. Der Partner kennt lediglich einen der beiden Brüder der Befragten, nicht aber ihre Mutter. Ihn in den Kreis der Herkunftsfamilie mit hineinzuzählen erscheint daher wenig plausibel. Noch schwerer lässt sich eine gute Begründung dafür finden, warum die beiden anderen mit dem Partner verbunden Personen der durch den K-Core definierten 6er Gruppe zugeordnet werden sollten.

Edge-Betweenness-Communities

Bei den bis hierhin betrachteten Berechnungsmethoden traten zwei wesentliche Probleme auf:

1. überschneiden sich die Subgruppen häufig (clique overlaps) und

2. führt die Berechnung von Cliquen und K-Cores nicht immer zu einer guten Aufteilung des Netzwerks im Sinne des Domänen-Begriffs, da häufig Angehörige verschiedener Domänen in einer Gruppe zusammengefasst werden (siehe $N$-Cliques und $K$-Cores in Abbildung 5.3) oder weil sie zusammenhängende Netzwerkdomänen in mehrere Cliquen zerstückeln (siehe Maximum Cliques und N-Cliques in Abbildung A.1 im Anhang).

Um diesen Problemen zu begegnen, braucht es explorative Berechnungsmethoden, die die Cluster nicht mehr von innen heraus, auf Basis direkter Beziehungen (Cliques) bzw. von Pfaddistanzen ( $N$-Cliques) oder auf Basis des Degrees der Personen im Cluster ( $k$-Cores) ermitteln, sondern aus einer Perspektive, die die Struktur des gesamten Netzwerks berücksichtigt. Die Subgruppen können von außen bestimmt werden, indem ihre interne Dichte systematisch mit der Dichte ihrer Umgebung (also des gesamten Netzwerks) abgeglichen wird. Eine geeignete Einteilung ist gefunden, sobald die Differenz zwischen der Beziehungsdichte 
innerhalb der Subgruppen und der Dichte des gesamten Netzwerks maximiert ist. Diese Methode liefert die besten Ergebnisse, ist aber aufwändiger in der Berechnung. So kommen zur Berechnung von Subgruppen nach der vierten Methode (Communities) in Anlehnung an Jansen (2003) mehrstufige Verfahren zur Anwendung.

Dafür stehen verschiedene Algorithmen (Community Detection Algorithms) zur Verfügung (ein Überblick über die Berechnungsmethoden mit dem r-package igraph findet sich bei Luke 2015, 118 ff.). Um zu überblicken, wie sich die verschiedenen Berechnungsmethoden im Ergebnis unterscheiden, empfiehlt sich abermals die Betrachtung der Visualisierung der Ergebnisse. Dabei stellte sich heraus, dass alle getesteten Algorithmen ${ }^{6}$ im hier verwendeten Sample identische Ergebnisse hervorbringen.

Zwei Beispiele für die so berechneten Communities in Netzwerken finden sich in Abbildung 5.3 und Abbildung A.1, jeweils unten rechts. Die Communities überschneiden sich nicht und stimmen weitgehend mit der Einteilung auf Basis der oben skizzierten visuellen Analyse überein. Es gibt nur noch einzelne Akteur*innen, die nicht so recht in die Subgruppen zu passen scheinen (z. B. der/die institutionelle Helfer*in in Abbildung A.1) bzw. bei denen erst die Analyse der Erzählungen über die Beziehungen Aufschluss darüber gibt, ob die Personen tatsächlich derselben Domäne zuzuordnen sind oder nicht (wie z. B. die drei nur mit dem Partner verbundenen Personen in der 6er-Community in Abbildung 5.3, unten rechts). Damit liefert die Community-Methode die am besten zu interpretierenden Ergebnisse für die weitere Analyse.

Auf Basis der Community-Zuordnungen wird die Modularität der Netzwerke berechnet. Die Modularität ist ein Strukturmaß, welches den Grad beschreibt, zu dem Netzwerke in Subgruppen zerfallen, die eine höhere Dichte als ihre Umgebung aufweisen (Luke, 2015, S. 115). Die Modularität steigt, wenn der Anteil der Beziehungen innerhalb der ermittelten Subgruppen an allen Beziehungen im Netzwerk hoch ist (Henning et al., 2012, 133 f.). Die Modularität sinkt hingegen mit steigendem Anteil an Beziehungen zwischen den Clustern. Ein exemplarischer Vergleich von Netzwerken mit hoher, mittlerer und niedriger Modularität wurde im vorangegangenen Abschnitt 5.1.1 vorgenommen (siehe Abbildung 5.2).

\footnotetext{
${ }^{6}$ Die Analysen wurden mit dem igraph-Package in R durchgeführt (Csardi und Nepusz 2006). Folgende Algorithmen wurden getestet: Walktrap, Edge-Betweenness, Fastgreedy, Label Propagation, Leading Eigenvector, Louvain.
} 


\subsubsection{Explorative Faktorenanalyse}

In diesem Abschnitt soll gezeigt werden, inwieweit sich die Varianz der bis hierhin beschriebenen Netzwerkvariablen - Netzwerkgröße, Netzwerkdichte, Modularität, Anteil familiärer Beziehungen, Anteil institutioneller Beziehungen, Anteil unterstützender Beziehungen und der EI-ndex, bezogen auf den Erwerbsstatus systematisch auf übergeordnete Dimensionen zurückführen lässt bzw. wie sich die Korrelationen zwischen den sieben Variablen ,durch einen Sammelbegriff zusammenfassen“ (Backhaus et al., 2016, S. 413) lassen.

Dazu wird eine Faktorenanalyse (Hauptkomponentenanalyse auf Basis der Pearson-Korrelationsmatrix mit dem principal-Befehl aus demem psych-Paket in R, Revelle, 2017) durchgeführt, in deren Rahmen stärker miteinander korrelierende Variablen zu latenten Dimensionen zusammengefasst werden (Backhaus et al., 2016, 412 ff.). Inwieweit die sieben Variablen miteinander korrelieren, zeigt die Korrelationsmatrix Abbildung 5.4. Auf der Mitteldiagonale sind Histogramme zu sehen, die die Häufigkeitsverteilungen der verwendeten Variablen abbilden. Links der Diagonale sind die Zusammenhänge zwischen allen möglichen Variablenpaaren in Form von Streudiagrammen (Scatterplots) zu sehen. Auf der X-Achse sind jeweils die Werte der im Histogramm in der entsprechenden Spalte abgebildeten Variable für jedes Netzwerk im Sample abgetragen, auf der Y-Achse die zum Histogramm in der jeweiligen Zeile gehörenden Variablenwerte. Die rote Linie zeigt den linearen Zusammenhang zwischen den Variablenpaaren als Regressionsgerade. Rechts der Mitteldiagonale der Korrelationsmatrix sind die Pearson-Korrelationskoeffizienten für jede mögliche Kombination der sieben Variablen eingetragen.

Die stärksten Korrelationen bestehen zwischen den Variablen Größe und Modularität (0,39 - je größer das Netzwerk, desto höher die Modularität), Dichte und Modularität (-0,48 - je höher die Dichte, desto geringer die Modularität), Dichte und Anteil familiärer Beziehungen $(0,39)$, dem Anteil institutioneller Beziehungen und dem EI-Index $(0,41)$ sowie dem Anteil unterstützender Beziehungen und dem EI-Index (0,30). Bei genauerer Betrachtung der Korrelationsmatrix lassen sich zwei Blöcke erkennen, in denen die Korrelationen zwischen den Variablen deutlich höher sind als außerhalb der Blöcke (hervorgehoben durch die roten Rechtecke in der Abbildung 5.4). Dies lässt sich als erstes Indiz dafür lesen, dass die Varianzen zwischen den Variablen Größe, Dichte und Modularität und den Variablen Anteil institutioneller Alteri, Anteil unterstützender Alteri und EI-Index gut durch zwei Faktoren erklären lassen (Backhaus et al., 2016, S. 395). Unklar ist die Zuordnung der Variable Anteil familiärer 


\section{Histogramme und Pearson-Korrelationen}

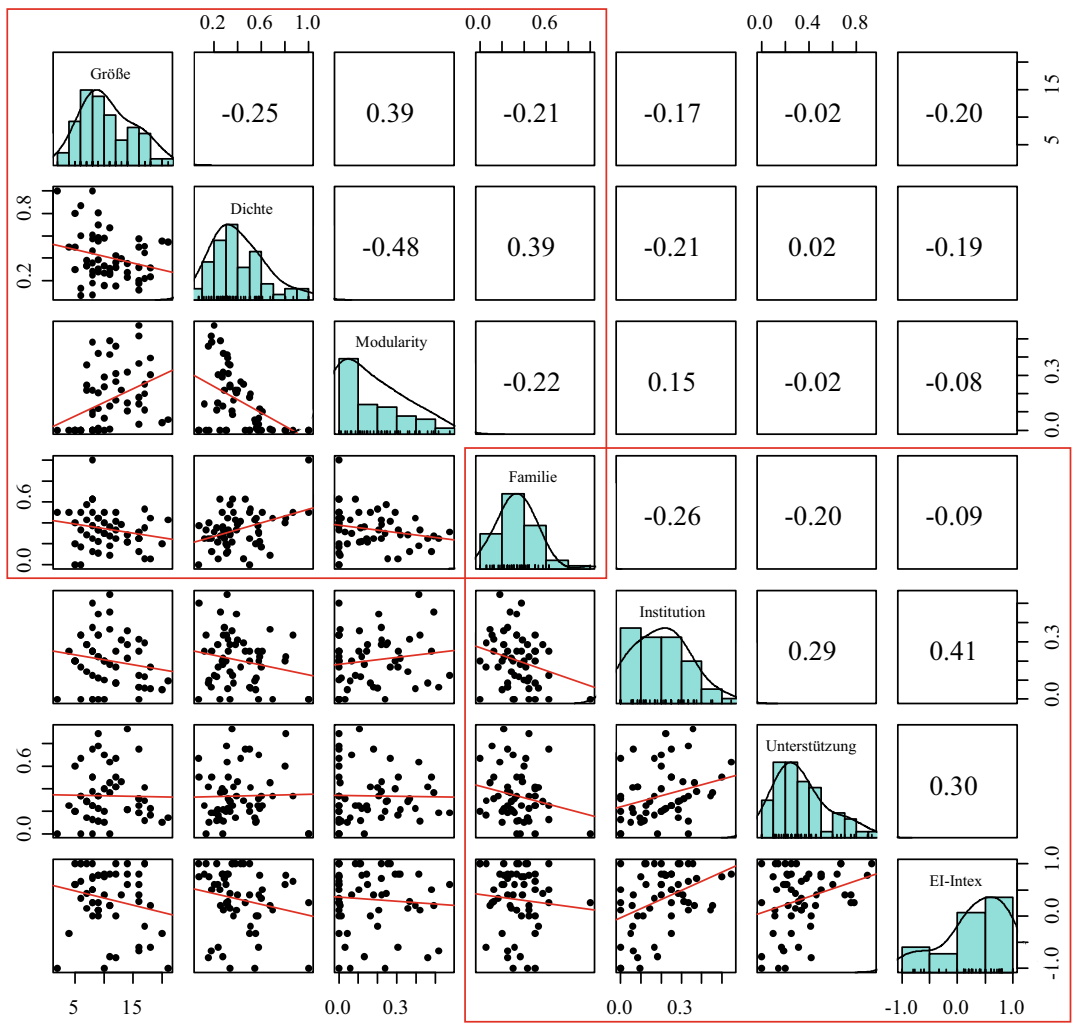

Abbildung 5.4 Korrelationsmatrix

Alteri, da diese relativ stark mit einzelnen Variablen aus beiden Blöcken korreliert (Korellationskoeffizient > 0,25 bei „Institution“" und „Dichte“).

Im nächsten Schritt soll nun herausgefunden werden, ob sich diese Korrelationen tatsächlich auf übergeordnete Faktoren zurückführen lassen. Die Bestimmung der Anzahl der zu findenden Faktoren erfordert den ,,subjektiven Eingriff des Anwenders“ (Backhaus et al., 2016, S. 415). Dazu wurden Lösungen mit zwei, drei und vier Komponenten berechnet und ausgewertet. Die Lösung mit zwei Komponenten stellte sich wie angenommen als die am besten zu interpretierende heraus, da hier die Faktorladungen am eindeutigsten verteilt sind. Die 
Komponentenmatrizen zu den Modellen mit drei, bzw. vier Faktoren befinden sich im Anhang in Tabelle A.1 und Tabelle A.2 im Anhang. Die Komponentenmatrix in Tabelle 5.2 zeigt die Faktorladungen ${ }^{7}$ der sieben Variablen in der Zwei-Komponenten-Lösung ${ }^{8}$. Die erste Komponente fasst die Variablen „GröBe“, „Dichte“, „Modularität“ und den „Anteil familiärer Beziehungen“ zusammen, sie beschreibt also vorrangig die Netzwerkstruktur. Auf die zweite Komponente laden hingegen drei Variablen, die Auskunft über die Netzwerkzusammensetzung (Anteil institutioneller Beziehungen, Anteil Unterstützung, EI-Index) geben. Der erste Faktor erklärt $29 \%$, der zweite Faktor $27 \%$ der Varianz aller betrachteten Variablen im Sample, das Gesamtmodell erklärt $56 \%$ der Varianz. Die beiden Faktoren korrelieren erwartungsgemäß nicht miteinander (PearsonKorrelationskoeffizient $=0$ ).

Tabelle 5.2 Faktorladungen der Hauptkomponentenanalyse

\begin{tabular}{l|l|l}
\hline & Netzwerkstruktur & Netzwerkzusammensetzung \\
\hline Größe & 0.66 & {$[-0.33]$} \\
\hline Dichte & -0.75 & \\
\hline Modularität & 0.80 & \\
\hline Anteil Familie & -0.60 & {$[-0.30]$} \\
\hline Anteil Institutionen & & 0.83 \\
\hline Anteil Unterstützung & & 0.63 \\
\hline EI-Index (Erwerb) & & 0.75 \\
\hline
\end{tabular}

Abbildung 5.5 zeigt eine Visualisierung des Ergebnisses der Hauptkomponentenanalyse. Die Ladungen jeder Variable auf die beiden Hauptkomponenten Netzwerkstruktur und Netzwerkzusammensetzung sind auf den beiden Achsen abgetragen. $\mathrm{Zu}$ sehen ist, dass die Netzwerkgröße und die Modularität die Dimension „Netzwerkstruktur“ positiv beeinflussen und in einem negativen Zusammenhang mit der Netzwerkdichte und dem Anteil familiärer Beziehungen stehen. Große, stark modularisierte Netzwerke im Sample verfügen also häufig über eine geringere Netzwerkdichte und einen geringeren Anteil familiärer

7 ,Die Faktorladung gibt dabei an, wieviel ein Faktor mit einer Ausgangsvariablen zu tun hat. Im mathematisch-statistischen Sinne sind Faktorladungen nichts anderes als eine Maßgröße für den Zusammenhang zwischen Variablen und Faktor, und das ist wiederum nichts anderes als ein Korrelationskoeffizient zwischen Faktor und Variablen." Backhaus et al. (2016, S. 400).

${ }^{8}$ Dargestellt sind Werte ab 0,3. 
Beziehungen. Die zweite Dimension „Netzwerkzusammensetzung“ verdeutlicht den positiven Zusammenhang zwischen dem Anteil institutioneller Beziehungen und dem Anteil unterstützender Beziehungen sowie einem hohen EI-Index. Demzufolge gibt es in Netzwerken mit viel Unterstützung und vielen institutionellen Akteur*innen relativ wenige Personen, die denselben Erwerbsstatus aufweisen wie Ego.

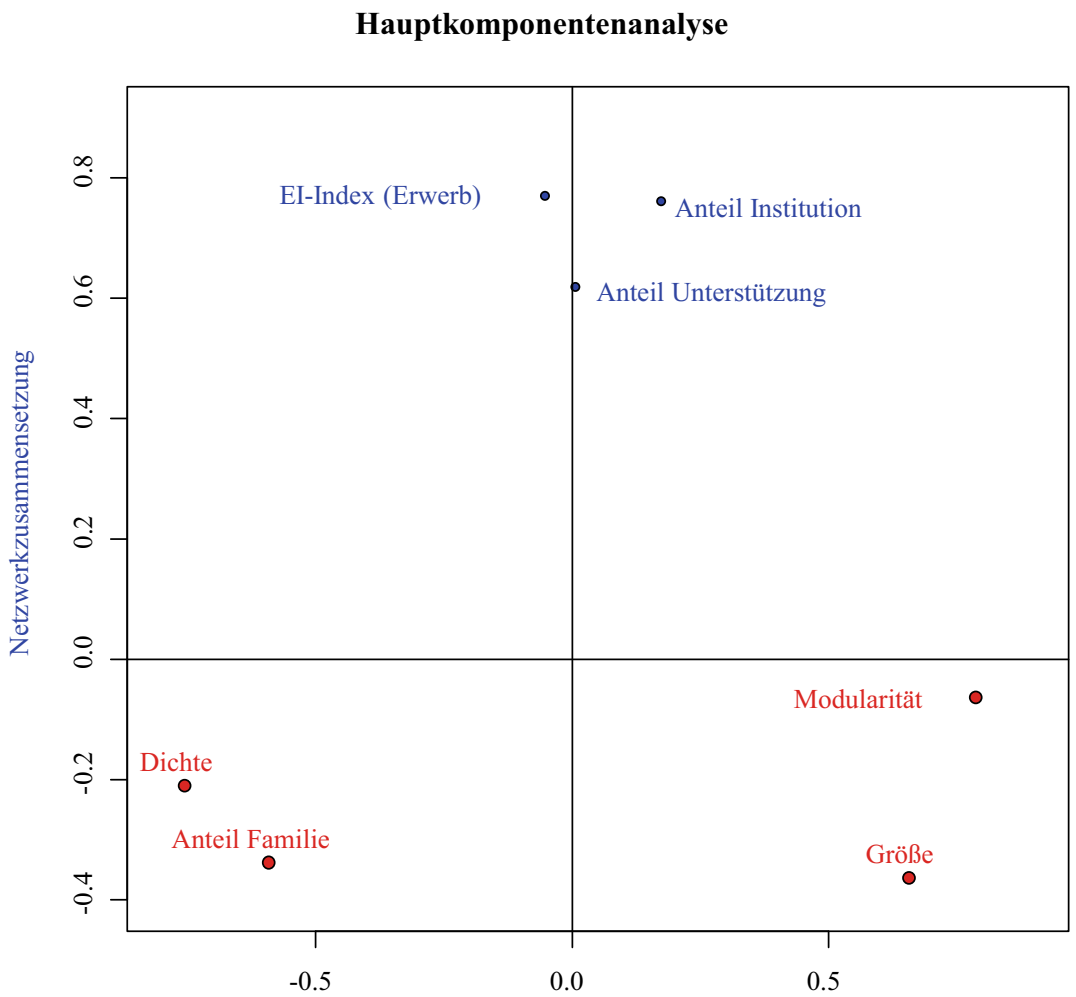

Netzwerkstruktur

Abbildung 5.5 Visualisierung der Hauptkomponentenanalyse

Dass die Variable „Anteil familiärer Beziehungen“ nicht auf den Faktor „Netzwerkzusammensetzung“ lädt, sondern auf den Faktor „Netzwerkstruktur“, erscheint verwunderlich. In der Literatur findet sich diese Beobachtung eines 
engen Zusammenhangs zwischen dem Anteil familiärer Beziehungen und der Netzwerkstruktur jedoch häufiger (z. B. bei Herz, 2014, S. 169 und bei Wellman \& Potter, 1999). Dies lässt sich als Ausdruck dafür lesen, dass überwiegend familiär geprägte Netzwerke eine eigene Struktur aufweisen, die durch eine hohe Dichte gekennzeichnet ist (Keim, 2011, S. 220). Studien zu sozialen Netzwerken von Menschen in Armut zeigen zudem, dass Netzwerke infolge von materieller Knappheit auf einen Kern aus familiären Kontakten zusammenschrumpfen können (Cattell, 2001; Stead et al., 2001) - die auf diese Weise reduzierten Netzwerke sind dann nicht nur besonders familiär geprägt, sondern auch eher klein und eng verbunden (hohe Dichte).

\subsubsection{Clusteranalyse}

In diesem Kapitel sollen Muster sozialer Netzwerkstrukturen anhand der sieben Variablen Netzwerkgröße, Netzwerkdichte, Modularität, Anteil familiärer Beziehungen, Anteil institutioneller Beziehungen, Anteil unterstützender Beziehungen und EI-Index (bezogen auf den Erwerbsstatus) in den egozentrierten Netzwerken der Befragten identifiziert werden. Die gesuchten Cluster sollen sich dadurch auszeichnen, dass die Varianz der sieben Variablen innerhalb der Cluster minimiert und dazwischen maximiert ist.

Im Folgenden wird die Vorgehensweise im Rahmen der Clusteranalyse erläutert, um darauf aufbauend die Entscheidung für eine Lösung aus drei Clustern zu begründen und diese schließlich in den Dimensionen der im vorangegangenen Abschnitt durchgeführten Faktorenanalyse (,Netzwerkstruktur“ und „Netzwerkzusammensetzung“) zu präsentieren.

\section{Erläuterung der Clusteranalyse}

Grundlage der Clusteranalyse bildet ein Datensatz, der die Variablenwerte zu jedem der 57 Fälle im Sample beinhaltet. Um Verzerrungen der Ergebnisse aufgrund unterschiedlicher Maßeinheiten der Variablen zu vermeiden, wurden die Variablenwerte skaliert ${ }^{9}$. Tabelle 5.3 enthält die skalierten Werte für die ersten fünf Fälle:

\footnotetext{
${ }^{9}$ Die Variablenwerte wurden um den Mittelwert zentriert und durch die Standardabweichung dividiert.
} 
Tabelle 5.3 Minimalbeispiel zur Berechnung der Distanzmatrix (I001-I005)

\begin{tabular}{l|r|r|l|l|l|l|l}
\hline & Größe & Dichte & Modularität & $\begin{array}{l}\text { Anteil } \\
\text { Familie }\end{array}$ & $\begin{array}{l}\text { Anteil } \\
\text { Institution }\end{array}$ & $\begin{array}{l}\text { Anteil } \\
\text { Unterstützung }\end{array}$ & EI-Index \\
\hline $\mathbf{I 0 0 1}$ & $-0,86$ & $-0,32$ & 1,14 & $-0,30$ & $-0,44$ & $-0,22$ & $-0,30$ \\
\hline $\mathbf{I 0 0 2}$ & $-2,00$ & 2,72 & $-0,96$ & 0,90 & $-1,49$ & $-1,48$ & $-2,27$ \\
\hline $\mathbf{I 0 0 3}$ & 0,06 & 1,22 & $-0,94$ & $-1,38$ & 1,20 & 0,52 & $-0,20$ \\
\hline $\mathbf{I 0 0 4}$ & 0,06 & $-0,68$ & 1,92 & $-0,37$ & 1,87 & 0,12 & $-0,20$ \\
\hline $\mathbf{I 0 0 5}$ & 1,21 & $-0,40$ & 1,19 & $-1,19$ & 0,82 & $-0,11$ & $-0,08$ \\
\hline
\end{tabular}

Auf Basis dieses Datensatzes wird eine Ähnlichkeits- bzw. Distanzmatrix berechnet, in der alle Fälle sowohl zeilenweise als auch spaltenweise abgetragen sind. Jede Zelle der Matrix gibt die Distanz zwischen den beiden Fällen im Sample an, die sich an dieser Stelle kreuzen. Sehr häufig wird die euklidische Distanz als Maß zur Berechnung der Nähe zwischen den einzelnen Fällen herangezogen (Backhaus et al., 2016, S. 469) ${ }^{10}$. Die Euklidische Distanz berechnet sich aus der Summe der quadrierten Differenzen der Variablenwerte im Ausgangsdatensatz. Die Euklidische Distanz zwischen dem Fall I001 und I002 berechnet sich auf folgende Weise:

$$
\begin{gathered}
d_{I 001 / I 002}^{2}=(-0,86+2)^{2}+(-0,32-2,72)^{2}+(1,14+, 096)^{2}+(-0,30-0,90)^{2} \\
+(-0,44+1,49)^{2}+(-0,22+1,48)^{2}+(-0,30+2,27)=22,97 \\
\rightarrow d_{I 001 / I 002}=4,79
\end{gathered}
$$

Die vollständige Distanzmatrix für das Minimalbeispiel aus Tabelle 5.3 sieht dann folgendermaßen aus:

\footnotetext{
${ }^{10}$ Im Anhang sind die Ergebnisse von Clusteranalysen auf Basis alternativer Distanzmaße dargestellt (Abbildung A.2 und Abbildung A.3). Die graphische Inspektion der Ergebnisse zeigt jedoch, dass sich die auf diese Weise ermittelten Cluster nicht so deutlich voneinander abgrenzen und sinnvoll interpretieren lassen wie jene, die unter Verwendung der euklidischen Distanz ermittelt wurden.
} 
Tabelle 5.4 Distanzmatrix der Fälle I001 bis I005

\begin{tabular}{l|l|l|l|l|l}
\hline & $\mathbf{I 0 0 1}$ & $\mathbf{I 0 0 2}$ & $\mathbf{I 0 0 3}$ & $\mathbf{I 0 0 4}$ & $\mathbf{I 0 0 5}$ \\
\hline $\mathbf{I 0 0 1}$ & 0 & 4,79 & 3,46 & 2,65 & 2,59 \\
\hline $\mathbf{I 0 0 2}$ & 4,79 & 0 & 5,22 & 6,62 & 6,41 \\
\hline $\mathbf{I 0 0 3}$ & 3,46 & 5,22 & 0 & 3,67 & 3,01 \\
\hline $\mathbf{I 0 0 4}$ & 2,65 & 6,62 & 3,67 & 0 & 1,94 \\
\hline $\mathbf{I 0 0 5}$ & 2,59 & 6,41 & 3,01 & 1,94 & 0 \\
\hline
\end{tabular}

Die Cluster werden auf Basis eines hierarchisch-agglomerativen Verfahrens berechnet $^{11}$, in dem schrittweise Fälle gruppiert werden, die sich in den Ausprägungen der Variablen ähneln (Backhaus et al., 2016, 478 f.): Im ersten Schritt stellt jeder einzelne Fall ein eigenes Cluster dar, dann werden die beiden Cluster zusammengefasst, die die geringsten euklidischen Distanzen miteinander aufweisen (im Minimalbeispiel: I004 und I005), um im folgenden Schritt erneut die beiden Cluster mit der geringsten Distanz zusammenzufassen (im Minimalbeispiel: I001 wird in das Cluster aus I004 und I005 integriert). Diese Prozedur kann so oft wiederholt werden, bis alle 57 Fälle wieder zu einem einzigen Cluster zusammengefasst sind.

Der Cluster-Algorithmus trifft keine Entscheidung über die endgültige Anzahl der zu bildenden Cluster. Es obliegt den Forschenden zu entscheiden, bei welchem Schritt die Zusammenfassung von Clustern abgebrochen werden soll. Die roten Rechtecke in Abbildung 5.6 zeigen sechs mögliche Einteilungen, die auf Basis der hier durchgeführten Clusteranalyse getroffen werden könnten. Die Entscheidung für eine Lösung mit zwei, drei oder vier Clustern liegt nahe, da die Aufteilung der Fälle auf die Cluster in diesen Lösungen relativ gleichmäßig ist und es nicht zur Bildung eines sehr kleinen Ausreißer-Clusters kommt wie z. B. bei den Lösungen mit 5 oder 6 Clustern. Als die am besten zu interpretierende Lösung wird im Folgenden das in Abbildung 5.7 noch einmal groß dargestellte Modell mit drei Clustern tiefergehend betrachtet.

\footnotetext{
${ }^{11}$ Die Clusteranalyse wurde unter Anwendung der „Hierarchical Clustering“-Funktion (hclust) des Stats-Pakets in R durchgeführt (R Core Team 2017). Zur Anwendung kam Ward's minimum variance method (,ward.d2“, Ward 1963), welche unter Voraussetzungen, die hier weitgehend erfüllt sind, die vergleichsweise treffendsten Cluster liefert (Backhaus et al. 2016, S. 489): Es wird ein metrisch skaliertes Distanzmaß verwandt, es gibt keine Ausreißer, die Variablen sind unkorreliert, die Gruppen sind etwa gleich groß und besitzen eine ähnliche Ausdehnung.
} 

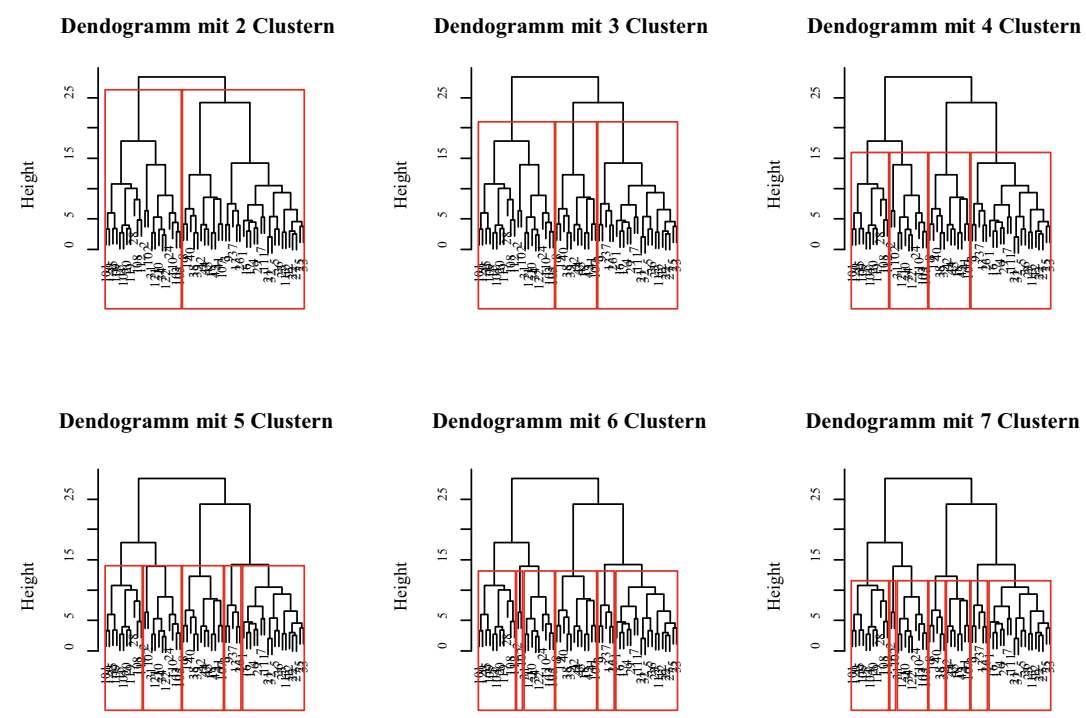

Abbildung 5.6 Hierarchisches Clusterverfahren - Dendogramme

Ergebnis der Clusteranalyse

Wenn man die 57 Fälle in den Dimensionen der Faktorenanalyse Netzwerkstruktur und Netzwerkzusammensetzung (siehe Abschnitt 5.1.3) abbildet und die in diesem Kapitel ermittelten Cluster einzeichnet, zeigt sich eine gut interpretierbare Lösung mit drei Clustern (Abbildung 5.8). Die drei Cluster bilden jeweils unterschiedliche Bereiche des Merkmalsraums ab. Die Cluster 1 und 3 beinhalten überwiegend Fälle mit eher größeren, stärker modularisierten Netzwerken, die über eine geringere Dichte sowie einen geringeren Anteil familiärer Alteri verfügen (überwiegend positive Werte auf der Dimension Netzwerkstruktur) während das Cluster 2 Fälle mit entgegengesetzten Struktureigenschaften zusammenfasst (überwiegend negative Werte in der Dimension Netzwerkstruktur: eher klein, hohe Dichte, geringe Modularität, familiär). Die Dimension Netzwerkzusammensetzung trennt hingegen das Cluster 3 von den übrigen beiden Clustern. Im Vergleich zu den Fällen in den Clustern 1 und 2 sind hier die Anteile an institutionellen Alteri und unterstützenden Beziehungen niedrig und der Anteil an Alteri mit demselben Erwerbsstatus wie Ego hoch (EI-Index negativ).

Ergänzend zur Abbildung der Ergebnisse der Clusteranalyse in den Dimensionen der Faktorenanalyse (Abbildung 5.8) sind die Mittelwerte der Variablen in 


\section{Cluster Dendogramm}

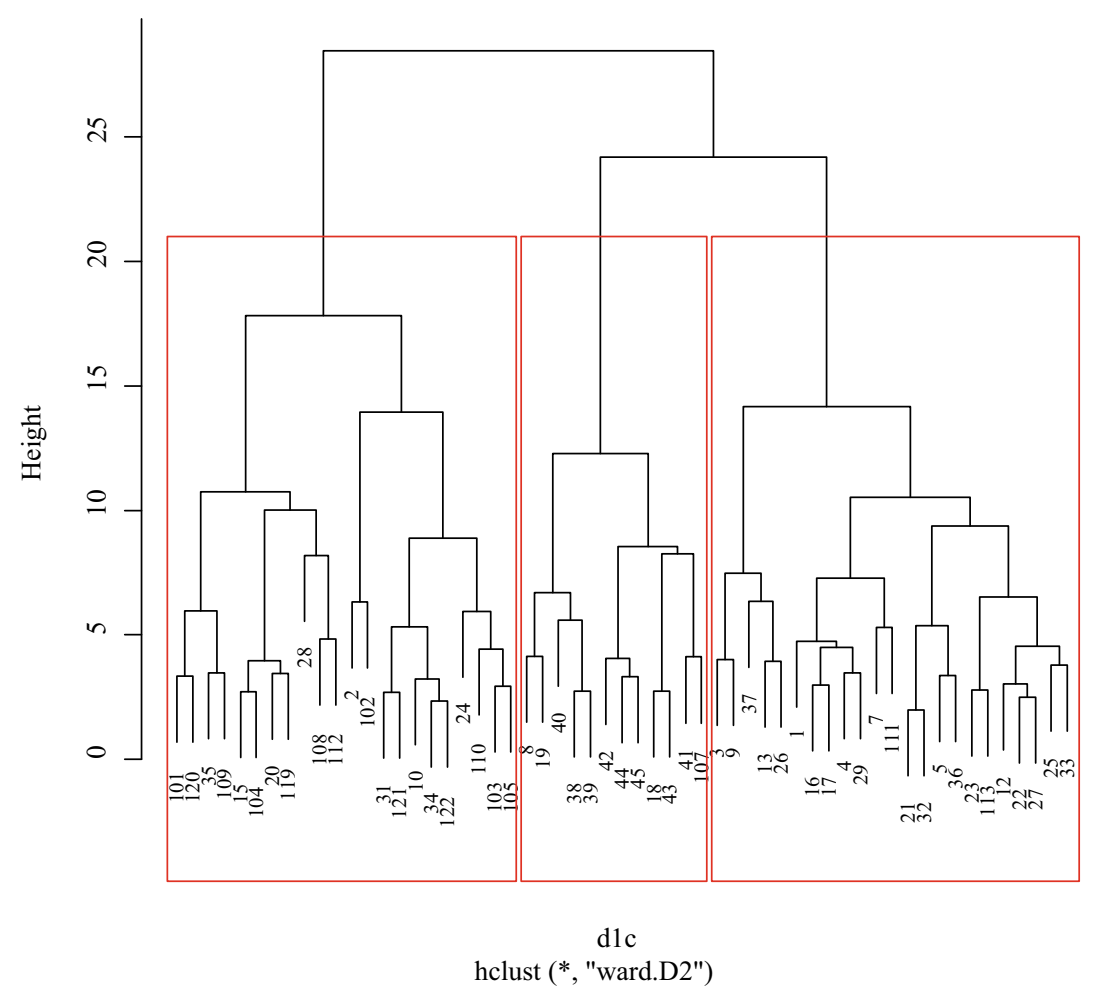

Abbildung 5.7 Dendogramm mit 3 Clustern

den drei Clustern in Tabelle 5.5 aufgelistet. Dabei sticht heraus, dass die Netzwerke in Cluster 1 einen besonders hohen mittleren Anteil institutioneller Alteri $(28,3 \%)$ sowie unterstützender Beziehungen (42,2\%) aufweisen und nur verhältnismäßig wenige Alteri vorkommen, die denselben Erwerbsstatus wie Ego haben (mittlerer EI-Index =0,528). Der Netzwerktypus in Cluster 1 wird daher auf Basis der quantitativen Analyse als „,institutionelles Unterstützungsnetzwerk“ bezeichnet.

Die Netzwerke in Cluster 2 sind mit durchschnittlich 7,6 Personen und einer mittleren Dichte von 0,528 sowie einer sehr niedrigen mittleren Modularität von 0,022 eher klein und eng verbunden. Der mittlere Anteil familiärer Alteri ist mit 


\section{Clusteranalyse}

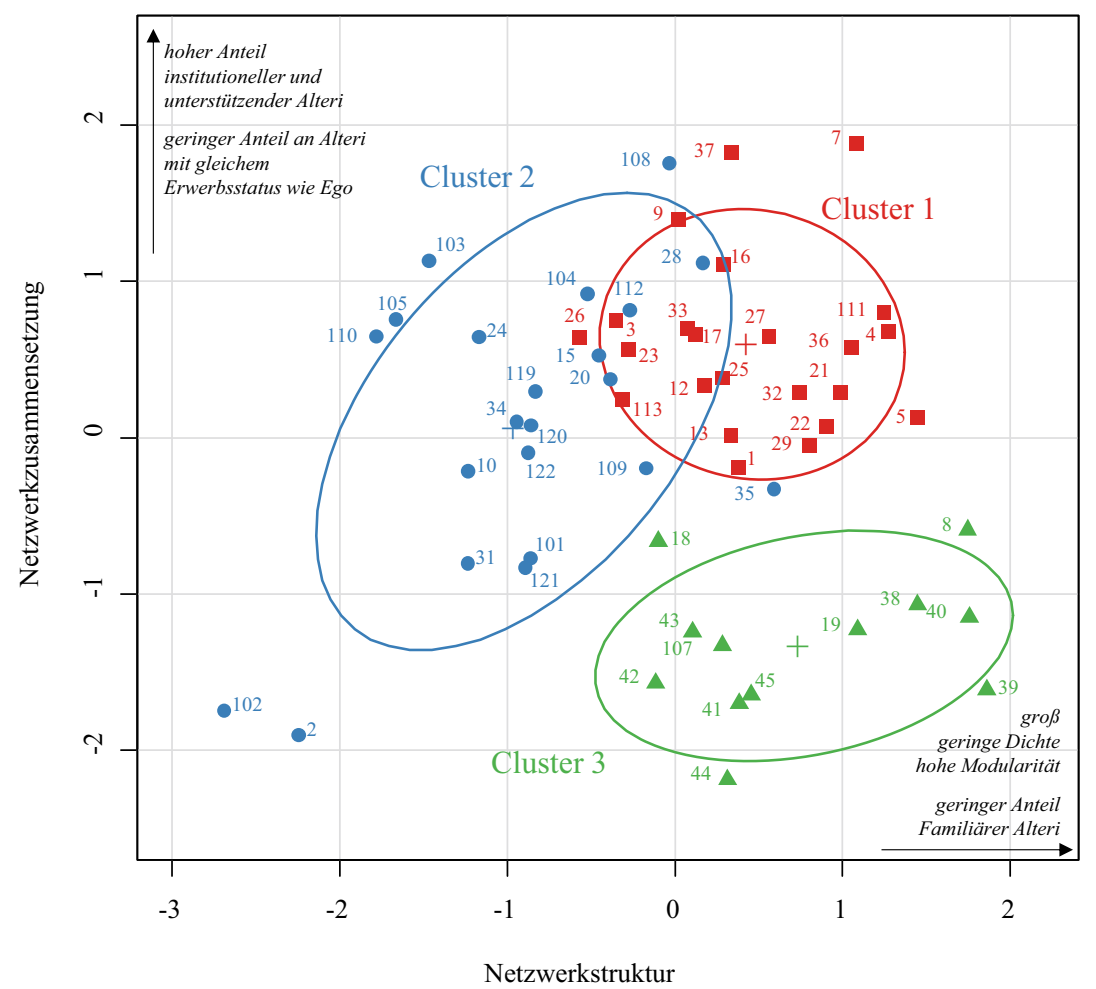

Abbildung 5.8 Ergebnis der Clusteranalyse in der Komponentenmatrix

39,3\% besonders hoch. Dieser Typus erhält daher die Bezeichnung: „kleines, eng verbundenes Familiennetzwerk“.

Das dritte Cluster zeichnet sich durch große Netzwerke mit durchschnittlich 15,8 Personen aus, die am stärksten modularisiert sind (mittlere Modularität = 0,282) und die geringsten mittleren Anteile institutioneller (8,2\%) und unterstützender $(19,4 \%)$ Beziehungen enthalten. Der mittlere Anteil an Alteri mit demselben Erwerbsstatus wie Ego ist in diesem Cluster besonders hoch (EIIndex $=-0,498)$. Dieser Netzwerktypus erhält daher die Bezeichnung: ,großes, verzweigtes Peer-Netzwerk“. 
Tabelle 5.5 Mittelwerte der Variablen in den Clustern

\begin{tabular}{l|l|l|l}
\hline & $\begin{array}{l}\text { Cluster 1 } \\
\text { institutionelles } \\
\text { Unterstützungsnetzwerk }\end{array}$ & $\begin{array}{l}\text { Cluster 2 } \\
\text { kleines, eng } \\
\text { verbundenes } \\
\text { Familiennetzwerk }\end{array}$ & $\begin{array}{l}\text { Cluster 3 } \\
\text { großes, } \\
\text { verzweigtes } \\
\text { Peer-Netzwerk }\end{array}$ \\
\hline Fallzahl & 23 & 22 & 12 \\
\hline Größe & 11,5 & 7,6 & 15,8 \\
\hline Dichte & 0,313 & 0,528 & 0,338 \\
\hline Modularität & 0,250 & 0,022 & 0,282 \\
\hline Anteil Familie & 0,3054 & 0,393 & 0,292 \\
\hline Anteil Institution & 0,283 & 0,169 & 0,082 \\
\hline Anteil & 0,422 & 0,310 & 0,194 \\
Unterstützung & & 0,451 & $-0,498$ \\
\hline EI-Index & 0,528 & &
\end{tabular}

Verteilung soziodemographischer Merkmale in den Netzwerkclustern

Tabelle 5.6 zeigt die Verteilung der soziodemographischen Eigenschaften der Egos in den drei Netzwerkclustern. Dabei zeigt sich eine relativ ähnliche Struktur der zu den Netzwerkclustern 1 und 2 gehörigen Egos im Hinblick auf Geschlecht, Alter, Bildung und Erwerbsstatus. Die zu diesen beiden Clustern gehörenden Egos sind deutlich älter (Mittelwert: 44,4, bzw. 44,3 Jahre) als die Egos in Cluster 3 (Mittelwert 25,8 Jahre), sie haben geringere Bildungsstände als die Egos in Cluster 3 und sind sehr viel häufiger erwerbslos oder in bereits in Rente. Während die Egos in Cluster 1 überwiegend allein leben, sind in Cluster 2 anteilig etwas mehr verheiratete Personen und in Cluster 3 etwas mehr in Partnerschaft lebende Personen vertreten.

Die Egos in Cluster 3 sind durchweg kinderlos, während es in den anderen beiden Clustern sowohl Alleinerziehende als auch in Partnerschaft oder Ehe lebende Egos mit Kindern gibt. Die deutlichsten Unterschiede zwischen den Clustern 1 und 2 gibt es im Hinblick auf die Herkunftsregion. In 13 der 16 Interviews, die in ländlichen Regionen geführt wurden, wurden Netzwerke erhoben, die dem Cluster 2 zugeordnet sind ${ }^{12}$. Diese Beobachtung lässt sich als ein erster Hinweis auf

${ }^{12}$ Anlässlich dieser sehr deutlichen Zuordnung der im ländlichen Raum erhobenen Netzwerke zu einem der drei Cluster wurde eine Überprüfung möglicher Interviewer*inneneffekte durchgeführt. 10 der 16 Interviews im ländlichen Raum wurden von einem Interviewer erhoben, der nur dort aktiv war. Die übrigen sechs Interviews im ländlichen Raum wurden von einer Interviewerin durchgeführt, die sowohl Interviews in 


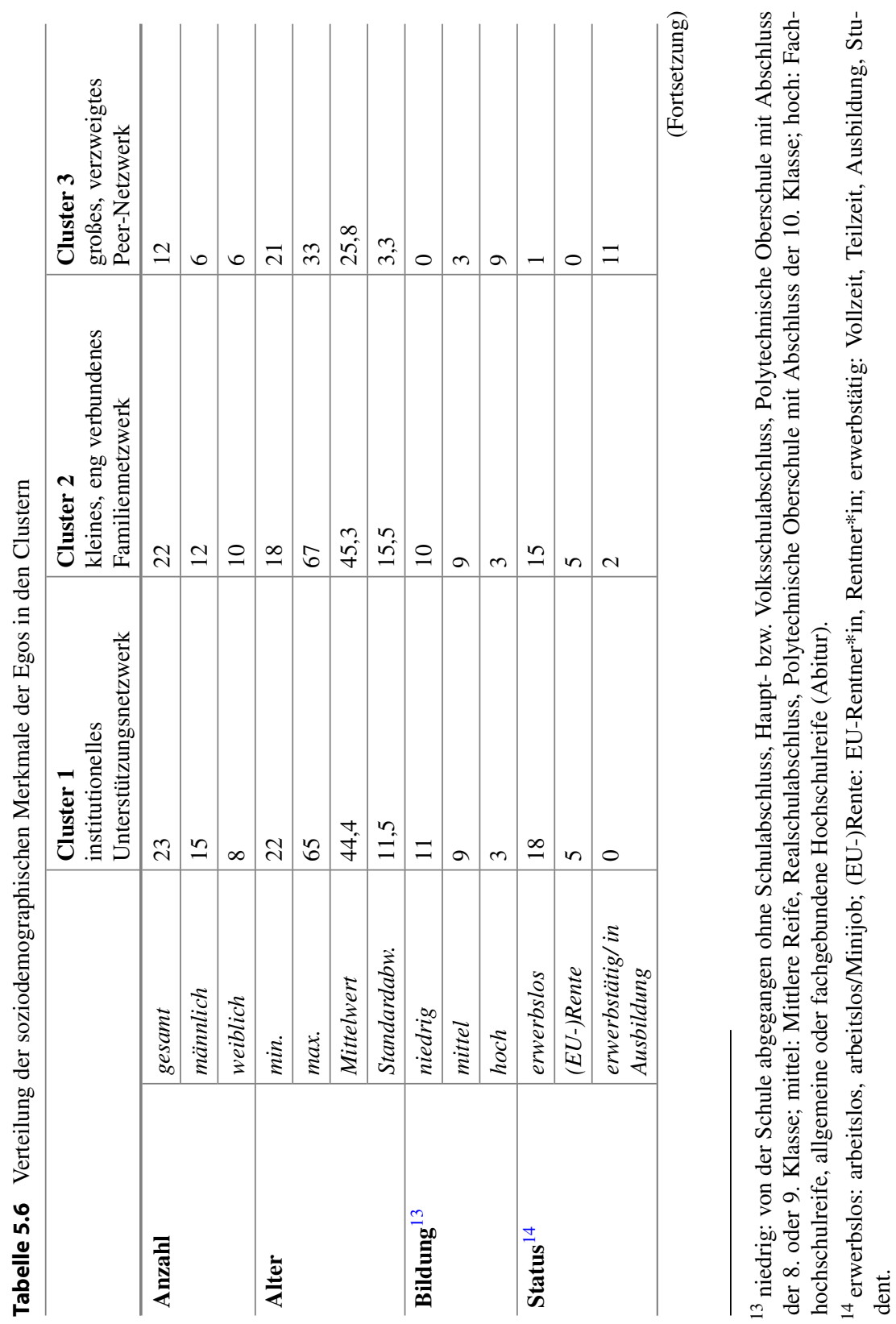




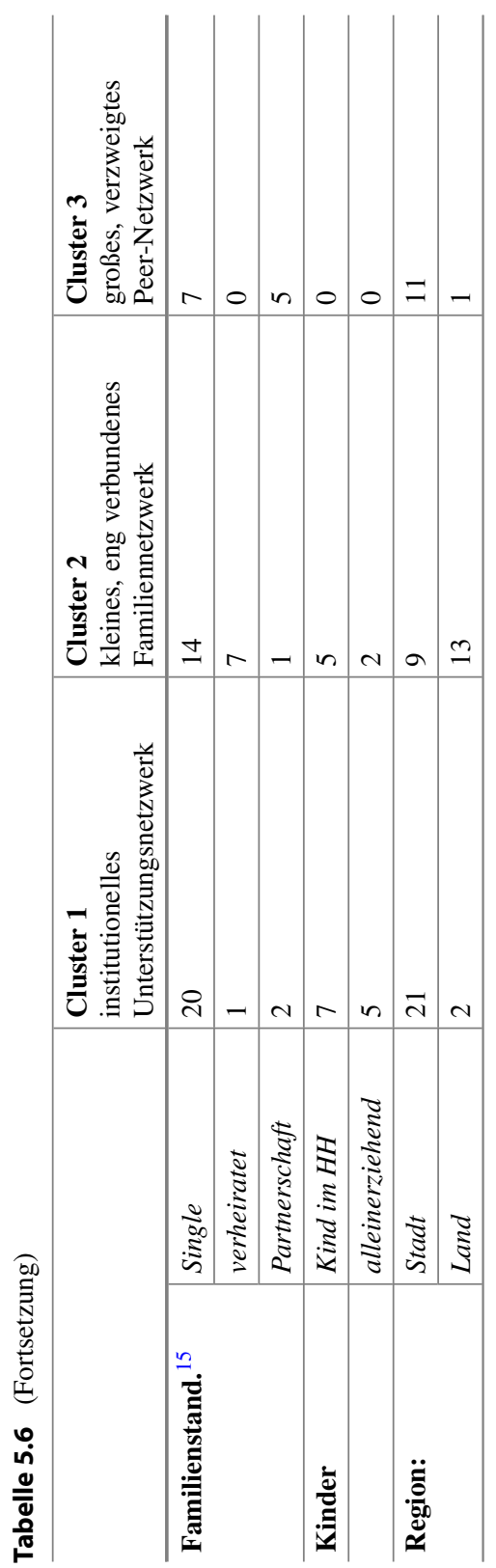

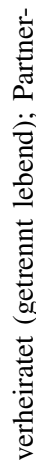

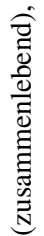

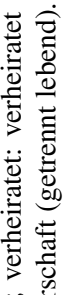

iิ

要

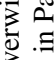

论

잉

Q

บ

$\stackrel{0}{\Xi}$

อิ

$\supseteqq \stackrel{\infty}{\Xi}$

胥

를

$\exists$ 궁

$\Xi$

ô

르

$\ddot{0} . \Xi$

的 
Zusammenhänge zwischen der sozial-räumlichen Umgebung und der Netzwerkstruktur deuten, die im qualitativen Teil der Analyse noch einmal tiefergehend betrachtet werden.

In diesem Kapitel konnten die drei Netzwerktypen ,institutionelles Unterstützungsnetzwerk“, „kleines, eng verbundenes Familiennetzwerk“, und „großes, verzweigtes Peer-Netzwerk" auf Basis einer multivariaten Strukturanalyse der Netzwerke im Sample ermittelt werden. Im Folgenden wird die qualitative Typologie dargestellt, um zu ermitteln, ob es Zusammenhänge zwischen den hier identifizierten Strukturtypen der egozentrierten Netzwerke und den Handlungsorientierungen der Befragten gibt.

\subsection{Qualitative Typologie}

Die qualitative Typologie wurde im Rahmen eines iterativen Prozesses erstellt, bei dem die qualitativen Analysen immer wieder vor dem Hintergrund der theoretischen Grundlage und der empirischen Literatur reflektiert wurden. Eine besondere Herausforderung bestand darin, die Wechselwirkungen zwischen Ungleichheiten und Netzwerken anhand des empirischen Materials herauszuarbeiten und in der Theoriearbeit aufzugreifen. So zeigen sich am Datenmaterial eindeutig Ungleichheiten in Bezug auf Handlungs- und Anpassungsfähigkeit der Befragten, die durch die Verfügbarkeit von Gelegenheitsstrukturen in der sozial-räumlichen Umgebung ermöglicht oder beschränkt wird. Während sich die Ungleichheitsforschung jedoch nicht explizit mit der Einbettung in soziale Netzwerke auseinandersetzt, interessiert sich die Netzwerkforschung nur am Rande für soziale Ungleichheiten. Daher mussten bestehende Konzepte im Rahmen eines intensiven Theorie-Empirie-Dialogs immer wieder (re-)formuliert, modifiziert und aufeinander bezogen werden. Zentral für die Ausarbeitung der Typologie sind die folgenden theoretisch-empirischen Überlegungen:

- Die soziale Lage der Akteur*innen soll aus der Logik ihrer Situation heraus verstanden werden, die hier als Einbettung in soziale Beziehungsstrukturen im Zeitverlauf operationalisiert wird.

der Stadt als auch im ländlichen Raum durchgeführt hat. Auch in ihren Interviews lassen sich deutliche Stadt-Land-Unterschiede in den Netzwerken nachweisen. Daher ist davon auszugehen, dass es sich hierbei nicht um einen systematischen Erhebungsfehler, sondern um einen tatsächlichen Stadt-Land-Unterschied handelt. 
- Ungleichheiten lassen sich aus der Betrachtung der Bewältigungschancen der Angehörigen dieser sozialen Lagen ableiten. Diese Chancen variieren in Abhängigkeit von der Verfügbarkeit materiell, sozial und räumlich strukturierter Gelegenheiten zur Etablierung von Identitäten.

- Soziale Beziehungsnetzwerke bilden die Brücke zwischen der Einbettung in strukturell vor- oder nachteilige Lagen und individuellen Handlungsweisen. Je nach Lage lassen sich unterschiedlich viele Ressourcen aus dem Netzwerk generieren.

- Die Bewältigungsstrategien werden an den über das Netzwerk zugänglichen Domänen ausgerichtet.

- Gleichzeitig reduziert die Einbindung in Netzwerkstrukturen die Bewältigungschancen durch die Festlegung der Akteur*innen auf bestimmte Identitäten.

- Diese Überlegungen wurden schließlich in die in Abschn. 2.3.2 eingeführte Definition überführt: Von Armut bedroht sind Akteur*innen dann, wenn sie infolge materieller Unsicherheiten in Abhängigkeitsverhältnisse geraten, die ihre Identität in zentralen Netzwerkdomänen gefährden oder Zugänge in Anerkennung generierende Domänen versperren. Von Armut betroffen sind sie sie dann, wenn sie in dieser Situation nicht in der Lage sind, diese Beschränkung durch ein Zurückgreifen auf alternative Identitäten aus anderen Domänen ihres Netzwerks zu kompensieren (Switching).

Typisiert wurde daher die Fähigkeit (Agency) der Befragten, ausgehend von der zu einem bestimmten Zeitpunkt gegebenen sozi-strukturellen Einbettung, ein Leben im Einklang mit ihren persönlichen und kollektiven Idealen, Interessen und Verbindlichkeiten (,personal and collective ideals, interests, and commitments“ Emirbayer \& Goodwin, 1994, S. 1443) zu führen. Dies kann entweder durch die Anpassung an eine gegebene Netzwerkstruktur erreicht werden (Beibehaltung des Netzwerks) oder durch die Veränderung des Netzwerks (siehe Tabelle 5.7). Die Agency ist hoch, wenn es den Befragten gelingt, annährend ein solches Leben im Einklang zu führen. Sie ist gering, wenn dies nicht oder nur teilweise gelingt.

Materielle Knappheit und ein Mangel an sozialer Teilhabe treten in allen vier Typen als Herausforderung zutage. Die Armut beschränkt sich daher nicht auf einen der vier Typen. Wie im Folgenden zu zeigen sein wird, muss Agency unter der in allen vier Typen relevanten Bedingung relativer Einkommensarmut hart erkämpft werden. Den beiden Typen mit hoher Agency gelingt dies besser als den anderen beiden Typen. Doch auch ihre Situation ist prekär. Wie lange sich diese Anstrengungen aufrechterhalten lassen und ob sie weiterhin erfolgreich sind 
Tabelle 5.7 Qualitative Typologie

\begin{tabular}{|c|c|c|c|}
\hline & \multicolumn{2}{|l|}{ Ausrichtung des Netzwerkhandelns } \\
\hline & & Beibehaltung des Netzwerks & Veränderung des Netzwerks \\
\hline \multirow[t]{2}{*}{ Agency } & hoch & $\begin{array}{l}\text { TYP 1: } \\
\text { Prekärstabil: Herstellung von } \\
\text { Agency in alternativen Domänen } \\
\text { im bestehenden Netzwerk }\end{array}$ & $\begin{array}{l}\text { TYP 4: } \\
\text { Ausbau von Agency } \\
\text { in allg. anerkannter Struktur }\end{array}$ \\
\hline & niedrig & $\begin{array}{l}\text { TYP 2: } \\
\text { Prekärlabil: Mangel an Agency } \\
\text { im bestehenden Netzwerk }\end{array}$ & $\begin{array}{l}\text { TYP 3: } \\
\text { Geschwächte Agency } \\
\text { und Suche nach neuer Struktur }\end{array}$ \\
\hline
\end{tabular}

(Typ 1) oder tatsächlich zur Überwindung der Armut führen (Typ 4), ist nicht abzusehen.

Tabelle 5.8 zeigt die soziodemographische Zusammensetzung der vier Typen. Dabei zeigen sich Zusammenhänge zwischen der Typenzuordnung und dem Alter der Befragten. Die Angehörigen der ersten beiden Typen sind im Mittel deutlich älter als die Angehörigen von Typ 3 und 4. Der Typ 4 sticht zudem durch einen besonders hohen Bildungsstand der Befragten heraus. Auch der berufliche Status scheint im Zusammenhang mit der Typenzuordnung zu stehen. Die Angehörigen des Typs 2 sind überwiegend erwerbslos, während sich erwerbstätige und bereits berentete Befragte in Typ 1 die Waage halten. Erwerbstätige bzw. in Ausbildung befindliche Befragte gibt es nur in Typ 3 und 4. In diesen Gruppen gibt es altersbedingt noch keine Rentner*innen. Auffällig ist, dass es in allen vier Typen - also im gesamten Sample - sehr viele alleinlebende Personen gibt (Familienstand: Single). Die meisten der Interviewten aus dem ländlichen Raum wurden Typ 2 zugeordnet.

Im Folgenden werden die vier Typen im Detail beschrieben. Jeder der vier Abschnitte zu den Typen beginnt mit einer zusammenfassenden Darstellung, bevor im Detail auf die Wahrnehmung der alltäglichen Lebenssituation (1), die Biographien der Befragten (2) und ihre soziale Einbindung (3) eingegangen wird. 
Tabelle 5.8 Soziodemographische Angaben zur qualitativen Typologie

\begin{tabular}{|c|c|c|c|c|c|}
\hline & & $\begin{array}{l}\text { Typ 1 } \\
\text { Prekärstabil: } \\
\text { Herstellung } \\
\text { von Agency } \\
\text { in } \\
\text { alternativen } \\
\text { Domänen }\end{array}$ & $\begin{array}{l}\text { Typ } 2 \\
\text { Prekärlabil: } \\
\text { Mangel an } \\
\text { Agency }\end{array}$ & $\begin{array}{l}\text { Typ } 3 \\
\text { Geschwächte } \\
\text { Agency }\end{array}$ & $\begin{array}{l}\text { Typ } 4 \\
\text { Ausbau } \\
\text { von } \\
\text { Agency }\end{array}$ \\
\hline \multirow[t]{3}{*}{ Anzahl } & gesamt & 16 & 16 & 17 & 8 \\
\hline & männlich & 6 & 9 & 7 & 4 \\
\hline & weiblich & 10 & 7 & 10 & 4 \\
\hline \multirow[t]{4}{*}{ Alter } & $\min$. & 34 & 18 & 22 & 21 \\
\hline & $\max$ & 67 & 64 & 52 & 31 \\
\hline & Mittelwert & 53,1 & 44,7 & 32,9 & 25,4 \\
\hline & Standardabw. & 8,7 & 15,9 & 7,7 & 3,0 \\
\hline \multirow[t]{3}{*}{ Bildung $^{16}$} & niedrig & 7 & 8 & 6 & 0 \\
\hline & mittel & 7 & 7 & 7 & 0 \\
\hline & hoch & 2 & 1 & 4 & 8 \\
\hline \multirow[t]{3}{*}{ Status $^{17}$} & erwerbslos & 8 & 14 & 12 & 0 \\
\hline & $($ EU-)Rente & 8 & 2 & 0 & 0 \\
\hline & $\begin{array}{l}\text { erwerbstätig/in } \\
\text { Ausbildung }\end{array}$ & 0 & 0 & 5 & 8 \\
\hline \multirow[t]{3}{*}{ Familienstand $^{18}$} & Single & 13 & 10 & 13 & 4 \\
\hline & verheiratet & 2 & 5 & 1 & 0 \\
\hline & Partnerschaft & 1 & 1 & 3 & 4 \\
\hline \multirow[t]{2}{*}{ Kinder } & Kind im $\mathrm{HH}$ & 0 & 3 & 9 & 0 \\
\hline & alleinerziehend & 0 & 2 & 5 & 0 \\
\hline \multirow[t]{2}{*}{ Region: } & Stadt & 13 & 7 & 13 & 8 \\
\hline & Land & 3 & 9 & 4 & 0 \\
\hline
\end{tabular}

${ }^{16}$ niedrig: von der Schule abgegangen ohne Schulabschluss, Haupt- bzw. Volksschulabschluss, Polytechnische Oberschule mit Abschluss der 8. oder 9. Klasse; mittel: Mittlere Reife, Realschulabschluss, Polytechnische Oberschule mit Abschluss der 10. Klasse; hoch: Fachhochschulreife, Allgemeine oder fachgebundene Hochschulreife (Abitur).

17 erwerbslos: arbeitslos, arbeitslos/Minijob; (EU-)Rente: EU-Rentner, Rentner; erwerbstätig: Vollzeit, Teilzeit, Ausbildung, Student.

${ }^{18}$ Single: ledig, in Trennung, geschieden, verwitwet; verheiratet: verheiratet (zusammenlebend), verheiratet (getrennt lebend); Partnerschaft: in Partnerschaft (zusammenlebend), in Partnerschaft (getrennt lebend). 


\subsubsection{Typ 1: Prekärstabil - Herstellung von Agency}

Die Befragten im Typ 1 „Prekärstabil - Herstellung von Agency in alternativen Domänen " sind seit vielen Jahren - oft seit Jahrzehnten - von Armut und Prekarität betroffen. Ihren alltäglichen Kämpfen um Anerkennung und Anschluss in der Erwerbsarbeitsgesellschaft stehen wiederkehrende Erfahrungen der Abwertung und Zurücksetzung entgegen. Sie sind häufig nur kurzzeitig beschäftigt und dann wieder lange arbeitslos. Sie befinden sich im ständigen Statuskampf, da es ihnen, wenn überhaupt, nur vorübergehend gelingt, ihren sozialen Status durch Arbeit zu verbessern. Die meisten haben keine Ersparnisse (mehr) und müssen penibel haushalten, um mit ihrem Einkommen über die Runden zu kommen.

Um nicht als arm wahrgenommen zu werden, legen sie großen Wert auf die Wahrung einer respektablen Erscheinung auf der Vorderbühne und gleichen die dafür nötigen Investitionen durch Einsparungen auf der Hinterbühne aus. Auf diesen Vorderbühnen gelingt es ihnen, nicht als arm oder bedürftig zu erscheinen, sondern als Person, die eine wichtige Funktion in einer zentralen Domäne ihres Netzwerks übernimmt. Unter Rückgriff auf diese Identitäten gelingt es den Befragten, auch über den konkreten Handlungszusammenhang hinaus Anerkennung und Teilhabe zu generieren.

Der Typ setzt sich zusammen aus:

- sechs erwerbslosen Personen (I004, I005, I007, I021, I101, I109), denen es gelingt, mithilfe von Jobs und Maßnahmen, aber auch abseits des Erwerbssystems Anerkennung generieren, z. B. als Künstler, Hausmeister im Reitverein oder Helferin in der Nachbarschaft,

- drei ehrenamtlich engagierten Rentnerinnen (I010, I029 und I031),

- zwei erwerbunfähigkeitsberenteten Männern (I001 und I017) und einer erwerbsslosen Frau (I111), die im Augenblick noch auf die Bewilligung ihrer Erwerbsunfähigkeitsrente wartet. Alle drei übernehmen Aufgaben in unterschiedlichen Domänen (Behindertensportverein, Stadtteilzentren, Nachbarschaft) sowie

- vier Mitgliedern eines Alkoholiker-Selbsthilfevereins (erwerbslos: I013 / EURente: I012, I015, I016).

Als alternativ werden viele in den Netzwerken der Befragten des Typs 1 auftauchenden Domänen deshalb bezeichnet, weil sie und ihre Rollen hier nicht nach vorgegebenen Mustern strukturiert sind wie im Bereich der Erwerbsarbeit oder der Familie. Die Befragten haben z. B. im Rahmen eines ehrenamtlichen 
Engagements oder einer regelmäßigen Aktivität in der Nachbarschaft die Möglichkeit, Identitäten abseits ihrer prekären Alltagserfahrungen auszubilden und zu stabilisieren. Ausgehend von dem hier erfahrenen Rückhalt widerstehen sie der Gefahr eines Rückfalls oder halten den wiederkehrenden Demütigungen auf dem Arbeitsmarkt stand und finden immer wieder neuen Mut, weiterzumachen.

Die Situation der Befragten lässt sich treffend mit dem Oxymoron Prekärstabil bezeichnen. Prekär ist nicht nur ihre materielle Situation, sondern auch ihr sozialer Status. Die Anerkennung der alternativen Identitäten basiert auf der Sichtbarkeit eines herausragenden Einsatzes, die die Aufwertung der eigenen Person durch Abgrenzung von weniger Engagierten Personen erst möglich macht. Allgemein anerkannte Formen der Statuszuweisung und -absicherung wie die unbefristete Vollzeitstelle oder die auskömmliche Rente als Höhepunkt eines „erfolgreichen“ Erwerbslebens stehen den Befragten nicht zur Verfügung. Stabil ist hingegen das, was die Befragten der prekären Situation entgegensetzen: Ihre Widerstands- und Selbstbehauptungskräfte sind erstaunlich robust und biographisch eingeübt. Fast alle verfügen über eine zeitlich überdauernde Netzwerkdomäne, aus der sie emotionale Unterstützung und sozialen Rückhalt beziehen (z. B. Partnerschaft, Familie, beste Freund*innen, Verein).

Wahrnehmung alltäglicher Herausforderungen, Bewältigungsstrategien und Perspektiven

Sich in einer Ordnung zurechtzufinden, in der der eigene Status langfristig nicht abgesichert werden kann, verursacht viele Demütigungen im Alltag und erfordert enorme Anpassungsleistungen. Die Befragten im Typ 1 „Prekärstabil: Herstellung von Agency in alternativen Domänen " begegnen diesen Zumutungen durch besondere Anstrengungen in den ihnen zur Verfügung stehenden Netzwerkdomänen und die Erschließung neuer Domänen. Die einen verlagern ihre Aktivitäten vollständig auf alternative Formen sozialer Teilhabe außerhalb des Erwerbssystems (Ehrenamt, Vereinsmitgliedschaft) oder engagieren sich als Rentner*innen in unterschiedlichen sozialen Kreisen (Familie, Vereine, Nachbarschaft). Die anderen kombinieren die in der Regel zeitlich befristeten Netzwerkressourcen aus dem Kontext des Erwerbssystems (MAE-Stellen ${ }^{19}$, Qualifizierungsmaßnahmen, Jobs, institutionelle Förderung und Beratung, ...) mit alternativen Gelegenheitsstrukturen wie Freundeskreisen, Vereinen und Nachbarschaften, im Rahmen derer sie feste Rollen einnehmen (Fälle zu den Netzwerken aus Abbildung 5.9). Insbesondere im Erwerbskontext versuchen sie, sich darüber hinaus immer wieder neue

\footnotetext{
${ }^{19}$ sogenannte Arbeitsgelegenheiten mit Mehraufwandsentschädigung, auch Ein-Euro-Jobs genannt.
} 
Domänen zu erschließen. Sie sind längst nicht mehr auf ihren Ausbildungsberuf oder eine biographisch konsistente Beschäftigung festgelegt. Viele wären bereit, jeden Job anzunehmen, den sie kriegen können, so wie die 52-jährige Astrid Schubert:

„Ich kann Ihnen gerne mal zeigen - meine Bewerbungen [...] von der Bürohilfe bis zum Lagerarbeiter, ich nehme erst mal alles, Sushi rollen, alles, ja. Ich bewerbe mich überall. Seit September habe ich wieder 15, 16 Bewerbungen geschrieben, ich hab original eine Antwort gekriegt, aber original eine. Weiß ich auch nicht, was da los ist. Also ich hab die nicht nur geschrieben, ich hab sie auch abgeschickt, aber nur eine einzige Antwort. “ Astrid Schubert, 52, I007\$337

Die Mühe, die Frau Schubert sich mit ihren Bewerbungen gegeben hat, wird nicht anerkannt, solange man es noch nicht einmal für nötig hält, ihr zu antworten. Die Teile der Welt, in denen Anerkennung, Status und Ressourcen durch Erwerbsarbeit zu erreichen sind, sind der Befragten schwer zugänglich. Dennoch ist das tägliche Suchen nach Arbeit und das Schreiben von Bewerbungen wichtiger Bestandteil ihrer Alltagsstruktur, und sie kommt mit dem Verweis auf diese Aktivitäten der Stigmatisierung als passive Arbeitslose zuvor ${ }^{20}$. Frau Schubert hat sich nichts vorzuwerfen, da sie alles in ihrer Macht Stehende getan hat, um in Arbeit zu kommen (allein „, seit September [...] 15, 16 Bewerbungen“).

Wichtig zur Aufrechterhaltung dieser Strategie ist, dass die Befragten hin und wieder Erfolg haben. Sie erlangen von Zeit zu Zeit Zugang zu sozialer Anerkennung und Teilhabe im oder am Rande des Erwerbssystems. Da diese Tätigkeiten in der Regel befristet sind, sind die Anstrengungen, die im Rahmen dieser Tätigkeiten erbracht wurden, jedoch schnell wieder entwertet. Daher versuchen sie diese Beschäftigungen so lange wie möglich aufrecht zu erhalten. Frau Schubert nimmt z. B. gerade an einer Qualifizierungsmaßnahme teil, die auf ihren Wunsch hin verlängert wurde, ebenso der 55-jährige Rolf Hausner:

„In D. [Ort der Maßnahme] bin ich jetzt eineinhalb Jahre. Normalerweise ist das ja auch bloß ein halbes Jahr. Aber ick hab det verlängert, verlängert, verlängert. Weil, ich will mich jetzt nicht irgendwie in Himmel heben, aber der Anton, der so ein bisschen Vorarbeiter macht, [sagte]: ,Du kannst viel mit Holz. Komm mal', so kam das. " Rolf Hausner, 55, I101§163

In der Aussage Rolf Hausners zeigt sich eines der zentralen Motive für die andauernde Suche nach Beschäftigungsmöglichkeiten: Er bekommt hier soziale

\footnotetext{
${ }^{20}$ zur Bedeutung sozialer Netzwerke im Umgang mit Stigmatisierung siehe auch: Knabe, Fischer et al. (2018).
} 
Anerkennung für sein Handeln. Der Vorarbeiter bestätigt, dass er handwerklich begabt ist und gebraucht wird. Doch der Zugang zu dieser Domäne wird durch eine dritte Kraft geregelt (siehe Abschnitt: „Visuelle Netzwerkanalyse“): Die Übereinkunft zwischen Herrn Hausner und dem Maßnahmeträger muss durch das Jobcenter bestätigt werden. Egal, wie unentbehrlich sich Herr Hausner durch seine Tätigkeit in der Maßnahme macht: Er kann dort nicht dauerhaft bleiben. Umso wichtiger im Sinne seines Bewältigungshandelns ist es, dass diese Aktivität nicht seine einzige Quelle sozialer Zugehörigkeit und Anerkennung ist. Herr Hausner kümmert sich darüber hinaus um seine Eltern und deren Haus und übernimmt ehrenamtliche Aufgaben als Hausmeister in einem Reitverein.

Im Anschluss an den jahrzehntelangen Kampf um Anerkennung in der Erwerbsarbeitsgesellschaft empfinden die älteren Befragten den Renteneintritt dann als einen befreienden Zurückgewinn an Autonomie bei der Gestaltung ihres alltäglichen Lebens - so wie die 65-jährige Ruth Kirchner:

„Und denn hieß es, ich kann mit 60 [in Rente] gehen. Also, und wie der Zeitpunkt denn dran war, da hab ich aber drei große Kreuze gemacht [Lachen], ich denk so, ihr könnt mich jetzt mal gerne haben. Ihr habt so lange nichts Richtiges für einen gehabt, und denn is doch $n$ bisschen mehr gewesen, also, wie ich mit gerechnet hatte." Ruth Kirchner, 65, I029§94

Das Ringen um Anerkennung hört mit dem Renteneintritt nicht einfach auf. Es wird aber befreit vom Erwerbsdruck und kann vollständig auf alternative Domänen sozialer Teilhabe verlagert werden, da die Identität nicht mehr durch den Makel der Arbeitslosigkeit befleckt wird. Der Zugewinn an Autonomie äußert sich für Frau Kirchner in der befreienden Erfahrung, sich nun nicht mehr vor den Behörden für ihre Situation rechtfertigen zu müssen (,ihr könnt mich mal gerne haben") und mit der Rente über ein gesichertes Einkommen zu verfügen. Auf Basis sozialer und gesellschaftlicher Aktivitäten schaffen es Frau Kirchner und die beiden anderen Rentnerinnen (Martina Müller und Hilde Wagner) in dieser Gruppe, in mehreren Domänen ihrer sozialen Netzwerke Anerkennung und Zugehörigkeit zu generieren.

Ebenfalls weitgehend vom Erwerbsdruck befreit sind die vier Befragten aus dem Alkoholiker-Selbsthilfeverein und die beiden erwerbsunfähigkeitsberenteten Männer mit geistiger Behinderung. Auch wenn sie teilweise noch als erwerbslos gelten, vollzieht sich ihre Identitätskonstruktion abseits des Erwerbssystems. Sie nehmen feste Rollen in Vereinen ein, die ihren Alltag strukturieren und den Zugang zu sozialer Anerkennung gewähren. Die noch als erwerbslos geltende 
Gabriele Fischer stellt sich und ihren Alltag zu Beginn des Interviews wie folgt vor:

\begin{abstract}
„Ich arbeite jetzt hier ehrenamtlich. Hoffe, dass ich mal wieder 'n 1-Euro-Job bekomme, aber so, äh, arbeitsmäßig wird bei mir nich mehr viel laufen, weil ich ja auch nich mehr die Jüngste bin, und von daher komm ich hierher, damit ich unter Leute bin. Ich hab 'n Lebensgefährten, is auch Alkoholiker, trinkt ab und zu, und dann distanzier' ich mich, wenn er trinkt, weil bei mir gibt's überhaupt keinen Alkohol mehr. " Gabriele Fischer, 57, I013§9
\end{abstract}

Ihren Alltag organisiert sie rund um die regelmäßigen Besuche im AlkoholikerSelbsthilfeverein. Der Verein ersetzt die Funktion der Arbeitsstelle (,,arbeitsmäßig wird bei mir nicht mehr viel laufen [...] von daher komm "ich hierher"), ermöglicht ihr die Ausübung einer sozial anerkannten Rolle (,Ich arbeite jetzt hier ehrenamtlich") und bietet Gelegenheit zu sozialem Austausch (,damit ich unter Leuten bin"). Darüber hinaus erfährt sie hier soziale Unterstützung im Umgang mit ihrer Alkoholsucht und ihrem Partner, von dem sie sich in den Verein zurückziehen kann, sobald er trinkt. MAE-Stellen und andere Maßnahmen des Jobcenters stellen eine zusätzliche Bewältigungsressource zur Aktivität im Verein dar, die sie durchaus gern annimmt (,Hoffe, dass ich mal wieder ,n 1-Euro-Job bekomme"), auf die sie aber nicht angewiesen ist, da sie ja noch den Verein hat (,von daher komm" ich hierher").

Auch Andrea Langhans kommt seit über 30 Jahren einmal wöchentlich zum Mittag in den Laden des Alkoholiker-Selbsthilfevereins. Die Gruppe stellt für sie die wichtigste Netzwerkdomäne neben dem Kreis aus ihren Geschwistern und deren Familien dar. Hier erfährt sie emotionalen Rückhalt und das Gefühl der Zugehörigkeit - sie ist dabei und wird es auch immer...

„....bleiben, bis wenn hier das Haus abbrennt oder ich in der Kiste schon bin (Lachen) joa ne, geht gar nicht anders, muss sein. Obwohl ich das vielleicht [...] alkoholmäßig nicht mehr brauchen würde. Aber ich brauch das persönlich für mich, weil, ich bin ja nu alleine, und man lernt ja auch viele Leute kennen und um die Jahre, ne, ist das ja logisch, dass man dann immer wiederkommt, ne. " Andrea Langhans, 59, I012\$54

Andrea Langhans kommt, obwohl sie das „alkoholmäßig vielleicht nicht mehr brauchen würde ". Was sie dort sucht, ist der soziale Austausch mit alten Bekannten, mit denen sie über die Jahre einen engen Kontakt aufgebaut hat - daher sei es "logisch, dass man wiederkommt". Der regelmäßige Besuch im Verein ist ihr wichtig, sie „braucht“ das für sich „persönlich“, denn der Kontext des 
Vereins - die Institution, der konkrete Ort, die Leute, die sich dort regelmäBig aufhalten - sichert ihre soziale Teilhabe dauerhaft ab. Sie muss hier nicht mehr um Zugehörigkeit kämpfen oder ihre Tauglichkeit unter Beweis stellen, sie braucht lediglich einmal in der Woche dort zu erscheinen und mitzumachen, um dabei zu bleiben.

Neben dem Engagement im Selbsthilfeverein ist sie ehrenamtlich in einem Stadtteilzentrum aktiv, wo sie zweimal in der Woche putzt ${ }^{21}$. Diese beiden Gelegenheiten zur regelmäßigen Ausübung einer sinnhaften Tätigkeit strukturieren ihren Alltag und stellen ihr soziale Rollen zur Verfügung, auf die sie bei der Beschreibung ihrer Person zurückgreifen kann, wie ihre ersten Sätze im Interview zeigen:

„Also, im Prinzip läuft bei mir die Woche immer gleich ab, jede Woche. Zu mindestens versuch ich das. Montags gehe ich arbeiten, ehrenamtlich, in der [Stadtteilzentrum, anonymisiert]. Dienstags hab ich meinen Einkaufstag, Arzttermine und sowas alles. Mittwochs bin ich immer hier [im Alkoholiker-Selbsthilfeverein] [...]. Und donnerstags einkaufen, Arzttermine [...]. Freitags geh ich wieder arbeiten [...]. Und Wochenende Sport, Fitnessstudio bin ich morgens gleich frühs um sechs, ja ist immer schön leer. Im Prinzip läuft's immer gleich ab. “ Andrea Langhans, 59, I012\$6

Die Befragte hat einen regelmäßigen Wochenrhythmus (,,im Prinzip läuft bei mir die Woche immer gleich ab"), der durch Fixpunkte, die sich aus ihrem Engagement ergeben, getaktet ist (,Montags gehe ich arbeiten“ / „Mittwochs bin ich immer hier" / „Freitags geh ich wieder arbeiten"). Diese Aktivitäten ermöglichen es ihr, sich als arbeitende aktive Person darzustellen, die sich ,ehrenamtlich“ einbringt.

Die Bewältigungsstrategien der Befragten in Typ 1 basieren auf der Einbindung in zwei Arten von Netzwerkdomänen: Dazu zählen erstens Kontexte aus starken, seit langer Zeit bestehenden Beziehungen zu engen Freund*innen und Familienmitgliedern oder innerhalb institutionalisierter Strukturen (Vereine), in denen die Befragten teilweise seit Jahrzehnten aktiv sind. Hier steht ihre Zugehörigkeit außer Frage, sie erfahren sozialen Rückhalt und emotionale Unterstützung. Zweitens generieren sie soziale Anerkennung durch ihr (überdurchschnittliches) Engagement in- weiteren Domänen ihrer Netzwerke und für diese. Dazu zählen Nachbarschaften, Stadtteilzentren, MAE-Stellen und andere Maßnahmen der Jobcenter oder auch informelle Interessengruppen (Kino- oder Fitnessgruppe). Diese Rollen strukturieren ihren Alltag, stiften Lebenssinn und ermöglichen ihnen die

\footnotetext{
${ }^{21}$ Das Stadtteilzentrum benannte sie nur im qualitativen Teil des Interviews und nicht bei der Netzwerkabfrage, daher ist es in der Abbildung 5.10 nicht zu sehen.
} 
Etablierung respektabler Identitäten innerhalb der konkreten Domänen und darüber hinaus. Da viele dieser Domänen nicht dauerhaft verfügbar sind, müssen sich viele der Befragten immer wieder neue Betätigungsfelder und Domänen der zweiten Art erschließen.

Biographie

Fast alle Befragten im Typ 1 „Prekärstabil: Herstellung von Anerkennung in alternativen Domänen" haben biographische Erfahrungen mit Statusverlusten gemacht. Die Erzählungen über den Umgang mit diesen Erfahrungen sind sehr aufschlussreich in Bezug auf ihre aktuellen Bewältigungsstrategien. Sabine Buchholz ist 52 Jahre alt. Sie ließ sich 1989 von ihrem Ehemann scheiden und beschreibt die Zeit seitdem so:

\begin{abstract}
„Ich hab mich dann scheiden lassen und hab meine Kinder alleine aufgezogen. Und immer gearbeitet. Bis ich [1990] aus' $m$ Babyjahr rausgekommen bin mit dem letzten Kind und dann der Konsum Pleite gemacht hatte. Und von da an ging 's bergrunter. Da war die Arbeitslosigkeit da, praktisch mit der Grenzöffnung. Ja, und denn immer mal zwischendurch irgendwo $n$ Job gesucht und gemacht oder ein vermittelt bekommen, aber ebend immer nich auf lange Zeit. Immer nur kurzfristige Sachen. Weil die ja meistens immer so drauf eingestellt warn, die Leute gar nicht lange zu beschäftigen. “ Sabine Buchholz, 52, I004§42
\end{abstract}

Seit der Wende findet Frau Buchholz „immer nur kurzfristige Sachen“. Das beschreibt sie nicht als ihr individuelles, sondern als ein strukturelles Problem, da die Unternehmen „,gar nicht darauf eingestellt“ seien, Mitarbeiter*innen ,lange $z u$ beschäftigen “. Diese Erfahrung steht im Gegensatz zu ihrem Anspruch, selbst für sich zu sorgen, schließlich habe sie ihre „Kinder alleine aufgezogen und immer gearbeitet [...] bis der Konsum Pleite gemacht hatte “. Auf das Arbeitslosengeld, welches sie nach der Pleite des Konsums erhielt, folgte bald die Sozialhilfe, dann „Arbeit statt Sozialhilfe“, ein Arbeitsmarktprogramm, in dessen Rahmen sie für eine Wohnungsbaugesellschaft Grundstücke pflegte. Später arbeitete sie in MAE-Stellen und als Aushilfe in Supermärkten. Eine Beschäftigung, mit der sie sich dauerhaft aus der Abhängigkeit von Arbeitsamt und Jobcenter hätte befreien können, fand sie nicht. Verglichen mit ihrem sozialen und beruflichen Status vor 1989/'90 als Verkäuferin im Konsum deutet sie diesen Verlauf als Abstieg (,,von da an ging's bergrunter").

Die Motivation zu einer auf Autonomie und Anerkennung unter den gegebenen Bedingungen ausgerichteten Handlungsstrategie ist oft biographisch bedingt: Befragte wie Sabine Buchholz halten auch nach sozialen Abstiegserfahrungen am Ethos einer eigenverantwortlichen Person fest, die ihre Entscheidungen selbst fällt 
und diese mit Stolz und Würde nach außen vertritt. Diese Haltung trifft insbesondere auf Personen zu, die in der DDR eine überdurchschnittliche Bildung und hohe berufliche Positionen erreicht hatten. So war die 58-jährige Susanne Hagen bis zum Beitritt der DDR zur BRD als studierte Agrarökonomin in der Landwirtschaft tätig. Schon zu DDR-Zeiten hat sie sich immer aktiv für ihre Belange eingesetzt und damit Erfolg gehabt, z. B., als sie Ende der 1980er Jahre aufgrund einer beruflichen Veränderung ihres damaligen Ehemannes umziehen musste:

„Es war natürlich schwierig, dann hier 'ne Wohnung zu kriegen, aber es war nur so möglich, dass ich immer wieder beim Landbaukombinat angerufen hab, bei der Verantwortlichen für Wohnung. Und ging der praktisch auf 'n Nerv, bis die dann gesacht hat, sie möcht das Wohnungsproblem der Familie Hagen endlich mal erledigt ham. " Susanne Hagen, 58, I109§194

Die Familie durfte schließlich in eine Neubauwohnung im Erstbezug einziehen. Anschließend kümmerte sich Frau Hagen auf gleiche Weise um eine Arbeitsstelle für sich:

„Dann hab ich das Telefonbuch genommen und hab geguckt, wo is der nächste Betrieb, und war dann bei der Milchvereinigung und hab da angerufen, und da wurde ich dann hinbestellt gleich. “ Susanne Hagen, 58, I109\$194

Auch diese Bemühung war erfolgreich, sie wurde in dem Betrieb angestellt. Als sie mit der Wende ihre Arbeit in der Landwirtschaft verliert, knüpft sie an diese Herangehensweise an und versucht sich selbst zu helfen, indem sie mit konkreten Vorstellungen an das Arbeitsamt herantritt:

\begin{abstract}
„Ich hatte mich relativ zeitig auch schon beim Arbeitsamt gemeldet und gefragt wegen 'ner Umschulung. Ich hatte ja die Idee, ich mach jetzt was Neues, was auf dem Markt gebraucht wird [...]. Und ich hatte auch was gelesen, und der Umweltbereich hat mich schon [...] länger interessiert, und da kriegte ich dann [...] 1990 ein Jahr 'ne Umschulung zum Umweltberater. “ Susanne Hagen, 58, I109\$194
\end{abstract}

Nach der Umschulung arbeitete sie in zwei ABM-Maßnahmen und in einem zunächst vom Arbeitsamt geförderten Projekt zur Entwicklung des Tourismus und lokaler Ökonomien in ihrer Region, welches nach der planmäßigen Reduktion der staatlichen Förderung eingestellt wurde ${ }^{22}$. In alle drei Stellen arbeitete

\footnotetext{
${ }^{22}$ Ein ähnliches Arbeitsmarktinstrument mit einem degressiv ausgestalteten Lohnkostenzuschuss gibt es mit dem Gesetz zur „Teilhabe am Arbeitsmarkt“ (§16i SGBII) auch heute wieder.
} 
sie sich mit großer Leidenschaft ein und musste jedes Mal erleben, wie nicht nur ihre Stelle auslief, sondern das gesamte Projekt wieder eingestellt und nicht mehr weiterentwickelt wurde. Für Frau Hagen bedeutete das eine wiederkehrende Arbeitslosigkeit, die jedes Mal auch mit der Vernichtung ihrer Arbeitsleistungen verbunden war: Sie baute einen Naturkostladen für lokale Produkte auf, der schließen musste, obwohl er gerade erst anlief. Später war sie an der Erarbeitung eines Bürgerbeteiligungskonzepts für die Entwicklung ihrer Region beteiligt, das nie umgesetzt wurde. Schließlich kartierte sie ein geplantes Naturschutzgebiet, bis auch dieses Projekt eingestellt wurde. Über diese Arbeit sagt sie im Interview:

„Und wir ham das och ruck zuck, äh, da gelernt. Und auch mit umgesetzt und eben für die Stadt diese Sachen gemacht, und nach einem Jahr ham sie gesacht, sie ham kein Geld mehr, also wahrscheinlich war das von Anfang an so. "Susanne Hagen, 58, I $109 \$ 258$

Seit Ende der 1990er Jahre arbeitete sie nicht mehr in solchen Maßnahmen, sondern teils mit mehrjähriger Unterbrechung im Dienstleistungsbereich (in 3 Callcentern sowie in einer Marketingabteilung und 2 Verwaltungen kleiner StartUp-Unternehmen), wo sie entweder blieb, bis die Firmen pleitegingen oder sie gekündigt wurde, als man ihre Stelle hätte entfristen müssen. Egal, ob öffentlich gefördert oder in der freien Wirtschaft: Die Erfahrung, dass nicht besonders fair mit ihr umgegangen wird (,wahrscheinlich war das von Anfang an so “), zieht sich durch ihre gesamte Erwerbsbiographie seit 1990.

Umso erstaunlicher ist es, dass die Befragten in dieser Gruppe nach Rückschlägen nicht verzagen und immer wieder neu anfangen. Fast alle haben ähnliche Wendeerfahrungen gemacht wie Susanne Hagen und Sabine Buchholz. Einige sind nach einer Weile sehr tief gefallen (Alkoholismus, Trennung, Verlust jeglicher Kontrolle) und haben im Zuge der Bewältigung dieser Krisen wieder Zugang in alternative Domänen gefunden, die ihnen ein gewisses $\mathrm{Maß}$ an Kontrolle über die eigene Identität zurückgeben und den Alltag wieder planbar machen (siehe oben). Bei allen basiert die zu beobachtende hohe Agency, man könnte auch sagen, ihre Widerständigkeit oder Resilienz, auf der Einbettung in alternative Domänen, die ihnen den nötigen Rückhalt geben, um in der Prekarität ihres Alltags nicht (mehr) unterzugehen.

Visuelle Netzwerkanalyse

Die Netzwerke der Befragten im Typ 1 „Prekärstabil: Herstellung von Agency in alternativen Domänen " sind auf den Abbildungen 5.9 und 5.10 dargestellt. Die erste Abbildung zeigt die Netzwerke der sechs erwerbslosen Befragten (darunter 
zwei, die gerade eine Qualifizierungsmaßnahme absolvieren: I005 und I007) und von drei Frauen, die bis zu ihrer Berentung aus Altersgründen in sehr ähnlichen Situationen lebten wie die übrigen sechs. Die zweite Abbildung (5.10) zeigt die Netzwerke von Personen mit gesundheitlichen Einschränkungen, die noch als erwerbslos gelten (I013, I111) oder aufgrund einer Erwerbsunfähigkeit berentet wurden (alle anderen). Ihre identitätsstiftenden Aktivitäten finden, abgesehen von unvermeidlichen Terminen beim Jobcenter in den Fällen I013 und I111, jenseits des Arbeitsmarktes statt.

Wie oben bereits gezeigt wurde, eint alle 16 Befragte, dass sie ihre Handlungsund Gestaltungsfähigkeit (Agency) durch die Verteilung ihrer Aktivitäten auf verschiedene Domänen im und neben dem Erwerbssystem vergrößern und dauerhaft absichern. Diese voneinander abgrenzbaren Domänen sind in allen Netzwerken erkennbar. Teils werden sie nur angedeutet als (isolierte) Personen oder Orte, die mit einem bestimmten Kontext assoziiert sind (wie z. B. die Freundin aus dem Chor im Netzwerk von Martina Müller oder der Reitverein bei Rolf Hausner in Abbildung 5.9). In anderen Netzwerken sind die Domänen als eng verbundene Teilgruppen im Netzwerk zu sehen, wie z. B. die mit dem Stadtteilzentrum verbundenen Knoten im Netzwerk von Sabine Buchholz in Abbildung 5.9 oder der Freundes- und Bekanntenkreis aus dem Alkoholiker-Selbsthilfe e. V. bei Gabriele Fischer in Abbildung 5.10.

Eine Ausnahme bildet das Netzwerk von Hilde Wagner (I031), bei der keine Domäne außerhalb des Kreises aus Freund*innen und Familienmitgliedern zu sehen ist. Dabei handelt es sich um ein methodisches Problem der standardisierten Netzwerkerhebung: Im qualitativen Teil des Interviews sprach sie sehr viel über ihre Arbeit als Leiterin eines Seniorentreffs, bei der Netzwerkabfrage benannte sie dann aber weder den Seniorentreff noch dessen Mitglieder. Erklären lässt sich das dadurch, dass sie stark zwischen dem persönlichen und dem professionellen Teil ihres Netzwerks trennt und nur persönliche und keine institutionalisierten Beziehungen genannt hat. Ohne Einbezug des qualitativen Teils des Interviews in die Netzwerkanalyse würde die Information über die bedeutende Netzwerkdomäne „Seniorentreff“" in ihrem Fall unberücksichtigt bleiben.

Die tiefergehende Betrachtung der Netzwerke gibt Anlass zur Analyse der hinter den Bewältigungsweisen liegenden Strukturen. So sind in einigen Netzwerken Gatekeeper und Broker zu sehen. Offensichtlich ist dies am Verhältnis zwischen Jobcenter und Maßnahme. Hierzu finden wir Hinweise in den Netzwerken von Annemarie Kolkowski und Astrid Schubert, wo Beziehungen zwischen Jobcenter und Mitarbeiter*innen der Maßnahmen eingezeichnet sind. Geht man dieser Spur in den Interviews weiter nach, stößt man auf eine komplexe Triade aus Maßnahmeteilnehmer*in, Jobcenter und Maßnahmeträger*in. Im Fall von Rolf Hausner 


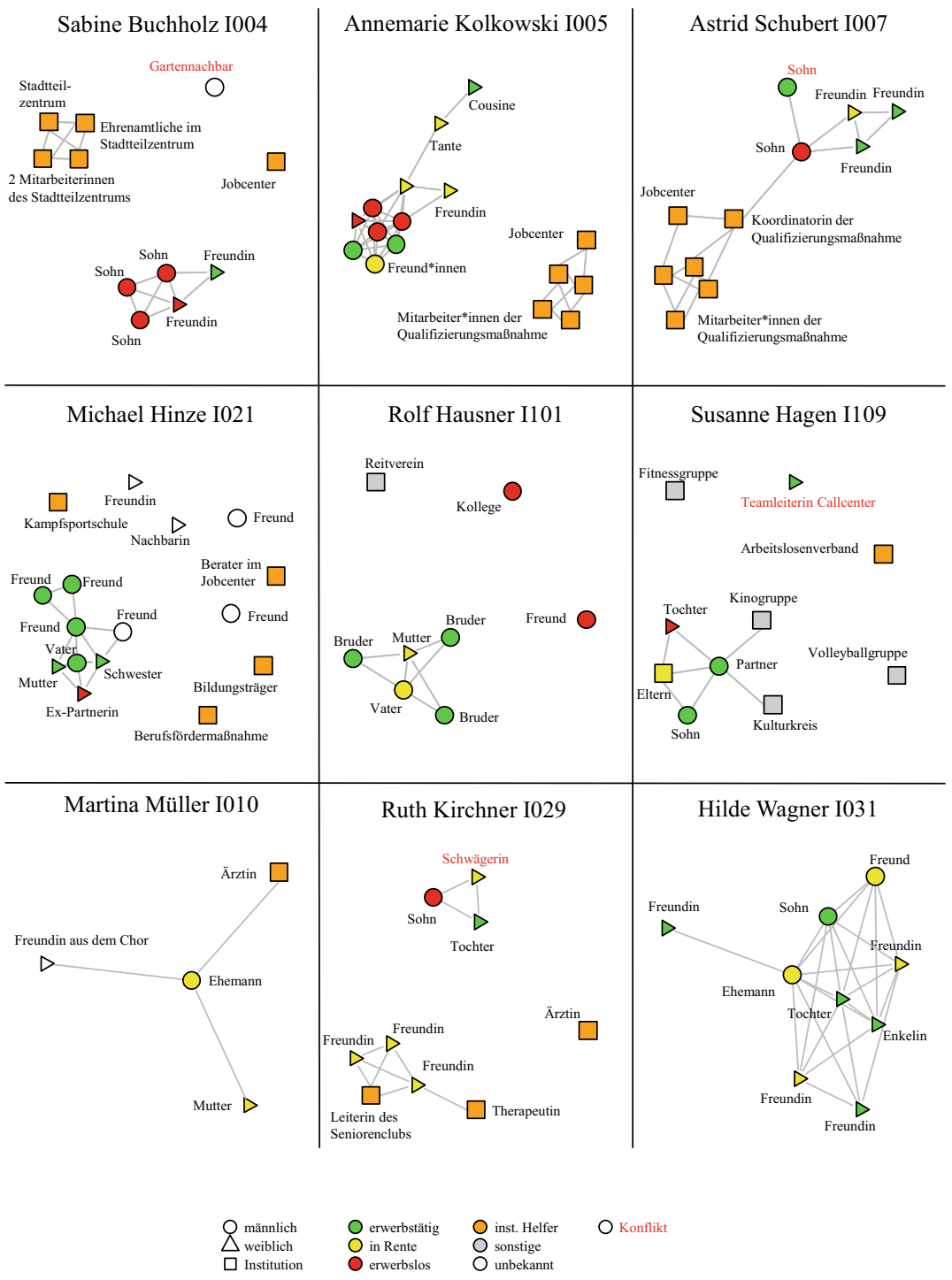

Abbildung 5.9 Netzwerke der Befragten in Typ 1 (Teil 1/2) 


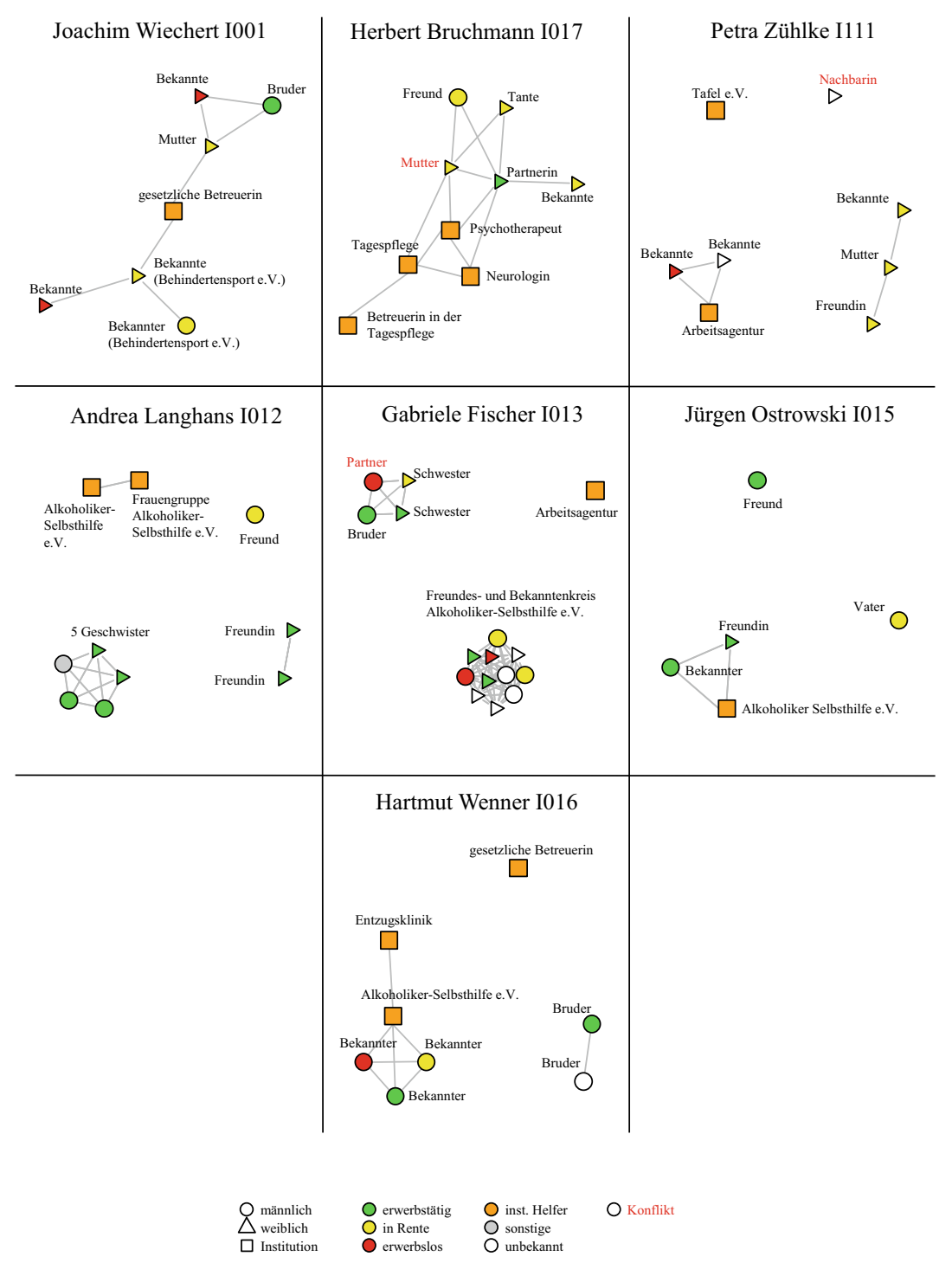

Abbildung 5.10 Netzwerke der Befragten in Typ 1(Teil 2/2) 
(der seine MAE-Stelle bei der Netzwerkabfrage nicht benannt hat) wurde dies oben bereits beschrieben: Hier zeigte sich in der Analyse des qualitativen Interviews, dass die Beziehung zwischen Teilnehmer und Träger der Maßnahme durch das Jobcenter initiiert, moderiert und beendet wird. Herr Hausner und sein Chef können zwar Einfluss darauf nehmen und versuchen, die Laufzeit der Maßnahme zu verlängern, die Entscheidung darüber fällt aber letztlich das Jobcenter.

Darüber hinaus gibt die Betrachtung der Netzwerke Anlass zur Analyse weiterer Gatekeeper: Ruth Kirchner (I029) ist auf Anraten ihrer Therapeutin einem Seniorenclub beigetreten. In ihrem Netzwerk gibt es zwei klar voneinander abgegrenzte Domänen - Familie und Seniorenclub (drei Freundinnen aus dem Club und die Leiterin) und zwei weitere Akteurinnen, die gar nicht (Ärztin) oder nur am Rande ${ }^{23}$ (Therapeutin) mit diesen Domänen in Verbindung stehen. Die Beziehung zwischen Therapeutin und der Freundin im Seniorenclub weist darauf hin, dass institutionelle Akteur*innen den Anstoß dazu geben können, Netzwerkressourcen offenzulegen und zu erschließen. Weitere Beispiele hierfür finden sich in den Netzwerken von Harmut Wenner (I016), in dessen Fall die Entzugsklinik den Kontakt zur Alkoholiker-Selbsthilfe vermittelt hat, bei der gesetzlichen Betreuerin, die im Netzwerk von Joachim Wiechert (I001) eine Verbindung zum Behindertensportverein herstellt, oder bei Herbert Bruchmann (017), dessen Neurologin und Psychotherapeutin in Verbindung mit der Tagespflegeeinrichtung stehen, die er besucht.

\subsubsection{Typ 2: Prekärlabil: Mangel an Agency}

Dem Typ 2 „Prekärlabil - Mangel an Agency“ wurden 16 Personen zugeordnet, die dauerhaft in prekären Verhältnissen leben und sich diesen gegenüber als abhängig oder ausgeliefert empfinden. Sie sie sind in relativ kleine und statische Netzwerke eingebunden, die um eine zentrale Domäne herum konzentriert sind und darüber hinaus nur wenige Bewältigungsressourcen bereithalten. Die Welt der Befragten befindet sich nicht in einem wohlgeordneten Zustand (Eunomia), sie lässt sich - in Anlehnung an Durkheim (1983) und Sammet (2014) - als anomisch oder fatalistisch beschreiben (siehe Literaturteil: 3.3.4). Den jüngeren Befragten erscheint die Welt eher unberechenbar bzw. anomisch, während die älteren Befragen sie als überreguliert, bzw. fatalistisch beschreiben. Intentionale Prozessstrukturen, die bei Sammet (2014) als „Bewältigung von Kontingenz“

${ }^{23}$ Die Therapeutin nimmt als Vermittlerin der Beziehung zum Seniorenclub eine Gatekeeperfunktion ein, ist selbst aber nicht in dem Kreis aktiv. 
(eher in Typ 1 zu finden) oder ,trotziges Aufbegehren“ (eher in Typ 3 zu finden) beschrieben werden, sind in keiner der beiden Teilgruppen zu finden. Die Befragten folgen eher einer „konditionalen Prozessstruktur“ (ebd.), sie ergeben sich der Situation, indem sie die sie umgebende Unordnung einfach „hinnehmen“ (ebd.) oder vor der übermächtigen Ordnung ,resignieren“ (ebd.).

Die jüngeren Befragten in dieser Gruppe setzen sich zusammen aus drei jungen Männern (I120, I121, I122) und vier Müttern mit brüchigen (Aus-)Bildungsund Erwerbsbiographien (I023, I025, I027, I033). Alle sieben sind auf der Suche nach einer Perspektive, ohne genau benennen zu können, wohin sie eigentlich wollen. Ihre Zukunft ist abhängig von institutionellen Akteur*innen und Angeboten, die sie bei der Jobsuche und der Organisation ihres Alltags unterstützen. Da sie die Strukturen dieser Hilfesysteme oft nicht durchschauen, sind sie darauf angewiesen, dass man ihnen den richtigen Rat zukommen lässt. Brechen diese Hilfen weg, sind sie orientierungslos und schnell mit der Situation überfordert.

Auch die materielle und berufliche Situation der älteren Befragten wird fast ausschließlich durch sozialstaatliche Akteur*innen bestimmt (I002, I009, I034, I102, I104, I105, I110, I112, I113). Da sie über die Jahrzehnte jedoch feststellen mussten, dass die Institutionen ihnen keinen Weg aus Armut und Unsicherheit bahnen konnten, wirken sie enttäuscht und resigniert. Sie empfinden sich als abhängig von einer als feindlich wahrgenommenen Umwelt. Die Interviews sind durchzogen von Erzählungen über negative Erfahrungen, die sie mit Institutionen ebenso wie mit Personen aus ihrer näheren (Familienangehörige, Freund*innen, Nachbar*innen) und weiteren (Kolleg*innen, Bekannte, institutionelle Helfer*innen) Umgebung gemacht haben. Das Gefühl, ungerecht behandelt und betrogen worden zu sein, führte in der Vergangenheit zur Aufgabe von Beziehungen. Da die wegbrechenden Beziehungen nicht durch neue kompensiert wurden, bestehen ihre Netzwerke aus sehr wenigen, überwiegend eng mit ihnen verbundenen Personen (starke Beziehungen).

Im Gegensatz zu den Befragten in Typ 1 schaffen die Angehörigen dieser Gruppe es kaum, Respektabilität und Anerkennung jenseits ihrer familienzentrierten Netzwerke zu generieren. Ihre Fähigkeit, ein Leben im Einklang mit ihren Vorstellungen zu führen (Agency), ist sehr begrenzt. Die einen haben den Glauben daran, diese Vorstellungen verwirklichen zu können, aufgegeben. Die anderen sind in Ermangelung von Vorbildern und Gelegenheiten außerstande, solche Vorstellungen zu formulieren, geschweige denn, diese umzusetzen. Die Befragten stehen daher hilflos vor ihren alltäglichen Problemen und wirken angeschlagen. Ihre Situation erscheint nicht nur prekär, sondern auch hochgradig vulnerabel, bzw. labil. 
Wahrnehmung alltäglicher Herausforderungen, Bewältigungsstrategien und Perspektiven

Die fatalistische Grundeinstellung der älteren Befragten in dieser Gruppe äußert sich in der subjektiven Wahrnehmung, um Lebens- und Teilhabechancen betrogen worden zu sein. So erwähnt der seit seiner Entlassung im Jahr 2002 überwiegend arbeitslose Manfred Großer (54) sehr viele Akteur*innen, von denen er sich hintergangen fühlt. Dazu gehören sein ehemaliger Chef, der ihm zu Unrecht gekündigt habe, das Jobcenter, welches immer nur fordere, aber niemals etwas anbiete, die Maßnahme, die nur zur Finanzierung der Angestellten diene, aber nicht den Klient*innen, genauso wie ehemalige Freunde und Bekannte, die seit der Wende nur noch auf ihren eigenen Vorteil bedacht seien. Und auch die Geflüchteten in seinem Ort liefern für Herrn Großer den sichtbaren Beweis für seine Überzeugung, dass an alle gedacht werde, nur nicht an Menschen wie ihn:

„Dat andre kommt rin, und ick soll auswandern? Ne, ich bin ja wohl bescheuert oder wat? Jeden Tach jehn se hier vorbei, dat andre Volk da. Ick muss dann, sach ich, ich muss dann - Ich geh nicht weg. “ Manfred Großer, 54, I110\$344

So abwegig dieser Vergleich erscheint - Herr Großer solle gehen, um den Geflüchteten Platz zu machen - so logisch ist Manfred Großers Referenz auf diese Gruppe: Er vergleicht sich nicht mit Angehörigen der gesellschaftlichen Mitte, sondern mit Menschen, die am Rand stehen. Denn auch er nimmt sich als ausgeschlossen wahr - als jemand, der besser gehen sollte, da er in seiner Region nicht mehr gebraucht wird.

Auch Ursula Tackel hat den Eindruck, dass man ihre Probleme nicht ernst genug nimmt und ihr keine passende Hilfe anbietet. Nachdem sie Mitte der 2000er Jahre arbeitslos wurde, sollte sie eine Umschulung von der Köchin zur Bürokauffrau machen, was sie als „perspektivloses“ Angebot bezeichnet und ablehnt. Sie kenne „auf Anhieb vier Kellner“, die umgeschult wurden und im Anschluss arbeitslos waren, und fasst zusammen:

„Das is natürlich Quatsch, man brauch nich Leute umschulen als Bürokaufleute, wenn keine gesucht werden. Das is ja perspektivlos. Ich brauch ja nich 'ne Umschulung machen, wenn ich weiß, nachher bin ich wieder am selben Punkt angelangt wie [vorher], ne? Is ja Quatsch. " Ursula Tackel, 51, I105\$118

Die Hoffnung auf einen Job hat sie seit langer Zeit aufgegeben. Sie erzählt, dass sie vom Jobcenter entweder Angebote bekommt, die sie aus gesundheitlichen Gründen nicht annehmen könne, oder solche, für die ihr die Kompetenzen fehlten. Bei ihren Besuchen im Jobcenter, sagt sie: 
„,kommt nichts bei raus, was soll dabei rauskommen? Sie [die Sachbearbeiterin der Befragten] hat ja selber keine Stellen, die sie mir anbieten könnte. Aber es is auch noch nie [...] ein richtiges Gespräch mit irgendjemandem Kompetenten gewesen [...]. Der ins Detail geht, sich mal mit dem Menschen richtig befasst. Das hat da nie einer gemacht. Das is weder bei meinem Mann passiert noch bei mir. [...] Man kommt da einfach hin, is 'ne Nummer, und man wird mit abgearbeitet. [...] Ich hab 'ne sehr nette Vermittlerin, aber erreichen tut sie nichts und ich nichts. Gar nix. " Ursula Tackel, 51, $\mathrm{I} 105 \S 120$

Die Bemühungen um Arbeit werden von beiden Seiten nur noch simuliert - die Sachbearbeiterin hat keine Stellen anzubieten, und Frau Tackel weiß von vornherein, dass ihre Bewerbungen nicht zum Erfolg führen werden (,was soll dabei rauskommen?"). Frau Tackel hat deshalb den Eindruck, nicht ernst genommen zu werden. Sie sei nur eine Nummer, die es abzuarbeiten gelte, aber kein Mensch, dem man helfen möchte oder könnte.

Die jüngeren Befragten benennen dagegen sehr viel seltener Schuldige für ihre Situation und nehmen Hilfe von außen bereitwillig an. Doch auch ihnen fehlen Kontexte und Anregungen, die über ihre aktuelle Situation hinausweisen, z. B. in Gestalt von Vorbildern und wegweisenden Akteur*innen, die in der Lage wären, Möglichkeitsräume und Gelegenheiten zur Aufnahme sinnstiftender Tätigkeiten aufzuzeigen. In Ermangelung solcher Möglichkeiten werden Ratschläge von Mitarbeiter*innen der Jobcenter und Maßnahmen befolgt - allerdings nur mit mäßiger Begeisterung, wie im folgenden Zitat des 18-jährigen Ralf Kühns deutlich wird:

„[S]ie [die Betreuerin in einer Qualifizierungsmaßnahme] versucht mehrere Dinge hier aus. Wat, wat, so, so, meine Stärke is, und jetzt ham wir auch noch ne Stärke jefunden beim Mauern. Ham mer gemauert. So, und da hat sie gesacht, ,da wern wir gucken, ne? Halt, denn fang ich halt wahrscheinlich sogar [an zu] mauern. " Ralf Kühn, 18, I121

Die Betreuerin schlägt das geeignete Berufsfeld vor und organisiert alles Weitere für Herrn Kühn: Sie ,,versucht mehrere Dinge hier aus“, nicht der Befragte selbst. Er äußert keine eigene Meinung zum Beruf des Maurers, ist aber einverstanden mit dem Vorschlag seiner Betreuerin, es einmal damit zu versuchen.

Mangels Erfolgs auf dem Arbeitsmarkt sind die Perspektiven der jüngeren Befragten eng mit Ämtern und Behörden verknüpft. Das trifft in besonderem Maße auf die vier Mütter in dieser Gruppe zu. Bei ihnen beeinflussen die Behörden nicht nur die materielle und berufliche Situation maßgeblich, sondern auch die Organisation von Partnerschaft, Elternschaft und Wohnung. Caroline Schmitt ist 24 Jahre alt, hat einen dreijährigen Sohn, der bei ihrem Exfreund 
lebt, und wohnt nicht weit entfernt in einer Ein-Zimmer-Wohnung in einem städtischen Neubaugebiet. Frau Schmitt begann nach ihrem Realschulabschluss ein Fachabitur, das sie nicht beendete. Seitdem ist sie, abgesehen von kurzen Unterbrechungen, arbeitslos. In der Wohnung des Ex-Freundes lebten zunächst alle drei, bis sich Frau Schmitt im Laufe einer langen Trennungsphase des Paares an das Jugendamt wandte (etwa anderthalb Jahre vor dem Interview), das den Sohn vorübergehend aus der Familie nahm. Die Trennung gestaltete sich aufgrund der Abhängigkeit Frau Schmitts vom Jobcenter als besonders schwierig. Das Jobcenter genehmigte ihren Auszug aus der Bedarfsgemeinschaft mit dem Ex-Partner erst nach der Intervention des Jugendamtes. Auslöser für das Eingreifen des Jugendamtes war eine psychische Erkrankung Frau Schmitts. Sie befand sich längere Zeit in stationärer psychiatrischer Behandlung. Zum Zeitpunkt des Interviews lebt Frau Schmitt allein und besucht ihren Sohn regelmäßig in der Wohnung ihres Ex-Partners. Sie absolviert eine vom Jobcenter vermittelte Bildungsmaßnahme, in der sie auf die Idee gebracht wurde, eine „Berufsausbildung im geschützten Rahmen“ als Bürokauffrau machen zu können. Dort würde sie dann eine besondere Betreuung in Bezug auf ihre psychischen Probleme erfahren. Sie selbst sehe sich außerstande, eine Beschäftigung zu finden, die mit ihren Bedürfnissen in Einklang zu bringen ist, und hofft daher auf die Vermittlung dieser Ausbildung durch das Jobcenter:

\begin{abstract}
„Aber im Großen und Ganzen ist halt, öhm (.), kann man da nicht so viel machen, also, weil da irgendwo andere Stellen denn wieder sagen "Ja, ok (.), zeig uns mal, ob du das wirklich kannst, und denn reden wir nochmal drüber, ob du das wert bist" so quasi (lächelt), also man ist halt immer irgendwo (.), also, ich bin irgendwie nur am Warten. Da muss dis Gutachten, damit der was machen kann, und, öhm, und ich warte nur drauf, dass die so nacheinander sich mal einigen, ob die, öh, meinen Fall wollen und, öh, und ob ich das wert bin. (ironisch) Das ist sehr schön für die Eigenmotivation und fürs Selbstwert, oh. Ja. “ Caroline Schmitt, 24, I027§134
\end{abstract}

Frau Schmitt fühlt sich in eine passive Situation gedrängt (,ich bin irgendwie nur am Warten"). Ihr ist unklar, wer wofür zuständig ist, sie hat das Gefühl, sich rechtfertigen zu müssen (,zeig uns mal, ob du das wirklich kannst “), weiß aber nicht, ob diese Rechtfertigung am Ende zum Erfolg führt, bzw. ob nicht „, irgendwo andere Stellen “ wieder ganz anders über ihre Lage und ihre Berechtigung auf die Ausbildung urteilen. Einen Plan B hat sie nicht. Der ironische Satz am Ende des Zitats deutet die negativen Auswirkungen dieser Situation auf ihr Selbstwirksamkeitsgefühl und ihre Selbstachtung an. 
Die Gemeinsamkeit zwischen den älteren und jüngeren Befragten im Typ 2 besteht in den konditionalen Prozessstrukturen: Sie nehmen ihre Situation durchaus als problematisch wahr, haben diesen Problemen aber nichts entgegenzusetzen, da ihr sozial-räumliches Umfeld ihnen nur sehr wenige Anknüpfungspunkte zur eigenständigen Verbesserung ihrer Situation bietet und sie nicht an einem möglichen Erfolg ihrer Handlungen zu glauben scheinen. Sie fühlen sich ausgeliefert und nehmen alltäglich und biographisch erfahrene Zumutungen schicksalhaft an - unabhängig davon, ob sie sich von höheren Mächten verraten und betrogen fühlen oder einfach nicht wissen, wohin sie sonst gehen sollen, um einen Schritt weiter zu kommen. Es fehlt an haltgebenden Strukturen, Inspiration von außen und positiven Beispielen. In den Erfahrungsräumen, in denen sie sich bewegen, ist Scheitern die Regel und Erfolg die Ausnahme. In dieser Situation scheint die Perspektive vieler Befragter, vollständig von behördlich vermittelten Angeboten und deren Reichweite abhängig zu sein.

Biographie

Die meisten der älteren Befragten haben es unter Aufwendung großer Anstrengungen geschafft, im Anschluss an die ersten Veränderungen nach der Wende wieder auf eigenen Füßen zu stehen, z. B. durch ABM-Stellen, Saisonarbeit im Tourismus, als Verkäuferin oder in Firmen, mit denen sich ehemalige Kolleg*innen selbständig gemacht hatten. Erst später führten gesundheitliche Einschränkungen und der damit einhergehende Verlust von Kompetenzen, der Verfall von Qualifikationen auf dem Arbeitsmarkt (die Berufsabschlüsse der Befragten werden nicht mehr nachgefragt) sowie die andauernd schlechte Arbeitsmarktlage dazu, dass die Befragten keine Arbeit mehr fanden oder frühzeitig berentet wurden.

Ihre Abstiegserfahrungen stehen im Widerspruch zu ihren Anstrengungen auf der Suche nach einer respektablen gesellschaftlichen Position. Sie widersprechen der bürgerlichen Erwartung, es mit Mühe und Fleiß zu etwas bringen zu können. Um dies zu verdeutlichen, soll im Folgenden noch einmal etwas detaillierter auf das Beispiel von Manfred Großer eingegangen werden. Er arbeitete in der DDR etwa 15 Jahre lang als Techniker in der Landwirtschaft und wurde mit der Wende entlassen. Nach kurzer Erwerbslosigkeit fing er in einem Entsorgungsbetrieb an, in dem er sich zum Schichtleiter hocharbeitete. Als er dort nach 10 Jahren aufgrund von Sparmaßnahmen gekündigt wurde, bot man ihm an, sich für einen bedeutend niedrigeren Lohn über eine Zeitarbeitsfirma erneut einstellen zu lassen: 
„Zehn Jahre lang [habe ich da gearbeitet]. Bis der andre Chef kam und sachte: ,Die Lohnnebenkosten sind so hoch', wat ick nie geglaubt hab: ,ihr müsst alle zur Zeitarbeiterfirma gehn. ' Für fünf Euro [...]. Ick sach: ,Seid ihr nich ganz dicht oder wat? Ich kann nich von von F. [Kleinstadt, sein Wohnort] bis nach N. fahren [ca. 30km entfernte Mittelstadt, Sitz der Firma] um für fünf Euro zu arbeiten. “ Manfred Großer, 54, I110§218

Er lehnt ab, da er die Begründung für die Kündigung für vorgeschoben hält (,wat ick nie geglaubt hab"), das Angebot der Weiterbeschäftigung als Zeitarbeiter als Provokation angesichts seiner Verdienste um die Firma empfindet (,Zehn Jahre lang “/ „Ihr seid doch nicht ganz dicht") und den angebotenen Lohn als Missachtung seiner Aufwendungen (,Ich kann nicht von F. bis nach N. fahren für fünf Euro “). Manfred Großer hat das Gefühl, um seinen Job betrogen worden zu sein. Beruflich bedeutete die Kündigung für ihn die Fortsetzung seines langen Abstiegs auf Raten: von der Fachkraft in der LPG zur ungelernten Kraft in der Entsorgungsfirma, vom Arbeitslosengeld zur Arbeitslosenhilfe und schließlich zum Arbeitslosengeld II. Außer „Umschulung, Umschulung, Umschulung “ (Manfred Großer, I110§236), hauptsächlich Computerlehrgänge, und einigen „Ein-EuroJobs “ (ebd.) in sozialen Projekten mit Kindern hat er seit der Entlassung nicht mehr gearbeitet.

Manfred Großer bereut es deshalb, nach der Wende nicht auf seine Verwandten aus den alten Bundesländern gehört zu haben:

„Ach, hätt ich doch bloß auf die Wessis gehört.“

Interviewer: „Wieso, wat ham die jesacht?““

„Meine Verwandtschaft [...] aus Hannover da hinten [hat gesagt]: ,Kommt her, wir ham hier Arbeit für Euch. ' Da hatten wir beide [der Befragte und seine Ehefrau] aber noch Arbeit. “ Manfred Großer, 54, I110§252ff.

...und nicht damit gerechnet, dass sich unsere berufliche Situation noch einmal dramatisch verschlechtern würde, so könnte man den Satz weiterführen. Nun betrachtet er sich selbst als den naiven Ostdeutschen, der auf die sprichwörtlichen blühenden Landschaften, die den Ostdeutschen einst versprochen wurden, gewartet hat und nun einsehen muss: „Da werden wir wohl lange warten. Dat wird nix mehr hier“ (I110\$623). Schließlich sei in seiner Region doch „alles kaputt gegangen“ (I110\$254) nach der Wende.

Die Identität der älteren Befragten bleibt infolge des Verlusts einer statussichernden Erwerbsarbeit dauerhaft beschädigt. Die Gelegenheiten zur Aufnahme 
neuer Jobs oder Erschließung alternativer Domänen sind selten und erweisen sich immer wieder als brüchig und unsicher. So bleibt der Rückzug in die Familie als letzte verlässliche Umgebung. Diese Erfahrungen führen mit der Zeit zu einem grundsätzlichen Misstrauen gegenüber allen Sphären jenseits der Kernfamilie. Zur Etablierung neuer Identitäten fehlt es daher nicht nur an Gelegenheiten, sondern auch an Offenheit gegenüber Neuem und am dafür nötigen kulturellen Kapital.

Dieser wiederkehrende oder dauerhafte Ausschluss aus sozialen Verkehrskreisen, in denen Anerkennung und Teilhabe erfahren werden können, verbindet die älteren mit den jüngeren Befragten. Einige von ihnen sind bereits in Haushalten aufgewachsen, die von relativer Einkommensarmut und Unsicherheit betroffen waren, und könnten die Kinder der älteren Befragten in dieser Gruppe sein. Sie haben niedrige Bildungsabschlüsse und bislang nur wenige oder gar keine Erfolgserlebnisse auf dem Arbeitsmarkt vorzuweisen.

Der 23-jährige Hans Sens (I120) hatte wenig Unterstützung in seinem Elternhaus erfahren und war schon sehr früh auf sich allein gestellt. Seine Mutter arbeitet als Reinigungskraft in der Schweiz und kommt nur halbjährlich nach Hause, und der Vater pendelt die Woche über zu seinem mehr als anderthalb Stunden entfernten Arbeitsort im Schiffbau. Die Eltern haben einen Umgang mit der schlechten Arbeitsmarktlage in ihrer Region gefunden und zahlen dafür den Preis des Pendlerlebens. Sie arbeiten viel, sind kaum zu Hause und haben nur wenig Verständnis für die Situation ihres Sohnes, dem der Einstieg in das Erwerbsleben bislang nicht gelungen ist. Seine Biographie beschreibt Herr Sens wie folgt:
„Na, eigentlich alles ganz normal abgelaufen. [...] Ne, ganz normal meine Schule gemacht. Ja, dann hab ich leider die Schule verkackt, nachher, musst ich nachher wiederholen, die ganze neunte Klasse musst ick wiederholen, hab ick dann au nich geschafft, so dann bin ick in Vorbereitungsjahr gegangen. Und hab dann da meinen Abschluss nachgeholt. [...] Naja, na n-Eltern och gesacht, naja, ohne Abschluss is heutzutage nix, ne? So, un da hab ick mich halt rangeklotzt so, halt mein Abschlu- mein Hauptschulabschluss nachgeholt so, [... “ Hans Sens, 23, I120§58-64.

Hier zeigt sich zunächst einmal, dass die Fördersysteme für Jugendliche ohne Schulabschluss in diesem Fall gut funktioniert haben: Er verließ die Hauptschule ohne Abschluss, holte diesen jedoch umgehend im Rahmen eines institutionell vermittelten Berufsvorbereitungsjahres nach. Dann begann er in einem Bildungszentrum eine zweijährige Lehre zum Trockenbauer (,,[..] wenn du det Vorbereitungsjahr bestehst un da dein Abschluss nachmachst, kriste gleich 'ne Lehrstelle dazu [...]“ I120\$60). Während der Ausbildung genoss er vor allem die Praktika in diversen Firmen, weil seine Arbeit dort einem unmittelbaren Zweck 
diente und nicht - wie in der Bauhalle des Ausbildungsträgers - gleich wieder zerstört wurde:

\begin{abstract}
„Na, die Ausbildung, die eigentlich übern Bildungsträger laufen, die sind eigentlich viel über Praktikum ausgestreckt. [...], dann haste deine Bauhalle da en bisschen, da kannst da en bisschen wat machen. [...] un wieder abge-wieder abgerissen so. Naja, das is halt die Scheiße. [...], dann haste halt über Firmen halt, weißt, dann praktische Erfahrungen gesammelt. [...] Klar hat das Spaß gemacht. Klar, hast viele Leute kennengelernt, hast da ma wat gelernt, hast da ma wat gelernt. "Hans Sens, 23, I120\$126-130
\end{abstract}

Herr Sens hebt die Erfahrung, bei der Arbeit „viele Leute“ kennengelernt zu haben und den Effekt, etwas gelernt zu haben, positiv hervor (, Klar hat das Spaß gemacht."). Doch leider gelingt es ihm nicht, daraus eine berufliche Perspektive aufzubauen. Er scheitert immer wieder an der theoretischen Abschlussprüfung. Auch die letzte Prüfung nach einem zusätzlichen dritten Jahr im Bildungszentrum führte nicht zum Erfolg. Weitere Prüfungsanläufe unternimmt er nicht, unter anderem deshalb, weil er die Prüfung dann selbst zahlen müsste:

„Klar, musst du aber selber bezahln. (.) Weißt? Ick hatt ja schon meine zwei Chancen gehabt, die Ausbildung wär ja dann eigentlich nur zwei Jahre gelaufen, [...] Un denn musst ick ja noch en Jahr dranhängen, mit zwei Nachprüfungen. Un hab denn o-ni bestanden. Weißt? Aber naja, ph, im Endeffekt (schlägt auf den Tisch) passiert. Muss mer halt mit durch, ne? " Hans Sens, 23, I120\$152

Wo genau er da ,halt mit durch“ muss, wird aus dem Zitat nicht ganz ersichtlich. Einen weiteren Prüfungsversuch, durch den er durchmüsste, plant er nicht. Wahrscheinlicher ist, dass er sich mehr oder weniger damit abfindet, mit dem Ziel Ausbildung gescheitert zu sein. Seitdem sind zwei Jahre im Arbeitslosengeld IIBezug vergangen. Zum Zeitpunkt des Interviews ist er in einer Arbeitsgelegenheit mit Mehraufwandsentschädigung (MAE) beschäftigt:

„Naja, da kam nachher das Hartz IV draus, ja. [...] Und denn bist du total abgeknickt (schlägt auf den Tisch), denn bin ick total abgeknickt. Ha ick nachher gar nischt mehr ange- nur zu Hause gesessen, dann hatteste ab und zu mal dein Sport gehabt [...], dann ganz froh, dat ick jetz, hier bin. Und den Job machen kann, wieder en geregelten Tagesablauf hab, wieder so dieset langsame Reinkommen so. Weißt ja, wenn du dann lieber fast, äh, über en Jahr zu Hause sitzt, dann is ja wohl logisch, dat de denn nich ma dein Arsch nich mehr bewegst. Weißt? Un deswegen passt dat eigentlich" Hans Sens, 23, I120§182 
Herr Sens spielt Fußball in einem Verein in der Gegend. Ohne die Beschäftigung in der Maßnahme blieben ihm nur der Sport und gelegentliche Treffen mit Freund*innen aus dem Ort als strukturierendes Element in seinem Alltag. Beides reicht für ihn nicht aus, um den eigenen Ansprüchen an das Leben gerecht zu werden (,Und denn bist du total abgeknickt“). In der Berufsbiographie von Hans Sens zeigt sich einmal mehr die vollständige Abhängigkeit von institutionellen Gatekeepern. Alle Impulse wurden durch Institutionen vermittelt, das Berufsvorbereitungsjahr und die Ausbildungen fanden innerhalb von öffentlich geförderten Institutionen statt, und auch die MAE-Stelle wurde durch das Jobcenter vermittelt. Auf dem freien Arbeitsmarkt konnte er bislang keine Erfolge erzielen. Herr Sens wirkt, als sei er in seinem Lebenslauf stecken geblieben und komme ohne fremde Hilfe da nicht wieder heraus.

Die vier Mütter haben ähnliche Ausgangbedingungen wie Herr Sens (geringe Bildung, keine abgeschlossene Berufsausbildung, relative Einkommensarmut und Prekarität bereits in der Herkunftsfamilie). Seit der Geburt ihres (ersten) Kindes haben sie zusätzlich zeitliche Restriktionen, die die Suche nach Erwerbsarbeit erschweren. Zum Extrem steigert sich die Orientierungslosigkeit im Fall von Laura Bernstein. Sie ist 42 Jahre alt, kommt ursprünglich aus dem Ruhrgebiet und ist Mutter von drei Kindern im Alter von 10, 15 und 17 Jahren. Seit der Trennung von ihrem Partner vor zwei Jahren lebt sie bei ihrem neuen Partner in Mecklenburg-Vorpommern, wohin sie nur ihre zehnjährige Tochter mitgenommen hat. Sie hat nach ihrem Hauptschulabschluss vier Jahre lang an einem Kiosk gejobbt und dann eine Ausbildung zur Kinderpflegerin begonnen, die sie aufgrund zu hoher Anforderungen und einer schwereren Erkrankung mit Krankenhausaufenthalt nicht beendete:

„Ja, ich war schon 'ne Weile aus der Schule raus. Die Anforderungen waren zu hoch. Da kam ich nicht so wirklich mit. Dann Krankheit noch und ja. (...) Ja, keine Lust mehr gehabt. Ja und dann hab ich gedacht, okay, dann machste doch keine Lehre mehr." Laura Bernstein, 42, I025\$222

Auch nach dem Abbruch der Ausbildung fand sie Jobs, mit denen sie auskommen konnte. Erst mit der Geburt des ersten Kindes wurde sie arbeitslos, davor arbeitete sie:

„ma inne Kneipe, ma putzen, anne Trinkhalle. Ja, bis ich dann schwanger geworden bin erste Mal. Dann war ich zu Hause. Dann wollt ich eigentlich, wo der Große zwei war, wollt ich eigentlich ne Schweißerlehre machen und hab aber keinen Platz gekriegt, ja, und dann kam der zweite auch schon. Ja. Nachher kam dann die Letzte." Laura Bernstein, 42, I025§212 
Bis „die Letzte“ kam, vergingen fünf Jahre, in denen sie nicht arbeitete und sich mangels besserer Alternativen auf die Mutterrolle zurückzog. Das Muster, nach gescheiterten Versuchen nicht weiterzumachen und sich bereitwillig der Situation zu ergeben (,keinen Platz gekriegt, ja, und dann kam der zweite auch schon“), zieht sich durch das ganze Interview. So begründet sie ihre Arbeitslosigkeit seit der Geburt der Tochter vor 10 Jahren wie folgt:

„Nee. Mal versucht, was zu kriegen. Aber wenn die meisten dann gehört haben, drei Kinder. Und wenn die ma krank werden, dann sind Se nicht einsetzbar und blablabla. Also dann, nix gekriegt. Nix gefunden. " Laura Bernstein, 42, I025§226

Sie wirkt gleichgültig gegenüber ihrer beruflichen Situation. Es scheint, als habe sie bereits jetzt mit dem Erwerbsleben abgeschlossen (,, Wenn mich keiner will, will mich keiner"):

„Mein Vadder hat nur immer, ,Such dir ma Arbeit‘. Ich so, ,Ja, Papa, mach ich'. Nur, mehr wie gucken und machen und tun kann ich ja nicht. Wenn mich keiner will, will mich keiner. Deswegen. Und da [ich] jetz, 17 Jahre aus ' $m$ Beruf raus bin, ist das jetz.t natürlich noch schwieriger. Weil, die meisten woll'n ja auch wat Jüngeret wie schon fast Omi. Ja, is ja so. “ Laura Bernstein, 42, I025§230

Sie hat die Pläne, eine Ausbildung zu machen, längst aufgegeben und glaubt nun nicht mehr daran, noch irgendeine Arbeitsstelle zu finden. Mit ihren 42 Jahren und der langen Erwerbslosigkeit hält sie sich für zu alt dafür (,,die meisten woll'n ja auch wat Jüngeret wie schon fast Omi“). Eine andere Perspektive erwähnt sie nicht. Hin und wieder nimmt sie an Maßnahmen teil, um nicht sanktioniert zu werden. Eine Kompensation durch den Partner findet nicht statt, er ist ebenfalls erwerbslos. Es gibt auch keine Hinweise auf alternative Domänen im Netzwerk von Laura Bernstein, in denen sie Zugehörigkeit und Teilhabe erfährt.

Dieser doch recht drastischen Falldarstellung muss eine einschränkende Bemerkung hinzugefügt werden: Die anderen drei Mütter Daniela Mirow, Caroline Schmitt und Stefanie Neun (und auch die drei jungen Männer I120-I122) sind weniger apathisch als Laura Bernstein. Zwar spielen auch bei ihnen Langzeitarbeitslosigkeit, Trennungen und Orientierungslosigkeit eine große Rolle, doch sorgen sie sich deutlich mehr um ihre Perspektive und möchten diese im Augenblick noch zum Wohl ihrer Kinder verbessern. Aber genau wie Laura Bernstein haben auch sie nur wenige eigene Ideen für ihre Zukunft und sind auf die (zufällige) Lenkung durch Institutionen angewiesen. Vielleicht haben sie auch deshalb noch etwas mehr Hoffnung, weil sie jünger sind. Es ist jedoch nicht auszuschließen, dass sie sich selbst und ihre Zukunft auf gleiche Weise aufgeben 
werden wie Laura Bernstein, wenn sich keine Handlungsmöglichkeiten auftun, die sie, geführt durch institutionelle Gatekeeper, ergreifen.

Visuelle Netzwerkanalyse

Die Netzwerke der älteren Befragten sind klein, eher familienzentriert und geschlossen (siehe Abbildung 5.11). Neben der Familie gibt es in den meisten Netzwerken nur ein- bis maximal zwei institutionelle Kontakte sowie einbis zwei Freund*innen, Nachbar*innen oder Bekannte. Einzig Manfred Großer (I110) nennt eine Gruppe von alten Kumpels, bzw. Freund*innen (, schon von DDR-Zeiten " I110\$673), deren Bedeutung er dann jedoch gleich wieder relativiert (, man sacht sich wat und dann geht man dann wieder auseinander und dann is gut “ I110\$667 / „umbringen würd ich mich für die nich “ I110\$705). Domänen jenseits des dicht vernetzten Kernnetzwerkes gibt es nur wenige - hier sind lediglich Institutionen zu finden, zu denen die Befragten eine asymmetrische Beziehung als Leistungsempfänger*in (Jobcenter), Teilnehmer*in (Maßnahme) oder Kund*in (Tafel e. V.) pflegen. Beziehungen in soziale Kreise, in denen die Befragten alternative Rollen ausüben und soziale Anerkennung generieren könnten, sind nicht vorhanden.

Die Netzwerke der jüngeren Befragten (siehe Abbildung 5.12) sind etwas gröBer, und es sind etwas mehr Freund*innen zu sehen als in den Netzwerken der Älteren. Die oben beschriebene große Bedeutung von Institutionen spiegelt sich in den Netzwerken in der hohen Zahl institutioneller Helfer*innen wider (als Quadrate eingezeichnete Knoten). Vergleichen mit den anderen Typen wirken auch die Netzwerke der Jüngeren klein und sehr eng verbunden (Abbildung 5.13).

Die Netzwerke der drei jungen Männer in der oberen Reihe der Abbildung 5.12, Hans Sens, Ralf Kühn und Ronni Schulze setzen sich vorwiegend aus Familienangehörigen und Personen in ähnlichen Lagen zusammen, die in ihrer näheren Umgebung leben. Bei den übrigen vier Visualisierungen in Abbildung 5.12 handelt es sich um die Netzwerke von erwerbslosen Müttern mit minderjährigen Kindern. Ihre Beziehungen werden stark durch die Kinder und mit ihnen in Verbindung stehende Akteur*innen geprägt (Kindsväter/Ex-Partner, (Schwieger-)Eltern, Partner, Familienhelferin, Jugendamt). Die um die Kinder herum angeordneten Knoten sind am engsten miteinander verbunden.

Nur Stefanie Neun hat einen davon abgrenzbaren Freundeskreis. Drei der vier im Netzwerk sichtbaren Freundinnen sind Freundinnen, die sie in der Ausbildung zur Systemgastronomin kennengelernt hat, die vierte ist eine Schulfreundin. Da die Freundinnen weiter entfernt leben, pflegt sie diese Kontakte eher durch regelmäßige Telefonate und Mails, aus denen sie emotionale Unterstützung bezieht. 




Abbildung 5.11 Netzwerke der Befragten in Typ 2 (Teil 1/2) 


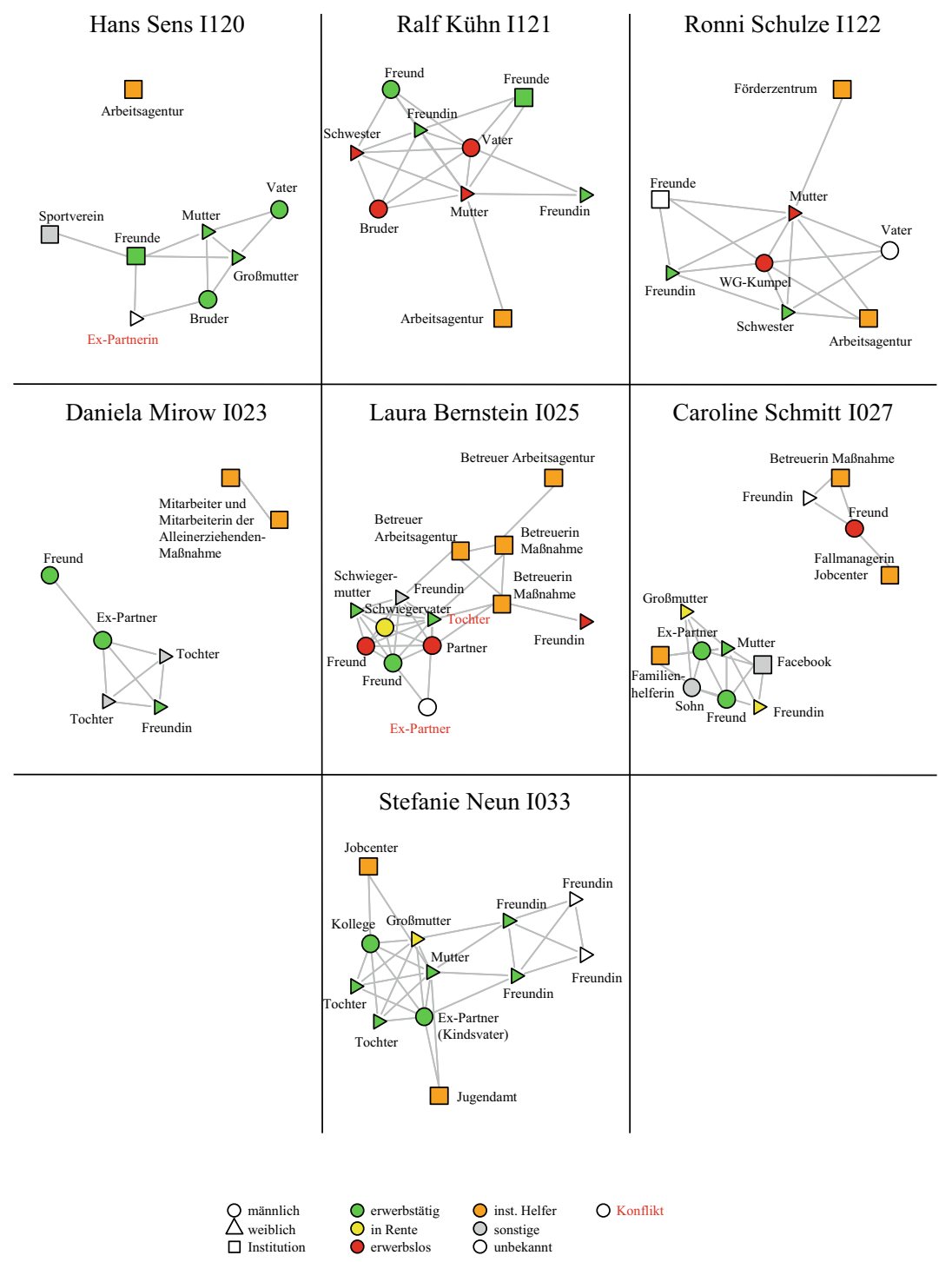

Abbildung 5.12 Netzwerke der Befragten in Typ 2 (Teil 2/2) 
Besonders interessant ist die Pflege von Beziehungen über elektronische Medien im Fall von Caroline Schmitt. Auf die Frage nach Personen, sozialen Gruppen oder Organisationen, die sie unterstützen, gab sie unter anderem Facebook an:

„Soziale Gruppen wär ja auch noch der Klassiker, sich bei Facebook auskotzen. Also, wenn jetzt so kommt, urgh, scheiß Amt, bla, Keks, wo ja denn immer so tolle gefällt-mirUnterstützung kommt, is seelisch ne super Unterstützung erst mal. " Caroline Schmitt, 24, I027

Sie erfährt bei der Bewältigung ihrer Probleme im Zuge der Arbeitslosigkeit Rückhalt durch ihre Facebook-Beiträge in Gruppen aus Personen, die sich in ähnlichen Lagen befinden. Darüber hinaus beobachtet sie alte Schulfreund*innen, die sie im realen Leben nicht mehr trifft, noch bei Facebook. Auf die Frage, ob sie sich gelegentlich mit Freund*innen treffe, antwortet sie:

„Eher weniger. Also meistens ist dann so über diese sozialen Netzwerke, dass man ma mit denen Kontakt aufnimmt, aber ansonsten, persönlich treffen ist also ist jetzt erst wieder so im Aufbau. Dass da was kommt. Ansonsten ist halt, bin ich eher so für mich. " Caroline Schmitt, 24, I027§38

Sie meidet Treffen mit Freund*innen aus Kostengründen, da sie nicht in der Lage ist, den anderen auch mal ein Getränk auszugeben. Die Treffen in der realen Welt kommen ,jetzt erst wieder so “, da sie im Rahmen der Maßnahme, die sie gerade besucht, neue Kontakte zu anderen Frauen in ähnlicher Lage geknüpft hat, mit denen sie sich nun mehr und mehr auch außerhalb der Maßnahme trifft.

Auch Daniela Mirow und Laura Bernstein nehmen an Qualifizierungsmaßnahmen teil, die auf die Bedürfnisse und Herausforderungen junger Mütter zugeschnitten sind und die als (befristet verfügbare) Domäne in ihren Netzwerken $\mathrm{zu}$ sehen sind.

Diese Beziehungen zu Freund*innen und Bekannten in ähnlichen Lagen ermöglichen den Befragten Zugang zu emotionaler und teilweise auch praktischer Unterstützung im Alltag (Geselligkeit, Rat, Rückhalt, Kinderbetreuung, ...). Was ihnen darüber hinaus fehlt, sind Beziehungen zu Gatekeepern, die über ihre aktuelle Situation hinausweisen und tatsächlich neue Perspektiven eröffnen. Hier bieten in der Regel die Maßnahmen der Jobcenter das einzige Fenster in die Welt jenseits ihrer familienzentrierten Kernnetzwerke. 


\subsubsection{Typ 3: Geschwächte Agency}

Die Lebenskonstruktion der Befragten im Typ 3 „Geschwächte Agency“ wurde durch einschneidende biographische Ereignisse umgeworfen. Dazu zählen Krisen und Brüche, die im Zusammenhang mit Flucht- und Migrationserfahrungen, psychischen und physischen Erkrankungen, Trennungen oder der Geburt oder schweren Erkrankung von Kindern stehen. Die Biographien der Befragten sind unterteilt in ein Leben davor und danach. Die 17 Fälle lassen sich anhand der biographischen Brüche systematisieren, die die Befragten erfahren haben:

- Sechs der Befragten sind nach Deutschland migriert bzw. geflüchtet und müssen ihre Lebensentwürfe nun mit den strukturellen Anforderungen ihres Ziellandes in Einklang bringen (I003, I018, I019, I020, I028, I036).

- Vier Befragte haben gesundheitliche Krisen durchlebt. Marie Neumann (I008) ist seit einem Behandlungsfehler bei einer Routineoperation körperlich beeinträchtigt, Jürgen Nobel (I022) und Corinna Sander (I107) suchen eine neue Perspektive nach psychischen Erkrankungen und Jochen Benkert (I108) ist dabei, nach Scheidung, Überschuldung und Alkoholsucht die Kontrolle über sein Leben wiederzuerlangen.

- Die übrigen sieben Befragten sind (überwiegend alleinerziehende) Mütter, deren Lebensentwürfe infolge der Geburt der Kinder (teilweise mit körperlicher oder geistiger Behinderung - I035, I103) nachhaltig verändert wurden (I024, I026, I032, I035, I037, I103, I119).

Die Befragten im Typ 3 benennen klare Ziele und haben eine genaue Vorstellung davon, wie sie diese erreichen können. Der Weg dorthin ist jedoch lang und mühevoll und das Ziel nicht ohne Hilfe von außen zu erreichen. Sie brauchen Unterstützung beim Erlernen von Kompetenzen (Sprachkurse, Anerkennung oder Erwerb von Berufsabschlüssen, Umschulungen), bei der Vermittlung in den Arbeitsmarkt (z. B. in behindertengerechte oder familienfreundliche Arbeitsplätze oder in das Erwerbssystem der BRD) sowie bei der Bewältigung und Vereinbarung von erhöhten alltäglichen Herausforderungen (z. B. Pflege von Angehörigen oder Kindern mit Behinderung). Sie sind auf unterschiedliche Weise in ihrem Bewältigungshandeln eingeschränkt, entweder rechtlich (durch fehlende Anerkennung von Berufsabschlüssen oder eine fehlende Arbeitserlaubnis), körperlich (durch chronische Erkrankungen), sozial (durch Verantwortung für Angehörige) oder räumlich (durch Regelungen im Asylgesetz wie die Residenzpflicht oder die Abhängigkeit von sozialer Unterstützung in der Umgebung). Sie können nicht ohne Weiteres an ihr Leben vor der Krise anknüpfen. 
Übersetzt in die White'sche Terminologie bedeutet die Krise einen Verlust von Identitäten (ein Flüchtling ist kein Student mehr, ein insolventer Alkoholiker kein sorgender Familienvater mehr usw.) und Domänen (Migranten, die ihre Freundeskreise im Herkunftsland aufgeben, Mütter, die ihren Job verlieren), bzw. die Veränderung von Identitäten innerhalb der Domänen, die den Befragten erhalten geblieben sind (von der hilfsbereiten und abenteuerlustigen Freundin zur hilfebedürftigen Patientin). Ihre Bewältigungschancen sind abhängig davon, ob es ihnen gelingt, in neuen und alten Domänen an die veränderte Situation angepasste Identitäten zu etablieren und abzusichern.

Wahrnehmung alltäglicher Herausforderungen, Bewältigungsstrategien und Perspektiven

Jennifer Krüger antwortet Folgendes auf die Frage: „Würden Sie sagen, dass Sie arm sind?":

„Also definitiv nicht, weil, wir könn uns trotzdem alles leisten. Es is zwar nich mein Geld, aber ich bin ja nunmal aufihn [= Partner der Befragten] angewiesen, und er sieht es auch ein und weiß halt auch, dass nicht alles geht. Und mein Ziel is ja jetzt auch, im September wieder ne Ausbildung zu machen, beziehungsweise weiterzumachen. Das kam ja durch die Schwangerschaft, dass ich nich weitermachen konnte, und dass ich dann endlich wieder mein eigenes Geld hab und auch $n$ bisschen unabhängiger bin. Das is mein Ziel. “ Jennifer Krüger, 25, I024§114

Das Zitat vereint vier wesentliche Aspekte, die die Selbstwahrnehmung der Befragten ausmachen:

1. Die Befragten nehmen sich eher nicht als arm wahr, da ihre Grundversorgung weitgehend gedeckt ist (,wir können uns trotzdem alles leisten“ - auch wenn "nicht alles geht")

2. Sie empfinden sich in ihrer momentanen Situation jedoch als abhängig von anderen (,ich bin ja nunmal auf ihn angewiesen“).

3. Die Abhängigkeit besteht erst seit kürzerer Zeit und entwickelte sich aus einer konkreten Ursache heraus (,Das kam ja durch die Schwangerschaft... “).

4. Die als störend wahrgenommene Abhängigkeit motiviert ein Bewältigungshandeln, das auf die Wiedererlangung eines gesicherten Status ausgerichtet ist (,dass ich dann endlich wieder mein eigenes Geld hab und auch n bisschen unabhängiger bin").

Die große Sehnsucht nach der Erlangung eines gesicherten Status in dieser Gruppe liegt darin begründet, dass die Befragten diesen in der Vergangenheit 
bereits innehatten oder sich auf einem aussichtsreichen Karriereweg befanden, wie Riad Ansara, der vor seiner Flucht aus Syrien das Abitur abgelegt hatte, das in Deutschland jedoch nicht anerkannt wurde.

„Ich wollt das Abitur wiederholen hier in Deutschland, um das studieren, was ich will. Aber ich muss das auch selbst finanzieren. " Riad Ansara, 23, I019\$265

Da diese Finanzierungsmöglichkeit ihm im Augenblick fehlt, absolviert er zunächst eine Ausbildung, ohne das Ziel „Abitur“ aufzugeben. Parallel zur Ausbildung sucht er nach Möglichkeiten, das Abitur erneut abzulegen. Herr Ansara musste akzeptieren, dass ihm der direkte Weg zum Studium infolge der Flucht versperrt ist. Nun muss er seine Strategien an die neuen Gegebenheiten anpassen (Ausbildung beenden $\rightarrow$ Abitur finanzieren und nachholen $\rightarrow$ Studienplatz suchen).

Häufig greifen die Befragten sehr gezielt auf institutionelle Angebote zurück und nutzen jede sich bietende Gelegenheit zur Erweiterung ihres Netzwerkes. Dies geschieht z. B. dadurch, dass sie in verschiedenen sozialen Kreisen immer wieder über ihre Probleme reden und so die Wahrscheinlichkeit steigern, Unterstützung aus dem Netzwerk zu generieren. Die seit einer missglückten Operation stark in ihrer Bewegung eingeschränkte Marie Neumann (I008) erzählt z. B., dass es ihr guttut, sich mit Personen mit einem ähnlichen Krankheitsbild auszutauschen. Dabei handelt es sich um eher schwache uniplexe Beziehungen, die auf das Thema „Krankheit“ beschränkt sind und die teilweise nur virtuell über Foren und soziale Netzwerke im Internet gepflegt werden. Da ihre Krankheit eher selten ist und in ihrem unmittelbaren Umfeld nicht vorkommt, musste sich Frau Neumann die Kontakte zu anderen Erkrankten erst erschließen. Kennengelernt hat sie diese Personen schließlich...:

„...durch Bekannte. Das kam durch Zufall. Man erzählt ja mal, ja, ich hab jetzt den Kollegen, äh, der hat das und das, und so kam das halt alles. Es is viel durch Gerede. Nich Gerede im schlechten Sinne, sondern man erzählt ja so. Man hat den und den neu kennengelernt, und so kam's denn halt. Und man kann ja viel über Internet halt, es gibt ja auch Foren. " Marie Neumann, 33, I008§115

Das Zitat zeigt, dass Marie Neumann den „Zufall“, durch den sie die unterstützenden Beziehungen aufnehmen konnte, dadurch wahrscheinlicher gemacht hat, dass sie verschiedenen Leuten von ihrer Krankheit erzählt und dass sie darüber hinaus im Internet gezielt nach Personen mit ähnlichen Symptomen gesucht hat. Darin kommen drei grundlegende Voraussetzungen für die Genese der Unterstützungsnetzwerke der Befragten im Typ 3 zum Ausdruck: 
1. Ein subjektives Bewusstsein für den eigenen Unterstützungsbedarf,

2. Offenheit im Umgang mit dem „Problem“ und

3. die Bereitschaft, neue Beziehungen einzugehen und Unterstützung anzunehmen.

Letzteres wird im folgenden Zitat noch deutlicher. Hier erzählt sie davon, wie sie zu der Praktikumsstelle in der Suchtberatungsstelle gekommen ist, in der sie seit einiger Zeit ehrenamtlich aktiv ist:

\begin{abstract}
„Dann hab ich n Praktikum gemacht im [Einzelhandel], klappte gar nich mit meinem Bein, also is ja viel stehen, Regale einräumen, wischen, und das ging gar nich mit dem, mit der Behinderung und denn, weil die Mutter von meiner Freundin, die arbeitet hier [in der Suchtberatungsstelle] als ehrenamtliche Helferin schon jahrelang, und dann kamen wir auf die Idee, hier mal anzufragen. Ich war auch erst sehr skeptisch, ich wollt eigentlich nur meine Zeit hier rumkriegen [die Befragte benötigte eine Praktikumsbescheinigung im Rahmen einer Maßnahme des Jobcenters], ähm, denk, du hast es nich weit von zu Hause, probierste's mal, die haben mich da auch genommen, und je länger ich, äh, hier bin, umso mehr gefällt mir das, und das Praktikum is jetzt zu Ende, und jetzt bin ich auch ehrenamtlich, äh, Mitarbeiter hier. Im Betreuten Wohnen jetzt. “ Marie Neumann, 33, I008\$117
\end{abstract}

Die Freundin der Befragten bildet auch in der Netzwerkabbildung (Abbildung 5.13, unten links) die - streng genommen über die nicht auf der Netzwerkkarte auftauchende Mutter der Freundin zustande gekommene - Brücke zwischen der Praktikumsstelle in der Suchtberatung (im Netzwerk als ,ehrenamtliche Beschäftigung" bezeichnet) und dem Freundeskreis. Das Zitat verdeutlicht, dass Impulse zur Annahme von Unterstützung und zur Erweiterung sozialer Kreise auch aus dem bestehenden Netzwerk kommen können, wenn die Interaktionspartner*innen den Zugriff auf außerhalb der konkreten Domäne liegende Ressourcen ermöglichen können. Marie Neumanns sehr heterogene Quellen sozialer Unterstützung resultieren aus einem Zusammenspiel ihrer eigenen Bemühungen und Aktivitäten im Netzwerk (über ihre Probleme reden, Unterstützung suchen und finden) und der Annahme von Anregungen aus dem Netzwerk (Unterstützung annehmen).

In einer früheren Analyse des hier verwendeten Materials konnte gezeigt werden, dass es Befragten wie Marie Neumann auch deshalb leichter fällt, die oben genannten drei Kriterien für die Generierung sozialer Unterstützung zu erfüllen, weil sie auf einen äußeren Umstand verweisen können (der Behandlungsfehler, der die Behinderung verursachte), der sie zu einem gewissen Grad vor der negativen Stigmatisierung ihrer Armutslage schützt (Knabe, Fischer et al., 2018). 
Eine weitere Strategie zur Erweiterung des sozialen Netzwerks findet sich im Fall von Tokas Mint. Ähnlich wie Riad Ansara hatte er in seiner mauretanischen Heimat bereits das Abitur abgelegt und eine Berufsausbildung abgeschlossen. Auf Basis seiner Erfahrungen im deutschen Asylsystem hat er sich eine Expertenrolle erarbeitet, die er einsetzt, um anderen zu helfen:

\begin{abstract}
„Ich helfe ihnen als Asylbewerber, weil ich bisschen Erfahrung hab [mit dem] Asylverfahren, wie das funktioniert. Wenn eine Brief bekommen, eine Bescheid von Bundesamt [für Migration und Flüchtlinge], wie viel Wochen hast du Zeit für eine Klage machen, welche Anwalt ist gut, welche ist nicht gut, was kannst du machen, was darfst du nicht. So, das weiß ich schon. Was ist erlaubt für Flüchtlinge, was ist nicht erlaubt. " Tokas Mint, 37, I003§265
\end{abstract}

Die im Zitat beschriebene Tätigkeit als Berater für andere Geflüchtete eröffnet Herrn Mint auch Kontakte zu nicht-Geflüchteten. Er tritt als Vermittler und Übersetzer bei Rechtsanwält*innen, Ärzt*innen, Opferberatungsstellen, Sozialarbeiter*innen im Asylbewerber*innenheim und politischen Initiativen auf - und sogar dann, wenn ein Bundestagsabgeordneter mit Geflüchteten in seinem Wahlkreis sprechen möchte. Diese Kontakte ähneln professionellen Beziehungen aus der Arbeitswelt und ermöglichen es ihm, Anerkennung zu generieren. Im Bedarfsfall kann er über diese Beziehungen auch selbst Unterstützung bekommen: Als er sich ein Bein brach, brachte ihn ein Bekannter aus einer antirassistischen Initiative mit dem Auto zum Arzt.

Die Fähigkeit, eigene Pläne zu definieren und umzusetzen, unterscheidet die Befragten im Typ 3 deutlich von den Angehörigen des Typs 2 „Prekärlabil Mangel an Agency“, bei denen derart konkrete Ideen und Perspektiven nicht zu finden sind. Die Agency der Befragten ist dennoch geschwächt, da sie ihre Ziele nur auf Umwegen erreichen können - sie müssen zunächst gute Lösungen für die davor liegenden Schwierigkeiten finden und sind dafür auf entsprechende Gelegenheitsstrukturen (Vermittlung und Beratung, Ausbildungsstelle, Weiterbildung) angewiesen.

\title{
Biographie
}

Die oben bereits erwähnte Marie Neumann ${ }^{24}$ ist aufgrund einer missglückten Routineoperation am Bein seit einigen Jahren stark in ihrer Mobilität eingeschränkt und gilt nur noch für drei Stunden am Tag als erwerbsfähig. Infolge des „Unfalls“, wie sie das Ereignis nennt, verlor sie ihren Job und trennte sich

\footnotetext{
${ }^{24}$ Ausführliche Fallporträts zu Marie Neumann finden sich in Knabe, Fischer et al. (2018) und in Klärner und Knabe (2016).
} 
von ihrem Partner. Nach einer längeren Zeit der Krise versucht sie nun, dieses Schicksal anzunehmen und eine neue, an die Situation angepasste Perspektive für sich zu finden:

\begin{abstract}
„Also, meine Einstellung hat sich da komplett geändert. Früher war ich so, ich hatte meinen Lebensplan, der ging dann von Stufe zu Stufe. Klappte der [Plan] nicht, dann hab ich mir $n$ andern Lebensplan erstellt für die nächsten Jahre [...]. Dann kam der Unfall, und jetzt hab ich da [...] zwei Jahre wirklich im Tief gesessen, die Welt gehasst und alles is Scheiße. Und dann hab ich mich da irgendwie rausgeholt [...]. Ich freu mich über jeden Tag, ich hab jeden Tag gute Laune [...]. Ich guck zwar schon, was in diesem Jahr kann ich alles erreichen und machen, aber eben nicht mehr so n Lebensplan wie vorher. “ Marie Neumann, 33, I008\$113
\end{abstract}

In dieser Beschreibung kommt sehr deutlich zum Ausdruck, dass auf das einschneidende Ereignis eine Phase der Umorientierung (,im Tief gesessen“) und Anpassung (,,dann hab ich mich da irgendwie rausgeholt“) folgte, die schließlich in eine neue Handlungsweise mündete, die einen Kompromiss aus den Ansprüchen und Möglichkeiten davor und danach bildet: Frau Neumann „guckt schon “ noch, was sie alles erreichen kann, macht aber nicht mehr ,so 'n Lebensplan wie vorher". Das bezieht sich sowohl auf mittel- und langfristige Lebenspläne als auch auf die unmittelbare Strukturierung des Alltags, denn:

„Früher konnte man mehr an einem Tag schaffen, jetzt geht's nicht mehr. " Marie Neumann, 33, I008§37

Allerdings bedeutet die Anpassung an die neue Situation nicht, dass sich Frau Neumann mit weniger zufriedengibt, sondern dass sie neue, ihrer dauerhaft veränderten Realität angepasste Ziele und Perspektiven definiert - sie ,schafft“ jetzt weniger „an einem Tag“, und das hat sie in den vergangenen Jahren zu akzeptieren gelernt.

Ähnliche Strategien finden sich auch bei den anderen Angehörigen dieser Gruppe. Die sechs Befragten (I003, I018, I019, I020, I028, I036) mit Migrationshintergrund sind dabei, sich eine Existenz und Perspektive in Deutschland aufzubauen, für die sie ihre Lebenserfahrungen aus den Herkunftsländern nur bedingt einsetzen können. Für die sieben Mütter (I024, I026, I032, I035, I037, I103, 119) bedeutete die Geburt ihres Kindes eine Zäsur in ihrer Erwerbsbiographie.

Auch Nadine Schulze, 32, sieht sich gezwungen, neue Wege zu finden. Sie lebt in einer Partnerschaft und hat einen fünfjährigen Sohn. Sie und ihr Partner haben beide eine Ausbildung in der Gastronomie absolviert. Seit der Geburt ihres 
Sohnes findet Frau Schulze jedoch keine Stelle mehr in diesem Bereich, da sich die Arbeitszeiten in ihrem Beruf nicht mit der Sorgearbeit vereinbaren lassen:

„Da mein Partner [...] auch in Schichten arbeitet, ist das eher schwierig, das unter einen Hut zu bringen. Ich wollt natürlich jetzt sehen, dass ich eine Umschulung kriege Richtung Pflege. “ Nadine Schulze, 32, I026\$127

Als Mutter ist sie in dieser Situation doppelt benachteiligt: Sie trägt die Hauptlast der Sorgearbeit für das gemeinsame Kind und muss dafür ihre bisherige berufliche Karriere aufgeben und sich komplett neu orientieren, während ihr Partner weiter in der Gastronomie arbeiten kann.

Nach der Elternzeit und erfolgloser Jobsuche ließ sie sich durch das Jobcenter wiederholt in Maßnahmen zur beruflichen Eingliederung junger Eltern vermitteln, deren Unterstützung und Beratung sie dankbar annimmt. Ihr wurden dort ein Kindergartenplatz und zwei Praktika in der Altenpflege vermittelt. Ihr Ziel ist es, eine Umschulung zur Altenpflegerin zu absolvieren und in diesem Bereich zu arbeiten, das Praktikum betrachtet sie daher als Chance:

„Ich fang um sechs an und [muss] dadurch natürlich zeitig aufstehen, auch für den Lütten, also für meinen Sohn, der muss natürlich beizeiten raus. Also, es is schon anstrengend, sach ich jetzt, ne. Aber man tut eigentlich alles, um wieder irgendwie in den Arbeitsmarkt zu kommen, sach ich mal. Also, von daher is es mir das eigentlich gut wert, weil eventuell 'ne Arbeitsstelle dahinterstehen könnte. " Nadine Schulze, 32, I026§8

Zwar ist ihre berufliche Perspektive an die institutionelle Unterstützung gebunden, sie entwickelt daraus aber eine eigene Motivation, die über ihre derzeitige Lage hinausweist. Sie formuliert das konkrete Ziel, in die Pflege zu gehen, und benennt die nötigen Schritte auf dem Weg dorthin (Praktikum $\rightarrow$ Umschulung $\rightarrow$ Übernahme als Mitarbeiterin).

Der biographische Bruch und die Fähigkeit, in dessen Folge sukzessive Handlungs- und Gestaltungsfähigkeit wiederzuerlangen, bildet die Gemeinsamkeit der 17 Fälle im Typ 3 „Geschwächte Agency“.

Visuelle Netzwerkanalyse

In Abbildung 5.14 sind die Netzwerke der sieben Mütter im Typ 3 zu sehen, Abbildung 5.13 zeigt die Netzwerke der sechs Migrant*innen (erste und zweite Reihe) sowie von drei Langzeitarbeitslosen (untere Reihe). Die Netzwerke der Befragten in Typ 3 „Neuorientierung nach der Krise“ ähneln sich dahingehend, 
dass sie ein Zentrum haben, von dem aus weitere soziale Kreise angesteuert werden, die jedoch häufig nur als isolierte Akteur*innen oder Orte und Institutionen im Netzwerk auftauchen. Zu sehen ist in den meisten Fällen ein Kernnetzwerk aus relativ vielen eng miteinander verbundenen Personen, umgeben von einer Peripherie aus Isolates oder kleineren, eher lose verbundenen Netzwerkkomponenten. Besonders deutlich ist diese Struktur in den Netzwerken von Sandra Holz in Abbildung 5.14 sowie von Sabou Abani und Jürgen Nobel in Abbildung 5.13 zu erkennen.

Diese Netzwerkstruktur erscheint logisch im Sinne der qualitativen Analysen: Die Befragten haben eine besondere Herausforderung zu bewältigen (Migration, Mutterschaft, Krankheit, ...) und sind dafür auf emotionalen Rückhalt und eine stabile und verlässliche soziale Umgebung angewiesen, die sich in den meisten Fällen aus Familienmitgliedern, Freund*innen oder Peers zusammensetzt. Da die Bewältigungsstrategien aber auf die mittelfristige Erweiterung ihrer Handlungsspielräume ausgerichtet sind, pflegen sie darüber hinaus auch Beziehungen in weitere soziale Kreise. Dabei handelt es sich in den meisten Fällen um Institutionen und Personen, die eine Gatekeeperfunktion haben (Jobcenter, Maßnahmeträger, Weiterbildungs- und Beratungseinrichtungen, Vereine, ...). Das Ziel der Befragten ist es, unter Rückgriff auf die Unterstützung durch diese Personen und Institutionen (wieder) in eine Position $\mathrm{zu}$ gelangen von der aus sie unabhängig agieren können (Arbeitserlaubnis, anerkannter Ausbildungsabschluss, gesicherte Kinderbetreuung, zu den Bedürfnissen passender Arbeitsplatz usw.).

Zusammenfassend betrachtet handelt es sich bei den Beziehungsstrukturen im Typ 3 „Geschwächte Agency“ um Netzwerke in Bewegung. Sie werden durch die Befragten ständig weiterentwickelt und strategisch zur Erreichung mittelfristiger Ziele genutzt. Die soziale Einbettung bietet Gelegenheiten zur Erweiterung der aktuell beschränkten Handlungsspielräume.

\subsubsection{Typ 4: Ausbau von Agency}

Der Typ 4 „Ausbau von Agency“ versammelt alle acht Studierenden im Sample. Die Befragten erleben relative Einkommensarmut als eine vorübergehende Phase finanzieller Knappheit, in der die Selbstverwirklichung durch den Erwerb kulturellen Kapitals und die Suche nach einer lebensweltlichen Orientierung Vorrang vor materiellen Ansprüchen hat. Die einen handeln dabei planvoll und strukturiert, das Studium dient ihnen als Mittel zum Zweck, und sie haben eine klare Vorstellung davon, wofür sie ihren Hochschulabschluss später einsetzen möchten. Die anderen gehen das Ziel der Verbesserung ihrer Lebenschancen 









Abbildung 5.14 Netzwerke der Befragten in Typ 3 (Teil 2/2) 
eher experimentell-spielerisch an und leisten sich längere Orientierungsphasen, in denen sie verschiedene Ausbildungen, Jobs und Studiengänge ausprobieren, bis sie das Richtige für sich finden. Die Befragten bezeichnen sich selbst nicht als arm, obgleich sie Erfahrungen mit materieller Knappheit im Alltag machen, die stellenweise als sehr belastend erlebt werden (z. B. Stress, Druck, Abhängigkeiten, Schulden). Im Gegensatz zu den Angehörigen der anderen drei Typen hat die relative Einkommensarmut in Typ 4 jedoch keine negativen Auswirkungen auf den sozialen Status der Befragten. Mit wenig Geld auskommen zu müssen erscheint den Befragten als ,normal“ in Anbetracht ihrer derzeitigen Lebensphase und ist in ihren großen Peer-Netzwerken weit verbreitet.

Wahrnehmung alltäglicher Herausforderungen, Bewältigungsstrategien und Perspektiven

Karsten Schwarz studiert Soziologie im Master und bezieht sich bei der Beantwortung der Frage, ob er sich als arm bezeichnen würde, auf die Definition der relativen Einkommensarmut, die er aus dem Studium kennt:

„In dieser Hinsicht [befinde ich mich] schon in der Bevölkerung, die unter der Armut lebt [...] allerdings fühl' ich mich nicht so - zumal ich als hoffentlich bald Master-Absolvent ne gewisse Perspektive einfach habe. Wenn man das jetzt über das Einkommen messen würde, dann wäre ich wahrscheinlich arm, aber subjektiv ist dem eigentlich nicht so gegeben. " Karsten Schwarz, 25, I038\$42

Ganz ähnlich wie Karsten Schwarz betrachten auch einige der anderen Befragten in dieser Gruppe ihr Studium als notwendige Voraussetzung, um später ein Einkommen jenseits der Armutsgrenze erzielen zu können. Die materielle Knappheit ist also nur vorübergehend, die Lebenssituation wird als selbstgewählt betrachtet und eher positiv bewertet. So ist der 24-jährige Karl Schmidt stolz darauf, nach einer durchwachsenen Schullaufbahn und einer abgebrochenen Ausbildung nun mit dem Studium das gefunden zu haben, was ihn wirklich „weiterbringt“:

„,[Ich] habe die Ausbildung nicht fertig gemacht und mich dann letztendlich für das Studium entschieden, das ich im Moment mache. Und das ist jetzt für mich auch im Moment erstmalig so der Punkt, wo ich denke, damit komm ich voran, das bringt mich weiter. Und deswegen ist für mich das eigentlich erklärend für-ja, auch meinen Alltag, weil ich jetzt endlich denke: Das, was ich tu, is auch sinnvoll, bringt mich voran. "Karl Schmidt, 24, I040§11

Das selbstgewählte Studium bezeichnet er als „erklärend“ für die Entbehrungen, die er dafür in Kauf nehmen muss. Schließlich hat er die Entscheidung 
dafür selbst getroffen (,habe mich [...] dafür entschieden“). Neben den mit dem Studium verbundenen materiellen Einschränkungen benennt er auch die Einschränkung von künstlerischen Aktivitäten und einen Verlust an freier Zeit, die er vorher mit Freund*innen verbracht hat.

Doch auch wenn die materiellen Einschränkungen vorübergehend und selbst gewählt sind, haben sie in einigen Fällen deutliche Auswirkungen auf die Alltagsgestaltung und das Wohlbefinden der Befragten. Den finanziellen Druck reduzieren sie dadurch, dass sie einem Job (oder einer selbständigen Tätigkeit, wie im Fall von Tom Reinke I041), nachgehen, wodurch Probleme der Vereinbarkeit von Arbeit und Studium sowie erhöhte Belastungen und Stress entstehen können. Maria Schmiede, die ihre laufenden Kosten durch die Arbeit in einem Studierendenclub finanziert, beklagt unter anderem auch gesundheitliche Folgen dieser Doppelbelastung:

„Sonst bin ich eigentlich nich jemand, der schnell krank wird, also, ich hab selten Schnupfen oder Grippe oder so was, aber halt durch das viele Arbeiten und die Uni bin ich halt auch dauermüde, und man fühlt sich denn auch oft schlapp. " Maria Schmiede, 24, I044§188

Lisa Müller hat sich nach dem Abitur und einer Ausbildung zur Köchin doch noch für ein Studium entschieden. Obwohl sie ein WG-Zimmer für eine geringe Miete von $200 € \mathrm{im}$ Monat gefunden hat, die von ihrer Mutter übernommen wird, empfindet sie großen Druck, neben dem Studium Geld verdienen zu müssen:

„Das heißt, die Miete is halt schon mal drinne, aber jetzt is halt wirklich dieser Druck aufgebaut, ich muss jetzt halt arbeiten gehen, um jeden Monat Geld aufs Konto zu bringen, damit das Konto halt gedeckt is. [...] Das is halt so, du bringst halt Geld auf die Bank, und das is halt weg, weil du im nächsten Monat wieder Geld auf die Bank bringen musst. Das is nen ekliges, richtig ekliges Gefühl. “ Lisa Müller, 25, I045§77

Die Frage, ob sie sich als arm bezeichnen würde, amüsiert Frau Müller trotzdem offenbar ist „Armut“ nicht die Kategorie, die sie von sich aus zur Beschreibung ihrer Lage wählen würde. Sie ist irritiert und muss zunächst darüber nachdenken, was es denn eigentlich bedeutet, arm zu sein:

„[Lachen] Geile Frage. Es is ja letztendlich immer was, was man vergleicht, so, man kann ja Reichtum nur also bewerten, wenn man sich vergleicht. Und ich glaube, dass es mir jetzt als Student mit meiner finanziellen Lage besser geht als manchen Familien, gerade in Mecklenburg-Vorpommern, wo beide vielleicht arbeitstätig im Durchschnitt 800 Euro verdienen. “ Lisa Müller, 25, I045§105 
Um die Frage zu beantworten, sucht sie nach einer Vergleichsgruppe und wählt das Beispiel einer Familie mit niedrigem Einkommen. Interessanterweise bewertet sie ihre Lage besser als die der genannten Familie, obwohl sie selbst - ginge man vom Nettoäquivalenzeinkommen aus - in sehr ähnlichen Verhältnissen lebt wie die von ihr beschriebene Familie ${ }^{25}$. In dem Moment, in dem sie sich jedoch „als Student" betrachtet, relativiert sie ihre Armutssituation. Im weiteren Verlauf des Interviews charakterisiert sie den Status der Studentin dadurch, dass sie nur für sich selbst sorgen muss, geringe Fixkosten hat und keine Verantwortung für weitere Personen trägt. In dieser Sichtweise ist der soziale Kontext (Verantwortung für eine Familie vs. nur für sich selbst sorgen) und der Status (,arbeitstätig“ mit geringem Einkommen vs. Studentin) ausschlaggebend dafür, ob die Situation als Armut wahrgenommen wird oder nicht.

Zusammenfassend kann festgehalten werden, dass materielle Knappheit von den Befragten in Typ 4 „Ausbau von Agency“ als vorübergehende Erscheinung wahrgenommen wird, die meist gar nicht oder nur ansatzweise mit dem Begriff der Armut assoziiert wird. Diese Auffassung ist mit der Erwartung verbunden, schon bald höhere Einkommen erzielen zu können. Tom Reinke bringt diese Wahrnehmung auf den Punkt, indem er sagt:

„Bei gleichem Budget würde ich mich in fünf Jahren vielleicht schon als arm bezeichnen. Zum aktuellen Zeitpunkt, in der aktuellen Situation reicht das Geld aus, um nicht arm zu sein. “ Tom Reinke, 21, I041§65

Biographie

Lisa Müller hat nach ihrer Ausbildung zur Köchin für einige Zeit gearbeitet, bis sie so viel Geld zusammenhatte, wie sie zum Leben brauchte. Den Rest der Zeit hat sie sich "frei" und ,selbstbestimmt" eingeteilt, wie sie sagt:

„Hab denn erst über ne Zeitarbeitsfirma auch gearbeitet und hatte denn dadurch eigentlich nen relativ gutes Einkommen. Ich hab [...] hab halt so viel gearbeitet, wie ich wollte. Was heißt, na sicher, wenn da Schicht war, denn war da halt auch Schicht, denn hab ich bis zum Ende gearbeitet, aber ich konnt mir halt freinehmen, wann ich wollte [...] also, konnte das halt unglaublich selbstbestimmt entscheiden. Das war echt

\footnotetext{
${ }^{25}$ Lisa Müller gibt in der standardisierten Abfrage am Ende des Interviews an, über ein Nettoeinkommen (inkl. des Mietzuschusses ihrer Mutter) von $770 €$ zu verfügen. Eine Familie mit zwei Erwachsenen mit einem Einkommen von je $800 €$ und zwei Kindern verfügt nach der neuen OECD-Skala (Gewichtungsfaktor: $1+0,5+0,3+0,3=2,1$ ) über ein Nettoäquivalenzeinkommen von $761 €$.
} 
cool. Und wie gesagt, ich hab halt auch weitaus besser verdient, mit weniger Arbeit. [..]. Lisa Müller, 25, I045§71

Diese Lebensphase stellt sie als sehr komfortabel und auskömmlich dar (,,weitaus besser verdient, mit weniger Arbeit"). Dennoch entschied sie sich aus dieser Situation heraus für die Aufnahme eines Studiums, die eine erhebliche Einschränkung ihrer materiellen Lage bedeutete:

„Joar, und dann hab ich einmal gedacht, ich möchte jetzt doch nochmal versuchen zu studieren. Jetzt hab ich meine Ausbildung, ich konnt mir das auch eigentlich relativ gut leisten. Hab mir das so durchgerechnet, hatt mir nen relativ billiges WG-Zimmer für 200 Euro gesucht und [...] konnt ich mir das halt leisten zu studieren. " Lisa Müller, 25, I045§71

Solche Spurwechsel von einem Ausbildungsberuf zum Studium sind typisch für die Lebensläufe der acht Studierenden im Sample. Dies ist vermutlich auf Herkunftseffekte der Befragten zurückzuführen: Im Rahmen der Studie wurden nur Studierende mit geringem Einkommen rekrutiert, die nicht vollständig von ihren Eltern finanziert werden. Daraus ergab sich ein Subsample aus Studierenden, die nicht unbedingt aus einkommensstarken Akademiker*innenhaushalten stammen und wo eher Karrieren jenseits einer universitären Laufbahn angestrebt werden. Fast alle Studierenden sind bereits vor einigen Jahren aus dem Elternhaus ausgezogen und haben vor Aufnahme des Studiums bereits gearbeitet oder eine Ausbildung absolviert.

Der bedeutendste Unterschied zwischen den Befragten im Typ 4 und allen anderen Befragten besteht darin, dass sie den Übergang zu ihrem jetzigen Status Student*in als bewusste und selbstbestimmte Entscheidung beschreiben. Obwohl sich Lisa Müllers finanzielle Situation mit dem Studium dramatisch verschlechtert hat, bezeichnet sie das Studium als etwas, das sie sich nach Abitur, Ausbildung und einer Orientierungsphase ,eigentlich relativ gut leisten“ konnte. Sie hat sich die Möglichkeit, zu studieren, selbst erarbeitet und nimmt die dafür nötigen Einschränkungen billigend in Kauf.

Viele der Befragten beschreiben ihre aktuelle Situation als eine Phase der Suche und Orientierung. Manchmal steht das Studium eher am Ende dieser Suche als letzte Station vor dem Übergang in den Wunschberuf (wie bei Lisa Müller), manchmal auch am Anfang, so wie bei Maria Schmiede, die ihr Leben seit dem Abitur so zusammenfasst:

„Also, ich habe [...] denn halt 2009 mein Abitur gemacht in Sachsen-Anhalt und bin denn direkt mit 19 frisch hierher gezogen zum Studium, Politik und Soziologie. Hab 
denn nach einem Semester [...] gewechselt auf Germanistik, weil ich damals dachte, mit Politik und Germanistik könnt ich zur Zeitung gehen. [...] Ja, hab denn aber den Schlendrian reingekricht, sag ich ma. Ich glaub, das war einfach alles noch zu neu, wenn man als Dorfkind irgendwie in ne große Stadt kommt, und denn is das alles so toll, alles frisch, und denn war's irgendwie nachher nich das Richtige, und hab das denn halt nich weiter gemacht [...]. War halt nur eingetragen, sag ich ma, dass ich halt da günstig noch weiterkomme, und hab denn ein Jahr schon bei uns im Club [Tanzlokal in der Universitätsstadt] gearbeitet, bin dann nach Hause, weil ich gedacht hab, ich bin vielleicht doch eher so der Arbeitstyp, der so ' $n$ regelmäßigen Arbeitsplan braucht und durch die Clubarbeit dacht ich, ne Ausbildung wär nich schlecht. Und hab dann ne Ausbildung als Veranstaltungskauffrau angefangen. [...] Das wär auch mein Ding gewesen, aber der Betrieb war so extrem furchtbar. [...] Und die Familie hat auch mich nen bisschen gedrängt, doch zu studieren, [...] weil sie halt der Meinung sind, dass es so verschenkter Grips is, wenn man jetzte nur ne Ausbildung macht [...] und hab mich denn doch entschieden, wieder zu studieren. Bin wieder [zurück] gezogen und studier jetzt Lehramt auf Geschichte und Sozialkunde und bin eigentlich auch ganz zufrieden, das jetzte zu machen. " Maria Schmiede, 24, I044\$182

Maria Schmiede hat mehrere Stationen durchlaufen (1. Studium abgebrochen, Ausbildung abgebrochen, 2. Studium angefangen) und ist am Ende unter dem Einfluss von elterlichem Rat in einem Lehramtsstudium gelandet, mit dem sie nun ,ganz zufrieden“ ist. Dieser Weg hat Auswirkungen auf ihre derzeitige und zukünftige materielle Lage, da sie Schulden angehäuft hat (BAB, BAföG, Studienkredit). Diese Strategie ist also durchaus riskant. Führt sie nicht in eine materiell gut ausgestattete und abgesicherte Lage, wie das beim Beruf der Lehrerin der Fall wäre, bleibt Maria Schmiede auf ihren Schulden sitzen.

Visuelle Netzwerkanalyse

Die Netzwerke der acht Befragten im Typ 4 „Ausbau von Agency“ sind vergleichsweise groß (Abbildung 5.15). Sie bestehen überwiegend aus Freund*innen in ähnlichen Lebensphasen (Studierende, Kolleg*innen) und Familienangehörigen. Im Vergleich zu den Netzwerken in den anderen Typen fällt auf, dass es kaum erwerbslose Personen und nur wenige institutionelle Akteur*innen gibt. Die Netzwerke sind also eher homogen in Bezug auf den Erwerbsstatus und den Beziehungstyp. Diese Beobachtung passt zu den qualitativen Analysen, die zeigen, dass die Studierenden ihren sozialen Status nicht problematisieren (wie z. B. die erwerbslosen Personen in den anderen Typen), da es in ihrem sozialen Umfeld normal und sozial anerkannt ist, zu studieren. Die meisten Befragten fühlen sich durch ihr Netzwerk unterstützt und müssen sich eher selten für ihre Situation rechtfertigen. Der 29-jährige Anton Gerdes beschreibt diese Form der Unterstützung wie folgt: 
„Ich kann mich glücklich schätzen, dass ich eine sehr intakte Familie habe. Wir halten auch immer zusammen - auch wie ich selber hergezogen bin, konnte ich auf meine Familie und meine Brüder sehr zählen. Mein Papa, der mir dann immer auch hilft, wenn es um Sachen packen geht [...], meine Mutti, die mir tatkräftig unter die Arme greift, [...] meine Brüder, die dann auch immer kommen und tragen helfen [...]. Weiß ich genau, ich kann fragen, und sie helfen mir und stehen mir auch zur Seite. Sonst hab ich Freunde, auf die ich zurückgreifen kann, die auch gerne bereit sind, mir zu helfen, und ich denke, ich hab da n-nen gutes Netzwerk, wo ich sagen kann, dass ich da gut aufgehoben bin und Unterstützung erfahre. " Anton Gerdes, 29, I043

Anton Gerdes hat nach dem Realschulabschluss und einer Ausbildung zum Tischler sein Fachabitur nachgeholt, Soziale Arbeit studiert und als Erzieher gearbeitet. Momentan hat er seine Erwerbstätigkeit unterbrochen, um einen Masterstudiengang zu absolvieren. Dafür bekommt er praktische (diverse Umzugshilfen), kognitive (Zugehörigkeit zu einer ,intakten Familie“) und emotionale Unterstützung (sozialen Rückhalt - „dass ich da gut aufgehoben bin“) von seiner Familie und seinen Freund*innen.

Visuell lassen sich zwei Strukturen voneinander unterscheiden: In den drei Netzwerken in der ersten Reihe der Abbildung 5.15 sind Teilgruppen zu erkennen, zwischen denen keine oder nur sehr wenige Beziehungen bestehen. Die Netzwerke zu den Interviews 41 bis 45 in der zweiten und dritten Reihe der Abbildung wirken im Vergleich dazu enger verbunden, da hier auf den ersten Blick kein Zerfall in Teilgruppen zu erkennen ist, wie z. B. bei Maria Schmiede, die bereits im qualitativen Teil des Interviews feststellt, dass sich die Kreise in ihrem Netzwerk aus Freund*innen, Kolleg*innen und Familie „,überschneiden“:

„Na, Freunde Schrägstrich Familie und halt gezwungenermaßen mit den Leuten auf Arbeit, wo aber ein Teil halt ja auch schon Freunde sind. Von daher überschneidet sich das auch immer nen bisschen bei mir, Freunde und Familie." Maria Schmiede, 24, I044\$24

In Netzwerken wie ihrem lassen sich unterschiedliche Domänen daher nur unter Berücksichtigung der Beziehungstypen erkennen. So gibt es z. B. im Netzwerk von Lisa Müller (I045) Kontakte zu Familienangehörigen, zu Freund*innen und zu Kolleg*innen. Da sie und ihre Kolleg*innen in einer Studierendenkneipe arbeiten, die auch die Freund*innen besuchen, kommt es zur Überschneidung dieser Kreise.

Der Kontakt der Befragten zu ihren Familien ist eher sporadisch, der Alltag wird neben Job und Studium vor allem durch Aktivitäten mit Freund*innen und Bekannten - und hier meistens durch gesellige Gelegenheiten (Partys, Konzerte, Kneipenbesuche) - strukturiert. Die Familie, insbesondere Eltern, Großeltern und 


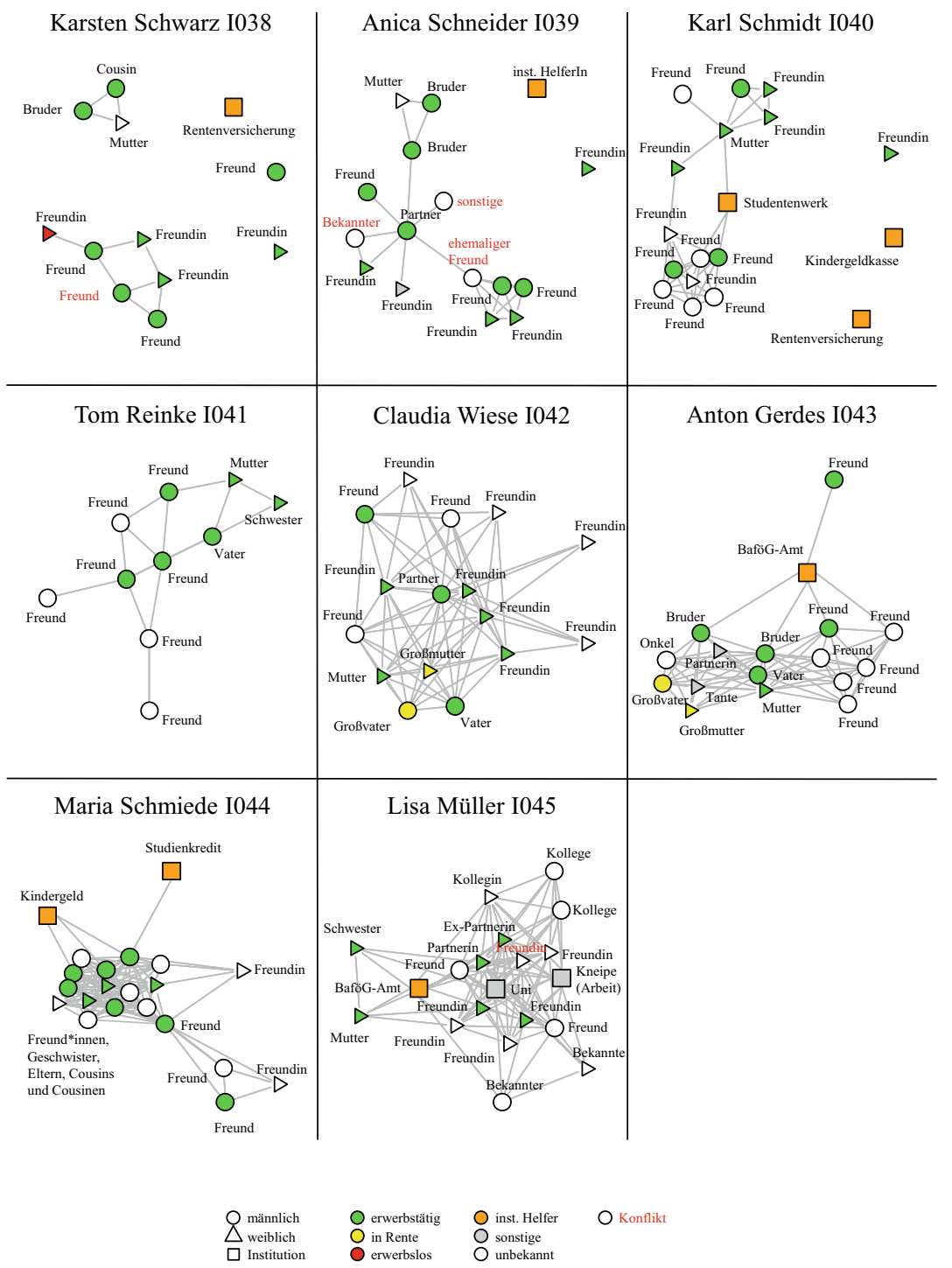

Abbildung 5.15 Netzwerke der Befragten in Typ 4 
in einigen Fällen auch die Partner*innen der Befragten, sind hingegen eine wichtige Quelle finanzieller Unterstützung, teils durch regelmäßige Zuwendungen wie die Übernahme von Mietkosten, teils spontan, wie im folgenden Beispiel von Tom Reinke:

„Ja- ab und zu kommen sie [Eltern des Befragten] mich auch besuchen und: dann gibt's meistens so am Ende auch noch ma so ' $n$ bisschen Geld- $n$ kleinen Fünfziger für den Aufenthalt und einfach als Dankeschön und halt für die nächste Zeit, so-. Darauf freu ich mich immer. (Lacht) Natürlich im ersten Sinne auf meine Eltern, aber- ja. Is immer was Nettes- irgendwie, was ich ganz gut finde. “ Tom Reinke, 21, I041§13

Zusammenfassend kann festgestellt werden, dass die Befragten im Typ 4 zwar durchaus von materieller Knappheit, aber nicht von sozialer Ausgrenzung betroffen sind. Ihr Status steht nicht infrage, sie haben anerkannte Rollen in verschiedenen sozialen Kreisen inne und Zugriff auf kognitive, emotionale, materielle und motivationale Unterstützung. Darüber hinaus verfügen sie über eine realistisch erscheinende Zukunftsperspektive. Damit lässt sich das Problem relativer Einkommensarmut in dieser Gruppe unter vergleichsweise günstigen Voraussetzungen bewältigen.

\subsubsection{Zusammenfassung}

In diesem Kapitel wurden die 57 Fälle im Rahmen der qualitativen Analyse in vier Typen unterteilt (siehe Tabelle 5.7: Qualitative Typologie). Leitend dafür war die Frage nach der Handlungs- und Gestaltungsfähigkeit der Befragten in ihren sozialen Beziehungsnetzwerken. So wurde untersucht, inwieweit die Befragten in der Lage sind, der materiellen Knappheit mit Handlungsweisen zu begegnen, die ihnen ein Leben im Einklang mit ihren persönlichen und kollektiven Idealen, Interessen und Verbindlichkeiten (,personal and collective ideals, interests, and commitments“ Emirbayer \& Goodwin, 1994, S. 1443) ermöglichen. Diese Fähigkeit wurde auf der ersten Dimension der Typologie als eher hohe oder eher niedrige Agency klassifiziert. Die zweite Dimension beschreibt die Ausrichtung des Netzwerkhandelns der Befragten. Auf der einen Seite stehen Befragte, deren Handlungspraktiken eher auf den Erhalt ihrer Netzwerke ausgerichtet sind (Beibehaltung des Netzwerks). Auf der anderen Seite stehen Befragte, deren Handlungsweisen eher auf eine mittelfristige Veränderung des Netzwerks hinauslaufen. 
Eine detaillierte Zusammenfassung der Typologie findet sich in Tabelle 5.9 sowie in den zusammenfassenden Einleitungen der Typenbeschreibungen in den vorangegangenen vier Abschnitten 5.2.1 bis 5.2.4. In allen vier Gruppen stellt sich die relative Einkommensarmut als ein Problem materieller Knappheit im Alltag dar. Der Typenvergleich zeigt jedoch, dass Armut sehr unterschiedliche Auswirkungen auf die soziale und gesellschaftliche Teilhabe der Befragten hat. Da wären zunächst die beiden Gruppen zu nennen, die sich in ihren bestehenden Netzwerkstrukturen so gut es geht an die Situation angepasst haben (Typ 1) oder mangels Alternative in ihnen verharren (Typ 2):

1. Prekärstabil - Herstellung von Agency in alternativen Domänen: Den mit vergleichsweise hohem kulturellen Kapital und dem Zugriff auf Gelegenheitsstrukturen ausgestatteten Befragten in Typ 1 gelingt es, der materiellen Knappheit und der weitgehenden Ausgrenzung aus dem Arbeitsmarkt durch die Etablierung alternativer Formen der sozialen Teilhabe (Ehrenamt, Engagement im Freundes- und Bekanntenkreis, Vereinsarbeit, ...) zu begegnen und diese im Idealfall langfristig zu stabilisieren.

2. Prekärlabil - Mangel an Agency: Insbesondere auf die vergleichsweise niedrig gebildeten Pesrosnen im Sample aus strukturschwachen Regionen wirkt die Armut stark ausgrenzend. Sie fühlen sich alleingelassen mit ihren alltäglichen Problemen, orientierungslos oder fremdbestimmt und haben nur wenige Strukturen zur Verfügung, um Pläne zu fassen und diese verwirklichen zu können.

Auf der anderen Seite stehen die beiden Typen, deren Handlungsweise auf den Ausbau und die Veränderung ihrer Netzwerke ausgerichtet sind:

3. Geschwächte Agency: Ein Teil der Befragten hat soziale, gesundheitliche und psychische Krisen durchlebt, die es ihnen unmöglich machen, ihr früheres Leben weiterzuführen. Sie müssen sich neue soziale Kreise erschließen und herausfinden, welche Rollen sie dort ausüben werden, um soziale Zugehörigkeit und Anerkennung zurück zu erlangen. Ihre Handlungsfähigkeit ist eingeschränkt, da sie für längere Zeit auf Unterstützung durch Personen und Institutionen angewiesen sein werden, um an die veränderte Situation angepasste Alltagspraxen und Identitäten zu finden und zu stabilisieren.

4. Ausbau von Agency: Die acht Studierenden im Sample erleben Armut nicht als Infragestellung ihrer sozialen Zugehörigkeit, sondern vorrangig als materielles Problem. Sie sind in ständiger Sorge darum, wie sie ihre bereits stark reduzierten Fixkosten gedeckt kriegen, und arbeiten in verschiedenen 










Aushilfsjobs, die sich teilweise nur schwer mit den Anforderungen ihres Studiums vereinbaren lassen. Diese Situation stellt sich ihnen jedoch als vorübergehende Phase im Lebenslauf dar, die im Sinne der langfristigen Verbesserung ihrer Statusposition in Kauf genommen wird.

Die Gruppe „der Armen“ ist also durchaus heterogen. Eine differenzierte Betrachtungsweise scheint daher angebracht. Als gesellschaftliches Problem stellt sich Armut vor allem dann dar, wenn Menschen aus sozialen Verkehrskreisen ausgeschlossen und außerstande sind, diese Ausgrenzung durch alternative Handlungsstrategien im Netzwerk zu kompensieren.

\subsection{Subjektive Wahrnehmung und strukturelle Einbindung}

Die hier durchgeführte Analyse wird von der Annahme geleitet, dass die Wahrnehmung und Bewältigung von Armut in engem Zusammenhang mit der Einbindung in die Strukturen sozialer Beziehungsnetzwerke steht. In den vorangegangenen beiden Abschnitten wurden beide Aspekte weitgehend getrennt voneinander betrachtet. Es wurden drei Cluster der Netzwerke der Befragten (Abschnitt 5.1) und vier qualitative Typen ihrer Wahrnehmungs- und Bewältigungsweisen (Abschnitt 5.2) herausgearbeitet. In diesem Abschnitt sollen diese beiden Typisierungen zusammengeführt und miteinander verglichen werden.

Sehr grob kann die eingangs aufgestellte Vermutung einer Systematik der Verteilung der qualitativen Typen in den quantitativen Clustern anhand des Pearson Chi-Quadrat-Tests bestätigt werden $\left(\mathrm{P}-\right.$ Value $\left.=1,31 * 10^{-7}\right)$. Eine eingehendere Betrachtung der Tabelle 5.10 gibt Aufschluss darüber, welche Netzwerke besonders häufig im Zusammenhang mit welchen Wahrnehmungs- und Bewältigungsweisen auftreten.

Tabelle 5.10 und Abbildung 5.16 zeigen die Verteilung der quantitativen Cluster innerhalb der vier qualitativen Typen. Darin zeigt sich eine Häufung des Clusters 1 ,,institutionelles Unterstützungsnetzwerk“ in Typ 1 „Prekärstabil: Herstellung von Agency in alternativen Domänen“. Elf der 16 Netzwerke in diesem Typ, bzw. 68,8 \% der Netzwerke, gehören dem Cluster 1 an, welches Netzwerke mit einem vergleichsweise hohen Anteil institutioneller und unterstützender Alteri zusammenfasst, von denen nur wenige denselben Erwerbsstatus wie Ego aufweisen. Diese Beobachtung deckt sich mit den qualitativen Analysen: die Befragten in Typ 1 sind in verschiedenen, oft institutionalisierten Kontexten aktiv (Ehrenamt, Verein, Kultur, Maßnahmen der Jobcenter ...) und treffen dort auf 
Tabelle 5.10 Kreuztabelle - qualitative und quantitative Typisierung, Angaben in \%

\begin{tabular}{|c|c|c|c|c|}
\hline & $\begin{array}{l}\text { Typ 1 } \\
\text { prekärstabil: } \\
\text { Herstellung von } \\
\text { Agency in } \\
\text { alternativen } \\
\text { Domänen } \\
n=16\end{array}$ & $\begin{array}{l}\text { Typ 2 } \\
\text { prekärlabil: } \\
\text { Mangel an } \\
\text { Agency } \\
n=16\end{array}$ & $\begin{array}{l}\text { Typ 3: } \\
\text { geschwächte } \\
\text { Agency } \\
n=17\end{array}$ & $\begin{array}{l}\text { Typ 4 } \\
\text { Ausbau } \\
\text { von } \\
\text { Agency } \\
n=8\end{array}$ \\
\hline $\begin{array}{l}\text { Cluster 1: Institutionelles } \\
\text { Unterstützungsnetzwerk }\end{array}$ & 68,8 & 37,5 & 35,3 & 0 \\
\hline $\begin{array}{l}\text { Cluster 2: Kleines, eng } \\
\text { verbundenes } \\
\text { Familiennetzwerk }\end{array}$ & 31,2 & 62,5 & 41,3 & 0 \\
\hline $\begin{array}{l}\text { Cluster 3: Großes, } \\
\text { verzweigtes } \\
\text { Peer-Netzwerk }\end{array}$ & 0 & 0 & 23,5 & 100 \\
\hline Summe & 100 & 100 & 100 & 100 \\
\hline
\end{tabular}

Menschen in unterschiedlichen sozialen Lagen. Da sie in diesen Kontexten selbst einen eigenen Beitrag leisten, fällt es ihnen vergleichsweise leicht, auch Unterstützung von den Personen und Institutionen in ihren Netzwerken anzunehmen (Reziprozitätsnorm).

In Typ 2 handelt es sich dagegen bei zehn von 16 Netzwerken, bzw. bei 62,5\% der Netzwerke, um kleine, eng verbundene Familiennetzwerke aus dem 2. Cluster. Auch dieser Zusammenhang erscheint plausibel im Kontext der qualitativen Analyse: Die älteren Befragten in dieser Gruppe hegen großes Misstrauen gegenüber Institutionen und Personen in ihrer Umgebung und ziehen sich deswegen oft in ihre Kernnetzwerke aus wenigen Familienangehörigen zurück. Die Jüngeren leben in besonders strukturschwachen Umgebungen, in denen es nur wenige Gelegenheiten zum Aufbau von Beziehungen gibt. Die Teilnahme an institutionalisierten Angeboten ist mit weiten Wegen verbunden oder nur sehr schwer mit den alltäglichen Anforderungen in Einklang zu bringen. Daher sind auch diese Netzwerke klein und geprägt durch einen hohen Anteil enger Freund*innen und familiärer Akteur*innen, die sich in der Regel auch untereinander gut kennen (hohe Beziehungsdichte).

Im Typ 3 ergibt sich ein weniger eindeutiges Bild: Hier finden sich sechs Netzwerke aus Cluster 1 (35,3\%), sieben Netzwerke aus Cluster 2 (41,3\%) und vier Netzwerke aus Cluster $3(23,5 \%)$. Da sich die Befragten infolge einer schweren Lebenskrise in einer Phase der Umorientierung und Suche nach neuen 


\section{Verteilung der Cluster innerhalb der qualitativen Typen}

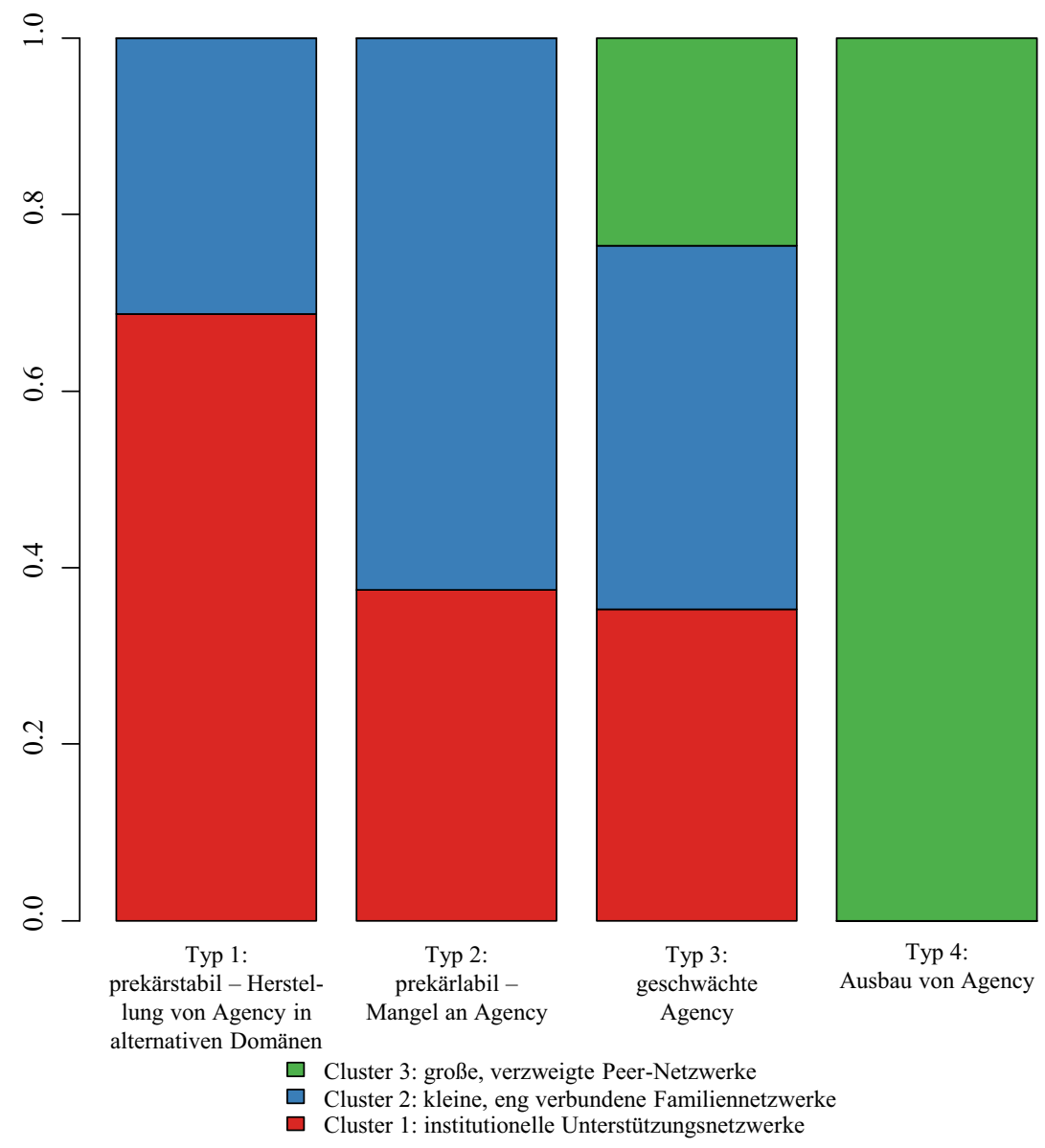

Abbildung 5.16 Verteilung der Cluster innerhalb der qualitativen Typen

Domänen und Identitäten befinden, ist auch dieses Ergebnis plausibel im Sinne der qualitativen Analyse. Je nachdem, wie weit die Befragten bereits Zugang zu neuen Gelegenheitsstrukturen gefunden haben, sind ihre Netzwerke offener oder geschlossener. Personen, die noch sehr viel Unterstützung zur Bewältigung 
der Krise benötigen, beziehen diese in der Regel vorrangig aus stabilen intensiven Beziehungen in der Familie - ihre Netzwerke entsprechen der in Cluster 2 zusammengefassten Struktur. Je weiter die Anpassung an die neue Situation fortschreitet, erfahren sie auch Unterstützung aus und Zugehörigkeit zu institutionalisierten Zusammenhängen (Cluster 2). Im Idealfall befinden sie sich irgendwann (wieder) auf Augenhöhe mit den meisten ihrer Alteri in einem großen, verzweigten Peer-Netzwerk (Cluster 3).

Die Netzwerke der Studierenden in Typ 4 weisen die einheitlichste Zusammensetzung auf. Alle acht Netzwerke gehören dem Cluster 3: ,großes, verzweigtes Peer-Netzwerk" an. Ihre Netzwerke sind besonders groß und reich an unterschiedlichen Domänen (hohe Modularität). Die Anteile institutioneller und unterstützender Beziehungen sind gering, dafür sind Anzahl und Anteil an Peers also an Personen, die ebenfalls studieren - besonders hoch. Diese Beschreibungen decken sich mit der Beobachtung weitgehend selbstbestimmter Strategien im Umgang mit der relativen Einkommensarmut (basierend auf BAföG, Studienkredit, Jobs und Unterstützung aus der Herkunftsfamilie) und der Wahrnehmung der eigenen materiellen Lage als normal im Kontext des Beziehungsnetzwerks.

Es kann festgehalten werden, dass die Netzwerkstrukturen von Menschen in relativer Einkommensarmut genauso heterogen sind wie ihre alltäglichen Herausforderungen und Bewältigungsstrategien. Eine spezifische Struktur, die sich als „Armutsnetzwerk“ beschreiben ließe, gibt es nicht. Auch kann das landläufige Klischee einer weitgehend isolierten und homogenen Gruppe der Armen nicht bestätigt werden. Die überwiegende Mehrzahl der Netzwerke weist Beziehungen in unterschiedliche soziale Kreise und zu Personen in gleicher, aber auch in unterschiedlicher sozialer Lage wie Ego auf. Die, gemessen auf Basis des Erwerbsstatus, homogensten Netzwerke finden sich ausgerechnet bei denjenigen, die innerhalb des Samples die größte Distanz zum Klischee ,der Armen“ aufweisen: in der Gruppe der Studierenden.

Dennoch fällt eine Netzwerkstruktur als besonders nachteilig ins Auge: die kleinen, eng verbundenen Familiennetzwerke im Cluster 2 bieten zwar emotionale und praktische Unterstützung bei der Bewältigung von Krisen und alltäglichen Problemlagen (z. B. bei einigen der Befragten in Typ 3), sie weisen aber kaum über die aktuelle Situation hinaus. ${ }^{26}$ Damit ist das Potenzial, über das sie zur

\footnotetext{
${ }^{26}$ Der Nutzen starker und schwacher Beziehungen unterscheidet sich in Abhängigkeit der jeweiligen Bewältigungssituation. In einer jüngeren Studie zum familiären Umgang mit den Folgen der Corona-Krise konnte gezeigt werden, dass die Bewältigung vorwiegend auf starken familiären Beziehungen beruht, während sich die schwächeren, über die Kernfamilie hinausgehenden Beziehungen in dieser Situation oft als wenig hilfreich erwiesen (Knabe et al. 2021).
} 
Verringerung der Auswirkungen der Armut verfügen am geringsten. Besonders häufig ist dieses Netzwerkcluster im Typ 2 „,Mangel an Agency“ zu finden. Dieser Netzwerktyp tritt also besonders oft in Verbindung mit Gefühlen der Resignation, Ohnmacht und Orientierungslosigkeit auf. Mehr als die Hälfte aller Angehörigen des Typs 2 leben in besonders strukturschwachen ländlichen Räumen, in denen die Verfügbarkeit von Gelegenheitsstrukturen zur Pflege und Aufnahme sozialer Beziehungen besonders gering ist.

Während die Bewältigungsstrategien in den Typen 1, 3 und 4 vor allem besser unterstützt und durch den Ausbau von Gelegenheitsstrukturen und finanzielle Anerkennung der Aktivitäten dauerhaft abgesichert werden müssten, erscheint es in den Fällen der Befragten in Typ 2 notwendig, von außen in die Netzwerke einzugreifen. Hilfreich wären mehr Beziehungen zu Gatekeepern, die tatsächlich in der Lage sind, Zugänge zu Möglichkeitsräumen herzustellen, in denen die Befragten die Erfahrung von Selbstwirksamkeit machen und wo sie sukzessive in die Lage versetzt werden, ihre eigene Zukunft zu planen und dauerhaft abzusichern. Diese und weitere Ansätze der Armutsbekämpfung werden im folgenden und letzten Kapitel diskutiert.

Open Access Dieses Kapitel wird unter der Creative Commons Namensnennung 4.0 International Lizenz (http://creativecommons.org/licenses/by/4.0/deed.de) veröffentlicht, welche die Nutzung, Vervielfältigung, Bearbeitung, Verbreitung und Wiedergabe in jeglichem Medium und Format erlaubt, sofern Sie den/die ursprünglichen Autor(en) und die Quelle ordnungsgemäß nennen, einen Link zur Creative Commons Lizenz beifügen und angeben, ob Änderungen vorgenommen wurden.

Die in diesem Kapitel enthaltenen Bilder und sonstiges Drittmaterial unterliegen ebenfalls der genannten Creative Commons Lizenz, sofern sich aus der Abbildungslegende nichts anderes ergibt. Sofern das betreffende Material nicht unter der genannten Creative Commons Lizenz steht und die betreffende Handlung nicht nach gesetzlichen Vorschriften erlaubt ist, ist für die oben aufgeführten Weiterverwendungen des Materials die Einwilligung des jeweiligen Rechteinhabers einzuholen.

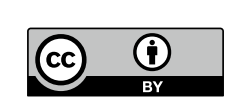

